\title{
Teil I: Forschungsoptionen zur Analyse decorativer Prinzipien
}

Die Untersuchung steht in der Tradition einer sehr großen Zahl an archäologischen Studien, auf die produktiv zurückgegriffen werden kann, von denen sie sich aber auch in einigen grundsätzlichen Aspekten unterscheidet. Einen wichtigen Ausgangspunkt stellen systematische Materialsammlungen einerseits, die detaillierte Publikation von Befunden andererseits dar. Pompejanische Wandmalereien und Pavimente sind in den Bänden Pompei: pitture e mosaici (PPM) auf vorbildliche Weise in ihrem Kontext publiziert worden. Erst durch sie kann eine vergleichende Analyse von Ausstattungsprinzipien auf eine systematische Basis gestellt werden. Darüber hinaus sind Detailstudien wie die Publikationsreihe Häuser in Pompeji von unschätzbarem Wert, ermöglichen sie doch eine Nahsicht auf den Befund, wie er im Rahmen komparativer Analysen nur eingeschränkt möglich ist. Jüngst tritt zu diesen Befundvorlagen die Neudiskussion einzelner Insulakomplexe hinzu, die unter anderem in der Reihe Rileggere Pompei publiziert werden. Schließlich existiert eine geradezu unüberschaubare Zahl an interpretierenden Arbeiten, die im Folgenden in Bezug auf bestimmte, für die hier verfolgte Fragestellung bedeutsame Zugriffsweisen diskutiert werden.

\section{Die Analyse von Decor-Elementen: Stil, Typologie, Ikonographie, Ikonologie}

Einen wichtigen Ausgangspunkt der Untersuchung stellen Forschungsbeiträge dar, die sich mit den formalen und inhaltlichen Qualitäten von Decor beschäftigen: Stil, Typologie, Ikonographie und Ikonologie. Ihre Methoden sind im Folgenden einer Diskussion zu unterziehen, um die Leistung dieser Ansätze, aber auch ihre Beschränkung konturieren zu können.

\subsection{Stil und Chronologien}

Der stilistische Zugang wird in der Forschung üblicherweise gewählt, um Bildwerke zu datieren und Werkstattgruppen zu unterscheiden ${ }^{1}$. Da auch für die vorliegende Untersuchung die historische Veränderung von Decor-Formen eine wichtige Rolle spielt, soll die Chronologiediskussion für Wandmalereien und Mosaiken kurz skizziert werden. Dabei fällt auf, dass sie sich nicht an ,stilistischen' Kriterien im engeren Sinn, sondern maßgeblich an technischen und motivischstrukturellen Gesichtspunkten orientiert. Für die Decken ist eine solche Diskussion aufgrund der schlechten Erhaltung nicht systematisch möglich².

Die römische Wandmalerei untergliederte August Mau im Jahr 1882 in vier sog. Stile, mit denen er unterschiedliche Decorationssysteme (d.h. nicht stilistische Einzelformen im engeren Sinne) bezeichnete ${ }^{3}$. Maus Interesse galt geradezu ausschließlich dem formalen Aufbau der Wand. Seine Überlegungen zur Organisation von Decor-Elementen sind bis heute einschlägig. Auch die Studien, die in Maus Folge eine weitere Untergliederung der Stile vornahmen und ihre zeitliche Einordnung diskutierten, sind einer formalen Analyse der Wandschemata verpflichtet. Für den ersten Stil gilt dies für Anne Laidlaw, für den zweiten Stil für Rolf Albert Tybout, für den dritten Stil für Frédéric Louis Bastet und Mariette de Vos, Wolfgang Ehrhardt und Renate Thomas, für den

1 Auf stilistischer Grundlage hat man etwa versucht, der Mosaikwerkstatt, die die Mosaiken der Casa del Fauno hergestellt hat, weitere Werke zuzuweisen; s. Meyboom 1977, bes. 72-74; Meyboom 1995, 91-95; Zevi 1998, $42-44$.

2 Lipps 2018.

3 Mau 1882. 
zweiten bis vierten Stil für Hendrik Gerard Beyen ${ }^{4}$. Einer vergleichbaren Anlage folgen auch die stärker resümierenden Darstellungen von Roger Ling und Alix Barbet ${ }^{5}$. Auf dieser Grundlage bildete sich der zumeist geteilte Forschungskonsens aus, dass der erste Stil in Pompeji in seinen ersten Ausprägungen auf das 4./3.Jh.v. Chr. zurückgehe, der zweiten Stil erst nach 80 v.Chr. sicher zu greifen ${ }^{6}$ und mit frühen Formen des dritten Stils in den letzten Jahrzehnten des 1.Jhs.v.Chr. zu rechnen sei. Unterschiedlich bewertet ist einerseits die Feindifferenzierung der Stile, andererseits wurde auf das Nebeneinander verschiedener Formphänomene hingewiesen. Beide Aspekte sollen kurz angerissen werden.

Insbesondere für den frühen ersten und zweiten Stil (sog. proto-erster und proto-zweiter Stil) ist auf die Parallelität der Entwicklung hingewiesen worden ${ }^{7}$. Für die Zeit des späten ersten Stils lässt sich die Frage stellen, inwieweit er mit dem frühen zweiten Stil zeitgleich verwendet wurde. So ist in der Casa del Fauno m. E. nicht auszuschließen, dass etwa gleichzeitig mit der Ausstattung der Räume im späten ersten Stil Raum (43/43) im zweiten Stil ausgemalt wurde ${ }^{8}$. Für den zweiten Stil steht außer Frage, dass Decor-Formen, die nacheinander entwickelt wurden, nebeneinander Verwendung fanden, um Räume visuell zu differenzieren ${ }^{9}$. Wandmalereien, die Perspektive und Tiefenräumlichkeit unterschiedlich behandeln, können folglich gleichzeitig sein. Für die Casa di Paquius Proculus/Cuspius Pansa (I 7,1) ist klar, dass Räume, die dem späten zweiten Stil und dem Kandelaberstil zuzuweisen sind, im Rahmen eines einzigen Ausstattungsvorgangs entstanden $\operatorname{sind}^{10}$. Die Untergliederung des dritten Stils wird noch immer intensiv diskutiert. Insbesondere die sehr kleinschrittige Gliederung von Bastet wurde zu Recht dafür kritisiert, dass sie zwar „inévitable pour construire une typologie de base“ sei, dass es sich jedoch um „séquences empiriques, en dernière analyse parfaitement arbitraires" handle ${ }^{11}$. So stellt sich erneut die Frage, inwieweit verschiedene Decor-Ausprägungen nicht auch gleichzeitig sein können ${ }^{12}$. Für den vierten Stil beobachtete Agnes Allroggen-Bedel am Beispiel der Villa von San Marco die „tatsächliche Ungleichzeitigkeit von scheinbar Gleichzeitigem“"13. Karl Schefold und Wolfgang Erhardt diskutierten die Möglichkeit intentionaler Rückgriffe auf ältere Stilstufen ${ }^{14}$. Der (Re-)Konstruktion einer idealtypischen Stilabfolge sind somit Grenzen gesetzt, stattdessen wird man mit einer relativ großen Bandbreite an gleichzeitig möglichen, unterschiedlichen Gestaltungsformen rechnen müssen, mit der Ungleichzeitigkeit des Gleichzeitigen.

\footnotetext{
4 Laidlaw 1985; Tybout 1989; Bastet - de Vos 1979; Ehrhardt 1987; Thomas 1995; Beyen 1938; 1960; mit Kritik an Beyens kleinteiliger Phasenabfolge Barbet 2009, 36f.

5 Ling 1991; Barbet 2009.

6 Häufig ging man daher davon aus, der zweite Stil sei von den Kolonisten eingeführt worden - s. Schefold 1952, 14; Zanker 1995; Zevi 1996a; Leach 2004, 69; ein Argument besteht darin, dass der erste Stil außerhalb der Mauern Pompejis selten ist und zahlreiche Villen prunkvoll im zweiten Stil ausgestattet wurden.

7 Esposito 2011; Pesando 2011; Torelli 2011; D’Auria 2014, 55-62; eine Synopse zu den verschiedenen Gliederungsoptionen der Stile bei Barbet 2009, 182.

8 So auch Zevi 1996, 39. Allerdings haben sich einige Forscher für eine lange Ausstattungsphase von 120 bis 80/75 v.Chr. ausgesprochen, sodass die Wandmalerei im zweiten Stil zu den spätesten Ausstattungselementen zählen würde; s. Pesando 1996, $197 \mathrm{f}$. Infrage käme schließlich auch eine nachträgliche Restaurierung.

9 Bereits Beyen 1938, 32f.; Bragantini 1995, 180f.; Tybout 2001, 37-40; Allroggen-Bedel 2014, 43; Barbet 2009, 36f.; Barbet 1968 benennt monochrom-weiße Wände mit weißen Linien, die in Voluten enden, als ,schematischen zweiten Stil'. Sie nennt dafür Beispiele aus Glanum, aber auch von anderen Orten des Mittelmeerraums und interpretiert ihn als Spätphase des zweiten Stils. Auch dies wäre zu überdenken, findet sich dieser Decor doch etwa auch in der Casa del Labirinto neben viel aufwendigeren Decor-Formen.

10 Ehrhardt 1998, 145.

11 Coarelli 2009, 7; darauf rekurrierend auch Pappalardo 1990, 230 f.

12 Bastet - de Vos 1979; anders Ehrhardt 1987; eine vergleichende Diskussion bei Peters - Moormann 1993a, 261-267; mit einer Forschungsgeschichte Thomas 1995.

13 Allroggen-Bedel 1993, 146-152.

14 Schefold 1953/1954, 119-122; Ehrhardt 1987, 133-148; von Allroggen-Bedel 1993, 151 ohne eingehende Diskussion aufgrund fehlender Fixdaten als spekulativ zurückgewiesen.
} 
Die Pavimentchronologie ist grundlegend von Marion Blake und Erich Pernice diskutiert worden $^{15}$. Sie basiert einerseits auf dem Wandel von Pavimenttechniken, andererseits auf der Veränderung der Motive. Auch Birgit Tang stützt sich für ihre Untersuchung von Opera signina auf diese Aspekte ${ }^{16} . \mathrm{Zu}$ den besonders alten Pavimentformen in Häusern des 4. und 3.Jhs. v. Chr. zählen Stampflehmböden ${ }^{17}$. Sie wurden im Verlauf des 3. und 2.Jhs. durch Estrich-Böden ersetzt, die dann über einen langen Zeitraum hinweg geschätzt wurden. So traten Estrichböden ohne Steinsetzung (Cocciopesto/Lavapesta) und mit Tessera-Decor (Opus signinum) ${ }^{18}$ in Kampanien bereits im frühen 3.Jh.v.Chr. auf ${ }^{19}$, waren im 2.Jh.v.Chr. besonders beliebt, wurden aber bis in die Kaiserzeit hinein für die Ausstattung von Räumen gewählt ${ }^{20}$. Schon frühzeitig standen damit verschiedene Pavimentqualitäten für eine differenzierte Ausstattung von Wohnräumen zur Verfügung ${ }^{21}$. Daneben traten ab dem 3.Jh.v.Chr. Tessellate ${ }^{22}$. Während es sich bei den frühen Mosaiken des späten 3. und beginnenden 2.Jhs.v.Chr. um relativ grobe Tessellate handelt ${ }^{23}$, traten mit dem späten 2.Jh.v.Chr. die besonders elaborierten Opera vermiculata auf. Im 2.Jh. kommen dann auch die aufwendigen Opera sectilia hinzu. An dieser Chronologie ist ablesbar, dass es zwischen dem 3. und 1.Jh.v.Chr. zu einer sukzessiven Steigerung des Pavimentluxus kam und immer mehr Optionen für eine visuelle Differenzierung der Böden zur Verfügung standen.

Auch der Wandel der Muster, die für die Opera signina und Mosaiken gewählt wurden, lässt sich aufgrund der genannten Schwierigkeiten nur in Ansätzen nachvollziehen ${ }^{24}$. Unregelmäßig behauene Tesserae sind in der Tendenz etwas früher und dem ersten Stil zuzurechnen, langrechteckige Tesserae scheinen mit dem zweiten Stil aufzutreten. Regelmäßig behauene Tesserae finden indes sowohl in Korrelation mit dem ersten als auch mit dem zweiten Stil Verwendung. Zu den charakteristischen frühen, im ersten Stil verbreiteten Mustern gehören Tessera-Reihen ${ }^{25}$, bei denen die Steinchen in großem Abstand gesetzt sind, Rautenmuster ${ }^{26}$ sowie, etwas später, verschiedene Mäander- und Swastikaformen ${ }^{27}$; alle genannten Decor-Formen können aber noch im zweiten Stil auftreten. Mit dem zweiten Stil kommt es zur Verfeinerung der Motive - sei es, dass der Mäander eine zentrale Mittel-Tessera erhält oder, dass an die Stelle einfacher Punktreihen komplexere

15 Blake 1930; Pernice 1938.

16 Zum Motivrepertoire Tang 2018, 23-53.

$17 \mathrm{Zu}$ den jüngeren Grabungsergebnissen in der Regio VI, s. Pesando 2012, 538; als einfache Pavimente (ohne zeitliche Differenzierung) bei Maratini 2017, 330.

18 Üblicherweise wird Opus signinum mit einem Cocciopesto-Paviment identifiziert - s. Rakob 1991, 220; skeptisch Blake 1930, bes. 22; Brem 2000, 71; dagegen Gros 2003; Opus signinum als Bezeichnung für alle Estrichböden bei Vassal 2006, 1. 13-32. Hier wird zur näheren Unterscheidung der Böden, gewissermaßen arbiträr, eine terminologische Unterscheidung von Estrichböden ohne und mit Steinsetzung eingeführt; andere Anwendungen der Terminologie, die sich um eine differenzierte (allerdings nicht unproblematische) Analyse antiker Quellen bemühen, etwa bei Carletti 2001.

19 Tang 2018, 100 mit Verweis auf die Casa del Chirurgo (VI 1,10); eine deutlich spätere Chronologie (Ende 3.Jh.v.Chr.) wurde vorgeschlagen von Vassal 2006, 43.

20 Pesando 2008, 167; Pesando 2012, 539; Tang 2018, bes. 89. 168; Tang 2018, 13 mit Hinweis auf eine Nutzung der Technik bis in die Spätantike.

21 Etwa das Beispiel der Protocasa del Granduca Michele (VI 5,5) - D’Auria 2010, 49 und wortgleich D'Auria 2011, 449: „In ciascun ambiente della casa, la pavimentazione scelta era adattata alla funzione della stanza: così negli ambienti di passaggio come i corridoi, si trovavano dei battuti, nelle stanze in cui si svolgevano attività domestiche o artigianali dei cocciopesti solidi e privi di decorazione oppure dei battuti e nelle stanze di rappresentanza dei pavimenti di maggior pregio, arricchiti da una decorazione.“

22 In der Protocasa del Centauro (VI 9,3.5) wurde im beginnenden 3.Jh. ein polychromes Tessellat als Mittelemblema im Tablinum inszeniert; Pesando 2008, 167f. mit Abb. 11f.; Tang 2018, 100 Abb. 135.

23 Pesando 2012, 540.

24 Zum Folgenden Pernice 1938; Tang 2018, bes. 91f. 94f. 102-105; Zulini 2011-12.

25 Vassal 2006, 49.76.

26 Vassal 2006, 77.

27 Vassal 2006, 77; bei Tang 2018, 100f. dazu exemplarisch die Casa del Centauro (VI 9,3-5) und die etwas späteren Estrich-Pavimente der Casa del Labirinto (beginnendes 1.Jh.v.Chr.). 
Kreuzsterne treten ${ }^{28}$. Mit auf Polygonen basierenden Netzmustern, besonders Hexagonen und komplexen Rosetten, kommen auch gänzlich neue Muster hinzu ${ }^{29}$. Einen relativchronologischen Anhaltspunkt gibt die Ausstattung von Cubiculum (d) in der Casa di Gavius Rufus (VII 2,16-17) ${ }^{30}$. Im ersten Stil war der Raum zunächst länger, bevor der rückwärtige Teil für einen Schrank abgetrennt wurde. Im nicht mehr sichtbaren Bereich hat sich der Stuck des ersten Stils erhalten, der vordere Raumteil wurde im zweiten Stil neu ausgemalt. In diesem Zusammenhang wurde der Raum mit einem Opus signinum pavimentiert. In den Cocciopesto ist ein Kreuzsternmuster eingesetzt, bestehend aus einer mittigen schwarzen und vier umgebenden, weißen Tesserae. Zur Schrankseite hin markiert ein Mäander die neue Schwelle. Damit ist die Gleichzeitigkeit dieser Pavimentform mit dem zweiten Stil gesichert. Für die relative Pavimentchronologie interessant sind zwei übereinanderliegende Pavimente in Tablinum (8) der Casa delle Forme di Creta (VII 4,62). Über einem Cocciopesto mit in Reihen verlegten Tesserae, in dessen Zentrum ein Mäander ein rechteckiges Emblema mit Rautenmuster einfasst, wird später ein weißes Tessellat verlegt ${ }^{31}$. Besonders komplexe geometrische Muster wurden schließlich in der Kaiserzeit umgesetzt ${ }^{32}$.

Tatsächlich fiel der Wandel der Wandsysteme nicht mit einem ähnlich signifikanten Wandel der Pavimenttechniken zusammen. Der Cocciopesto-Boden von Korridor (4) und Triclinium (5) der Casa del Labirinto ist mit einer Wand zweiten Stils verbunden, während ein sehr ähnliches Paviment der Casa del Citarista (I 4,5) mit einer Wand des ersten Stils zusammengeht ${ }^{33}$. Auch die Tessellatmosaiken lassen sich nicht linear mit Wandmalereistilen korrelieren. So gehen in der Casa del Fauno mit den Wänden ersten Stils aufwendige mosaizierte Emblemata in Opus vermiculatum, Opera sectilia und schwarz-weiße Tessellatmosaiken (mit und ohne schwarze Rahmung) ${ }^{34}$ zusammen, wie sie andernorts in Häusern mit Wand-Decor im zweiten Stil auftreten. Dies spricht dafür, dass diese Pavimentformen bereits im ersten Stil entwickelt waren, bevor sie dann im zweiten Stil prominent wurden ${ }^{35}$. Im Verlauf des 1.Jhs.v. Chr. verdrängten schwarz-weiße Tessellate die polychromen Emblemata ${ }^{36}$.

Tatsächlich dürfte der Übergang zum zweiten Stil optisch zunächst keinen signifikanten Einschnitt markiert haben. Der Wand-Decor wurde zwar malerisch umgesetzt, aber in seinem Aufbau nicht grundsätzlich verändert, an den Böden ist in dieser Zeit überhaupt kein signifikanter Wandel greifbar. Die Raumwirkung dürfte daher zunächst weitgehend unverändert geblieben sein, wenn auch nun etwas stärker mit illusionistischen Mitteln gearbeitet wurde.

28 Tang 2018, 103: „At Pompeii in Regio VI all floors (ceramics aggregate) showing crosslets are dated no earlier than the late Republican period (1st century BC).“

29 Tang 2018, 103.

30 PPM VI (1996) 530-585 s. v. VII 2, 16-17, Casa di M. Gavius Rufus (V. Sampaolo) 536-539 Abb. 8-14; Anguissola 2010, 81-83 Abb. 25f. Taf. 2,4.

31 PPM VII (1997) 140-153 s. v. VII 4, 62, Casa delle Forme di Creta (M. Staub-Gierow) 153 Abb. 20.

32 Tang 2018, 104. 169.

33 Strocka 1991, 97.

34 Laut Pernice 1938, 33f. treten diese Pavimentformen am Übergang zum zweiten Stil auf - diesen Übergang datiert er in das beginnende 1.Jh. v. Chr.

35 Pesando 1996, 197f. geht allerdings von einer sehr langen Ausstattungsphase aus, die für ihn von etwa 120 v. Chr. bis 80/75 v. Chr. reicht. Für das Opus sectile des Tablinums sieht er durch einen stilistischen Vergleich mit dem Opus sectile des Apollotempels eine Datierung in oskische Zeit gegeben - ist doch mit letzterem eine oskische Inschrift aufgefunden worden. Für das Emblema in Raum 30/42 weist er darauf hin, dass es in ein Tessellatmosaik zweiten Stils eingesetzt worden sei. Das Fischmosaik von Triclinium 12/35 datiert er über typologische Parallelen in die Jahre 100/90 v. Chr. Ein längerer Ausstattungsprozess ist in der Tat wahrscheinlich, da die Ausstattungselemente aber in einer systematischen Beziehung zueinander stehen (s. u.), scheint mir eine Phasendauer von fast 50 Jahren zu hoch gegriffen. Plausibler schiene mir eine Datierung aller Elemente in die Jahre zwischen 110/90 v. Chr. Dies ist umso wahrscheinlicher, weil Pesando selbst die Herstellung der Mosaiken in einer einzigen Werkstatt annimmt.

36 Clarke 1982, 666-673. 
Eine nochmals andere Situation ist bei der Skulptur anzutreffen. Die über Jahrhunderte nacheinander ausgebildeten Stilformen waren im späten Hellenismus nebeneinander verfügbar ${ }^{37}$. Dieser Stilpluralismus führte dazu, dass spezifische Stilformen und ihre Ausdruckswerte für bestimmte Bildinhalte als besonders geeignet erachtet wurden. Das Prinzip der Adäquatheit ist auch auf die Verwendung von Stilformen angewandt worden ${ }^{38}$. Der Stil der Skulpturen lässt sich somit auf seine atmosphärischen und kommunikativen Ausdruckswerte hin befragen. Dieses Phänomen wird in den Häusern Pompejis jedoch erst mit augusteischer Zeit relevant, als Skulpturen in größerer Zahl erworben und aufgestellt wurden.

Der an der Skulptur besonders klar zutage tretende ästhetische und kommunikative Wert von Stil bzw. von Formphänomenen darf für alle Ausstattungsformen vorausgesetzt werden. Der grundlegende Wandel der decorativen Systeme gibt daher dazu Anlass, nach den sich ändernden Raumatmosphären und den damit einhergehenden Semantisierungen zu fragen ${ }^{39}$.

\subsection{Typologie und Bildschemata: Decoscapes}

Mit der Erstellung von Typologien wird in der Forschung zumeist das Ziel verfolgt, für ornamentale Einzelformen, etwa Kapitelle oder Gesimse ${ }^{40}$, eine verlässliche Chronologie zu schaffen. Zugleich gibt die Bildung von Typenreihen Aufschluss über die lokale, regionale, bisweilen sogar überregionale Durchmusterung von Decor-Kulturen. Typenreihen zeugen damit von der Existenz enträumlichter Objectscapes und Decoscapes ${ }^{41}$ und fordern die Frage nach ihrer jeweiligen kontextuellen Ausprägung und ihren spezifischen Verwendungs- und Assoziationszusammenhängen heraus ${ }^{42}$.

Eine Typenbildung lässt sich jedoch nicht nur für ornamentale Einzelformen, sondern auch für Bilder diskutieren. Bereits frühzeitig ist erkannt worden, dass in der spätrepublikanischen und frühkaiserzeitlichen Wandmalerei nicht nur Einzelfiguren auf immer wiederkehrende Haltungsschemata festgelegt waren ${ }^{43}$, sondern auch für komplexe Bildkonstellationen Schemata Verwendung fanden. Häufig hat man die Vorlagen in ,Griechenland“ lokalisieren wollen ${ }^{44}$. Die Suche nach vermeintlich ,griechischen' und, römischen' Konzepten macht jedoch gerade im 2. und 1.Jh.v. Chr. wenig Sinn ${ }^{45}$. Sehr viel plausibler lässt sich der Mittelmeerraum, das vorrömische und römische

37 Zum Stilpluralismus: von Blanckenhagen 1942; Brendel 1979, 122-137; Hölscher 1987; Elsner 2006, 270-276.

38 Hölscher 1987, bes. 37-42 geht von einer Semantisierung von Stil aus; Elsner 2014, bes. 21 spricht allgemeiner von einer rhetorischen Funktion.

39 Simmel [1907] 2009, 764: „Die innere Bedeutsamkeit der Kunststile läßt sich als eine Folge der verschiedenen Distanzen auslegen, die sie zwischen uns und den Dingen herstellen. Alle Kunst verändert die Blickweite, in die wir uns ursprünglich und natürlich zu der Wirklichkeit stellen. “ Zur Konstitution von Atmosphären, s. hier S. 45-49.

40 Etwa Cocco 1975 (korinthisch-italische Kapitelle); Fadda 1975 (Impluvien).

41 Appadurai 1990, 1181 führt den Terminus '-scape' ein „to indicate that all these [ethnoscapes, mediascapes, technoscapes, financescapes, ideoscapes] are not objectively given relations [...] but rather that they are deeply perspectival constructs, inflected very much by historical, linguistic and political situatedness of different sorts of actors." Mit diesen Termini verweist er auf die Spannung zwischen räumlich verankerten und enträumlichten Praktiken. Jedes materielle Objekt nimmt einen konkreten Locus ein und ist zugleich in Praktiken eingebunden, die die räumliche Verortung transgredieren.

42 Für die dorische Ordnung in Italien, s. Maschek 2012.

43 Diese werden dann durch Attribute und weitere Bilddetails spezifiziert, s. etwa Elsner - Squire 2016, 192.

44 Solche Überlegungen wurden für den Masonry Style angestellt; s. etwa Bruno 1969, 316f.; Leach 2004, 61f. hingegen mit Verweis auf den lokalen Variantenreichtum. In ähnlicher Weise wurden die Ursprünge des zweiten Stils kontrovers diskutiert - Fittschen 1976, 539-557 etwa sprach sich für einen griechischen, Wesenberg 1985, 475f. für einen italischen Ursprung aus. Besonders intensiv diskutiert wurde die Frage für die Wandbilder des dritten und vierten Stils; eine gut begründete, kritische Position etwa bei Schmaltz 1989a; eine umfängliche kritische Diskussion jüngst bei Prehn 2018, 4-17 (der allerdings unreflektiert ein modernes, negatives Konzept von Kopie zugrunde legt).

45 Jüngst hat Wallace-Hadrill 2010, 9-32 die mit Hellenisierung und Romanisierung verbundenen Vorstellungen kritisch diskutiert; auch er hält jedoch letztlich an der Gegenüberstellung von Griechenland und Rom (unter Hinzufügung der jeweils ,lokalen` Kultur) fest. Auch Wallace-Hadrill 2010, 26 stellt in Anlehnung an Otto Brendel infrage, 
Italien eingeschlossen, als ein (nicht national zergliedertes) Netzwerk beschreiben, das nach geografischen Räumen, Akteursgruppen und Handlungssituationen strukturiert ist. Je nach Kontext waren unterschiedliche kulturelle Formen verschiedener Zeitstellung und regionaler "Herkunft synchron verfügbar. Und je nach Kontext kam es zu unterschiedlichen Modi der Aneignung und Anwendung - etwa von Sprache, Kleidung, aber eben auch von Bildmedien und Bildschemata ${ }^{46}$. Jas Elsner beschreibt diesen Prozess wie folgt ${ }^{47}$ : „It is a world of creative reformulation, of often eclectic and syncretistic admixtures of various earlier elements, of considerable connoisseurial knowledge and antiquarian esteem, of the old forms beeing adapted to new ends." Visuelle Formeln bilden die Basis für den Bildentwurf. Dies gilt für das einzelne Haltungsschema, das durch weitere Bilddetails spezifiziert wird, es gilt aber auch für das Bildschema als Ganzes. Dieses wird einerseits in Bezug auf das jeweilige Bildmedium modifiziert, d.h. für die jeweilige Bildform und Bildfunktion passend gemacht ${ }^{48}$. Andererseits wird es - und dies ist für die nachfolgende Untersuchung bedeutsam - in Bezug auf seinen Anbringungskontext und sein Zusammenspiel mit anderen Decor-Elementen zugeschnitten. Grundsätzlich können Bildschemata als Versatzstücke begriffen werden, die in Bezug auf spezifische Wahrnehmungssituationen visuelles Argumentieren ermöglichen ${ }^{49}$. Sie konstituieren neue Sinnzusammenhänge, Decoscapes. Ein Ziel des Buches besteht folglich darin, über die Verwendung von Bild- und Decor-Stereotypen die Strategien der additiven Erzeugung von Sinnsequenzen im Kontext des römischen Wohnens aufzudecken.

\subsection{Ikonographie und Ikonologie}

Die Mehrzahl der Studien zum römischen Decor gilt der Ikonographie von Bildern. Insbesondere im Bereich der Wandmalerei haben einzelne Bildthemen wie Mythen- und Landschaftsbilder oder

dass römische und griechische Kunst klar unterscheidbar seien. Er schließt daraus allerdings, dass ,griechisch` den kulturellen Aspekt des Austauschprozesses beschreiben würde, ,römisch' den Aspekt politischer Strukturen (WallaceHadrill 2010, 26f. 41). Die italische Bevölkerung habe nebeneinander verschiedene kulturelle Systeme (und Sprachen) aktiv gebrauchen können, „in full awareness of their difference“ (S. 28). Zwar werden einige Kulturmerkmale (Sprache; Kleidung) einen expliziten Distinktionscharakter besessen haben, aber man wird infrage stellen dürfen, dass alle Kulturmerkmale (Kunst, Architektur, etc.) auf die Opposition Griechenland/Rom verrechnet wurden. Die hellenistische Kultur war bereits seit langem die ,eigene‘ Kultur, Vitruvs Einlassungen zum ,griechischen' Haus beschreiben nicht die Realitäten seiner Zeit, sondern eine fiktive historisierende Vorstellung. Es ist hinreichend bekannt (und für die Casa del Fauno im Detail untersucht, s. u.), dass in Italien auch sehr intensiv Einflüsse aus Alexandria, dem Nahen Osten, Nordafrika und Kleinasien rezipiert wurden, die man kaum pauschal als ,griechisch` zusammenfassen wird. Die in der Forschung stark gemachte Opposition von Griechenland und Rom mag sich nicht zuletzt aus der Tradition einer textbasierten Forschung ableiten, wo der sprachliche Unterschied (Griechisch/Latein) vermeintlich klar zutage tritt. Aber selbst hier könnte man auf lokale Sprachen, etwa im griechisch-römischen Ägypten, oder die zahllosen regionalen Ausprägungen der beiden Sprachen verweisen. Kritisch zur Wandmalerei und deren, griechischem` Ursprung etwa Bergmann 1995, bes. 84-94.

46 Wallace-Hadrill 2010, 26 führt dafür den Begriff des ,code-switching‘ ein. Er bezeichnet damit die Anwendung jeweils für einen Kontext angemessener Verhaltensformen und Kulturtechniken. Tatsächlich wird sich zeigen, dass nicht nur existierende Codes angewandt, sondern kulturelle Muster an den jeweiligen Verwendungskontext angepasst werden.

47 Elsner 2006, 271.

48 Für Wandmalerei etwa Bergmann 1995; allgemein Boschung 2017, 67-79.

49 Für die Rhetorik spricht Quintilian von tropus - Quint. inst. 8,6,1-59; 8,6,67-76; 9,1,3-7; 9,2,44-53; insbesondere Quint. inst. 9,1,4: Est igitur tropos sermo a naturali et principali significatione translatus ad aliam ornandae orationis gratia, vel, ut plerique grammatici finiunt, dictio ab eo loco, in quo propria est, translata in eum, in quo propria non est. Das Extrahieren von Elementen aus ihrem ursprünglichen Erzählkontext erlaubt eine abstraktere Verwendung; vgl. Brilliant 1984, 73. Die Argumentationsfigur ist damit jener von Aby Warburg verwandt, der für diesen Transpositionsprozess von Bildideen von ,Bilderfahrzeugen“ spricht. Dieser Terminus ist in der Kunstgeschichte jedoch auf derart vielfältige Phänomene bezogen worden (vgl. Beyer et al. 2018), dass hier auf diese Metapher verzichtet wird. 
,Stillleben ${ }^{50}$ gleich mehrere monografische Behandlungen erfahren, für andere Gattungen gilt Ähnliches ${ }^{51}$. Üblicherweise liegt der Fokus ikonographischer Studien auf einer möglichst präzisen Benennung des Bildthemas. Im Fall der mythologischen Bilder bedeutet dies, dass die dem Bildentwurf zugrunde liegende schriftliche Mythenversion identifiziert wird und die Modifikationen, die das Bild vornimmt, diskutiert werden. Traditionelle ikonographisch-ikonologische Studien, die in der Tradition von Erwin Panofsky nach dem Bildsinn und symbolischen Bildbedeutungen fragen $^{52}$, lassen sich jedoch aus verschiedenen Perspektiven als ungenügend beschreiben.

Üblicherweise setzen ikonographische Studien die Eindeutigkeit von Bildinhalten voraus: Ein Bild ,bedeute' für verschiedene Betrachter jeweils dasselbe. Dies darf man aus verschiedenen Gründen infrage stellen. Schon einzelne Bildelemente sind durch Nichteindeutigkeit charakterisiert $^{53}$, erlauben eine Vielzahl an Assoziationen, die sich dem Betrachter je nach Kenntnishorizont (der in Abhängigkeit von der sozialen und kulturellen Zugehörigkeit unterschiedlich ausfallen mag), spezifischen Rezeptionserwartungen, momentaner Gefühlslage, Interesse bzw. Desinteresse erschließen können. Schon für einzelne Motive darf man folglich mit unterschiedlichen Rezeptionsformen rechnen ${ }^{54}$. Zwar ergibt sich für die einzelnen Bildelemente eine gewisse semantische Vereindeutigung durch ihre Kombination - der ikonographische Zusammenhang stellt einen Deutungsrahmen her. Doch auch das Gesamtbild ist prinzipiell für sehr unterschiedliche Diskurse offen ${ }^{55}$.

Indirekt bestätigt dies Vitruv, der vom Architekten ein historisches Wissen verlangt, das es ihm ermöglicht, die verwendeten (Bild-)Formeln erläutern zu können (Vitr. 1,1,5). So vermöge ein historisch gebildeter Architekt, weibliche Marmorstatuen quae caryatides dicuntur als Darstellungen der Bürgerinnen der persertreuen, dann aber von den Griechen besiegten, peloponnesischen Stadt Karya zu erklären. Dass diese pseudo-historische, aitiologisch motivierte und ,erfundene‘ Referenz der Karyatiden-Statuen in der Bevölkerung gerade nicht präsent war, ergibt sich daraus, dass der Architekt über solche Bedeutungen auf Nachfrage Rechenschaft ablegen können müsse ${ }^{56}$.

Während uns Vitruvs Beispiel zeigt, dass nicht alle Rezipienten auf denselben Wissenshorizont zugreifen können, bezeugen andere Quellen dezidiert individuelle Modi der Bildrezeption ${ }^{57}$. Bei

50 Mythenbilder etwa: Hodske 2007; Lorenz 2008; ,Stillleben‘: Beyen 1928; Eckstein 1957; Croisille 1965; kritisch zum Konzept dieser (modernen) Kategorie, s. Squire 2017, bes. 206f. - daher im Folgenden in Anführungszeichen.

51 Zu Mythenbildern Muth 1998; zu Achill auf Mosaiken etwa Russenberger 2002.

52 Panofsky 1939, 3-31; Panofsky 1975, bes. 36-50; zur Methode Eberlein 2008, bes. 179-182.

53 Grundlegend Eco 1998, der jedoch darüber hinaus unterscheidet, wie stark dem Betrachter eine aktive Rolle bei der Herstellung eines Kunstwerks zukommt. Hier spricht er im engeren Sinn von offenen Kunstwerken.

54 Zu den neuen Ergebnissen zur Müller-Lyer-Täuschung Henrich u.a. 2010; zur kulturellen und historischen Gebundenheit von Bild-Wahrnehmung etwa Foucault 1995; mit einer entsprechenden Lektüre Foucaults Prinz 2016, 184f.; zum „period eye“ Baxandall 2013; Geurts 2002, bes. 5 in Bezug auf das verkörperte Wahrnehmungswissen in einer afrikanischen Gemeinschaft; aus kunsthistorischer Perspektive Berger 1998, bes. 8-25; Freedberg 1989; Bryson 1991, bes. 72f.; aus archäologischer Perspektive etwa Clarke 2003, bes. 9-13; in Bezug auf römische Kunst Zanker 2000, 219f.; Elsner 2014; Mayer 2012, 178 zu Recht mit dem Hinweis, dass Deutungen, die von einer festgeschriebenen Bildbedeutung ausgehen, „milieu blind“ sind. Nicht nur soziale, sondern kulturelle Faktoren im weitesten Sinn sind hier in Rechnung zu stellen.

55 Zur Vereindeutigung der Bildbedeutung durch räumlichen Kontext, Betrachterhaltung und die Kombination mit anderen Bildelementen Zanker 2000, 216.

56 Perry 2005, 46 geht optimistischer von der Existenz einer verbindlichen „coherent, explanatory narrative“ aus. Übrigens liefern auch heutige Architekten Narrative, die die von ihnen gewählten Bauformen inhaltlich besetzen und aufwerten - man denke an Daniel Libeskind und seine ,Betextung des Jüdischen Museums in Berlin. So können einige semantische Ebenen des Baus lediglich in den Entwürfen sowie über die Stellungnahmen Libeskinds in den Medien nachvollzogen werden. Dies gilt insbesondere für die vier ,Grunddimensionen': der fragmentierte Davidstern, der sich aus dem unsichtbaren Netz kultureller Beziehungen zwischen Juden und Deutschen in Berlin ergibt; die unvollendete Oper 'Moses und Aron' von Arnold Schönberg; die Namen der ermordeten Berliner Juden; die Apokalypse Walter Benjamins. Sie finden ihren Niederschlag ausschließlich in der graphischen Gestaltung der Entwürfe und in ihrer Verbalisierung durch Libeskind (Libeskind 1991; 1994).

57 Zu diesem Aspekt ausführlich Elsner 2007. 
Plutarch ist es Porcia, die Frau des Brutus, die ein Bild, das den Abschied Hectors von Andromache zum Gegenstand hat, auf ihre eigene Situation, den Abschied ihres Mannes Brutus, bezieht ${ }^{58}$. Brutus deutet seinem Freund Acilius gegenüber den Mythos in Differenz zur eigenen Situation: Anders als Andromache sei Porcia keine Hausfrau, sondern kämpfe im Geiste wie die Männer fürs Vaterland. In Petrons Satyricon kommt der emotionalen Disposition des Betrachters eine wichtige Rolle bei der Bildrezeption zu. Der Held der Erzählung, Encolpius, war nach dem Gastmahl bei Trimalchio von seinem Geliebten, dem Knaben Giton, verlassen worden. In dieser Stimmung

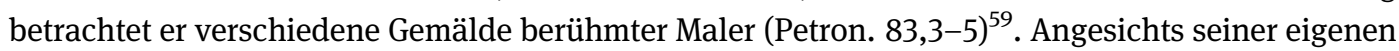
Situation neidet er den Göttern ihren Erfolg in Liebesdingen. Die dargestellten Mythen könnten jedoch unterschiedlicher nicht sein. Es handelt sich um die Entführung des Ganymed, den Raub des Hylas und die Verwandlung des Hyacinthus. Persönliche emotionale Situation und Bildwahrnehmung sind hier ineinander verwoben.

An dieser Stelle sei die Frage nach der Spezifik und Offenheit von Bildern noch einmal konkreter vom Bildthema ausgehend gestellt. Einzelne Bildmotive - eine Theatermaske, eine Mänade, ein Löwe - oder auch handlungsarme Bildzusammenhänge wie Landschaftsbilder und ,Stillleben` besitzen grundsätzlich einen sehr weiten, offenen Assoziationshorizont, der insbesondere durch das kulturelle Wissen der Zeit spezifiziert wird. Darüber hinausgehend können Bilder aber gezielt darauf angelegt sein, konkurrierende Assoziationen zu motivieren. In der Casa del Fauno trifft dies auf ein Mosaik mit einem geflügelten Wesen zu, das einen Skyphos haltend auf einem Tiger-Löwen reitet (Abb. 24) ${ }^{60}$. Ihm sind Züge der Amor-Ikonographie wie der BacchusIkonographie eingeschrieben ${ }^{61}$. Dieses Phänomen wird in der Forschung meist negiert, der ,Fehler wird entweder in einem antiken Missverständnis ${ }^{62}$ oder bei dem nicht hinreichend informierten modernen Betrachter gesucht. In Rechnung zu stellen wäre allerdings, dass solche Polyvalenzen gewollt sein können ${ }^{63}$. Im Fall des Amor-Bacchus erlaubt es die hybride Bildschöpfung etwa, aphrodisische und dionysische Assoziationen eng aufeinander zu beziehen.

Bei narrativen Bildern stellt der mythologische Erzählzusammenhang zwar eine gewisse Vereindeutigung her. Allerdings können bereits die Protagonisten selbst uneindeutig charakterisiert sein und so potenziell auf verschiedene Narrationen verweisen ${ }^{64}$. Schon das Verhältnis der Bilder zur Mythenerzählung kann sich vielfältig und spannungsreich ausnehmen. Offenheit ergibt sich aber vor allem durch verschiedene mögliche Rezeptionsebenen. Mythenbilder erlauben verschiedene paradigmatische Rezeptionsformen, wie sich am Beispiel des Encolpius gezeigt hat ${ }^{65}$.

Aus der prinzipiellen Offenheit der Bilder ergibt sich für die Untersuchung, dass verschiedene Framings benannt werden, die das Bildverständnis vereindeutigt haben können ${ }^{66}$ :

58 Plut. Brutus 23; vgl. Zanker 1999, 40.

59 Ausführlich Weber 1995, 114-116; vgl. Muth 1999a, bes. 109f.; Zanker 1999, 41.

60 Mayer 2012, 174-176 verweist auf die Darstellung eines Jünglings im Narcissus-Schema, bei dem der Verweis auf die Spiegelepisode fortgelassen ist und sich so die Frage stellt, ob überhaupt noch Narcissus gemeint ist.

61 Ausführlich Pesando 1996, 213.

62 In Bezug auf den Tiger-Löwen etwa Zevi 1998, 37: „Das Tier ist gewissermaßen ein Zwitter aus Tiger und Löwe [...]. Diese Unsicherheit einer naturgetreuen Darstellung ist überraschend angesichts des virtuosen Naturalismus bei anderen emblemata. Sie zeigt, daß man mit dem Aussehen des Tigers wenig vertraut war.“

63 Zur Polysemie im griechischen Kontext Osborne 2012.

64 s.u. S. 451-454.

65 Die Erschließung der vielfältigen Referenzebenen erfordert daher eine bildwissenschaftlich informierte Kontextanalyse, vgl. Muth 1998, 36-45; Lorenz 2008, 28-31; vgl. Newby 2016, bes. 2f. 9, mit weiterer Literatur. In einzelnen Fällen geben antike Bild-Ensembles selbst einen Hinweis für eine solche Aktualisierung. Dies gilt etwa für das Kapitell der Casa dei Capitelli figurati (VII 4,57), auf dem ein dionysisches und ein lebensweltliches Paar nebeneinander erscheinen. Es gilt aber auch für die Darstellungen von Porträts in der Wandmalerei, die auf Mythenbilder bezogen werden; s. dazu Bergmann 2018.

66 Zur Rahmenanalyse Goffman 1980; jüngst grundlegend zur Frame-Semantik in der Linguistik Busse 2012. 
1) der räumliche und mediale Kontext. Bilder sind durch ihr Medium, ihre Größe und ihre räumliche Platzierung auf ein spezifisches Verhältnis zum menschlichen Körper festgelegt ${ }^{67}$. Wenn etwa eine deutlich unterlebensgroße Skulptur in der Blick- und Bewegungsachse eines Hauses präsentiert wird, vermag ein erwachsener Betrachter sie leicht zu ,überblicken' und als Decor des Raumes wahrzunehmen. Ein Wandbild, das auf Augenhöhe erfahrbar wird, fordert eine intensivere Wahrnehmung ein als ,liminale‘ Bilder in der Sockel- oder Oberzone der Wand. Während Wandbilder als ,Gegenüber erfahrbar werden, sind Mosaikpavimente nur in Schrägsicht wahrnehmbar. Ein mit Decor-Elementen ausgestatteter Lectus bietet sich für eine konkrete Nutzung an, ein bebildertes Funktionsobjekt muss in die Hand genommen werden. Insbesondere jene Decor-Elemente, die wie Wandmalereien und Pavimente mit ihrem architektonischen Träger verbunden und dadurch auf einen spezifischen räumlichen Kontext festgelegt sind, rechnen mit bestimmten Betrachterhaltungen - etwa Bewegung und Ruhe. Verschiedene ,Betrachterhaltungen' korrelieren wiederum mit spezifischen Aufmerksamkeitsregimes. Es ist folglich erwartbar, dass Aufenthaltsräume (Tablina, Alae, Triclinia, Oeci, Cubicula) andere Decor-Strategien aufweisen als Räume der Bewegung (Fauces, Atrien, Peristyle) ${ }^{68}$ : In ersteren darf man eine intensive, in letzteren eine beiläufige Form der Betrachtung voraussetzen. Aber auch innerhalb eines Aufenthaltsraumes werden durch die Präsentationsform von Bildern unterschiedliche Aufmerksamkeiten nahegelegt.

2) der Bezug zu anderen Bildern. Der traditionelle Fokus der Ikonographie und Ikonologie auf das (Einzel-)Bild hat zur Folge, dass das Zusammenwirken verschiedener Bilder in dicht ausgestatteten Bildräumen aus dem Blick gerät. Gerade dieses Zusammenwirken stellt jedoch wiederum Vereindeutigungen her und öffnet andererseits Metadiskurse. Entscheidend ist dabei auch das Nebeneinander von Alt und Neu, von Fremd und Eigen ${ }^{69}$.

3) der visuelle Kontext im Decor-Zusammenhang. Der Fokus auf Bilder hat zur Folge, dass ihnen ein Status zugewiesen wird, den sie in der antiken Wahrnehmung kaum besessen haben, nahmen Bilder doch einen konkreten Ort innerhalb eines umfassenden Decor-Systems ein. Es ist diese visuelle Verortung in Bezug auf andere Decor-Elemente, die Bild-Wirkung und BildBedeutung mit generiert ${ }^{70}$. Architektur, Bilder und nicht-bildliche Elemente wirken bei der Erzeugung von Decor-Räumen zusammen. Eine systematische Trennung von ,Bild‘ und ,Ornament" ist deshalb aufzugeben, sie bestimmen sich in ihrem ontologischen und visuellen Status wechselseitig. Das intrinsische Verhältnis von Bild und Ornament wie auch von Ornament und Architektur wird sich als konstitutiv für die Ausbildung spezifischer decorativer Prinzipien erweisen: für die visuelle Organisation des Ambiente und damit auch für die Steuerung von Aufmerksamkeit ${ }^{71}$.

4) der Handlungskontext, in den der Betrachter eingebunden ist. Wahrnehmungspsychologische Studien erlauben die Annahme, dass der Handlungskontext maßgeblich zur Steuerung von Aufmerksamkeiten beiträgt und selektive Formen der Wahrnehmung motiviert ${ }^{72}$. Eine zentrale Rolle spielt die emotionale Disposition der Akteure ${ }^{73}$. Ein und derselbe Decor-Raum wie das Atrium muss folglich von einem antiken Betrachter je nachdem, welcher sinn- und

$67 \mathrm{Zu}$ Aspekten des Embodiment Bielfeldt 2018.

68 Mit dieser Beobachtung bereits Corlàita Scagliarini 1974, $18 \mathrm{f}$.

69 Zanker 1994, 287.

70 Der Begriff wird hier eingeführt in Bezug auf den von Zanker benutzten Begriff des Bild-Raums bzw. der RaumBühnen, s. Zanker 1994, 287; Zanker 2000, 205.

71 Exemplarisch ist diese Wechselbeziehung für frühgriechische Gefäße diskutiert, vgl. Haug 2015; für die pompejanische Wandmalerei am Beispiel der Casa degli Amorini dorati (VI 16,7.38), s. Platt 2018; s. hier ausführlich S. 540-547. 72 Goldstein 2008.

73 Kampen 2012 thematisiert für die Emotion der Trauer, die man im Haus anlassbezogen voraussetzen darf, wie die emotionale Situation das Bildverständnis formt und umgekehrt Bildformen eine emotionale Kontrolle befördern. Ihr Ausgangspunkt ist die Hilflosigkeit der Väter angesichts des Sterbens ihrer Kinder, wie sie etwa im Bild des Icarus greifbar wird. 
kohärenzstiftenden Handlung er nachgeht, ganz unterschiedlich wahrgenommen worden sein. Umgekehrt unterliegen dieselben Bildobjekte, wenn sie in unterschiedliche räumliche Kontexte und damit potenziell auch in unterschiedliche Handlungssituationen eingebunden waren, einer verschiedenartigen Wahrnehmung ${ }^{74}$.

Die genannten ,Framings' sollen im Folgenden systematischer entwickelt werden - in Bezug auf das Verhältnis der Decor-Elemente untereinander sowie zum umgebenden Raum einerseits sowie in Bezug auf das Verhältnis von Decor-Raum und Betrachter andererseits.

\section{Decor und Raum}

Die räumliche Gebundenheit von Decor-Elementen hat eine ganz unmittelbare Konsequenz für ihre Gestaltung: Sie stehen nicht isoliert, sondern in einem durch ihre räumliche Anbringung vorstrukturierten Zusammenhang.

\subsection{Die ästhetische Ordnung des Decor-Raumes}

Eine erste, vorgängige Ordnung des Decor-Raums wird durch die Architektur hergestellt, die häufig mit der Kontrastierung von konträr aufeinander bezogenen Raumqualitäten arbeitet: weit/eng; tief/hoch; flach/steil; offen/geschlossen; hell/dunkel. Dabei können verschiedene Materialien bzw. Materialqualitäten kontrastierend aufeinander bezogen werden: etwa weich/hart; flüssig/fest; künstlich/natürlich. Indem sich solche Kontraste auf spezifische räumliche Arrangements beziehen, entsteht eine räumliche Ordnung. Besonders wirkmächtige Strukturprinzipien sind Symmetrie, Rhythmus und Axialität (von Bewegung und Blick).

Die architektonische Raumordnung kann durch Decor-Elemente verstärkt, aber auch unterlaufen werden. Diese lassen sich ebenfalls entlang von binären Strukturkategorien beschreiben: einfach/komplex; zweidimensional/dreidimensional; floral/geometrisch; monochrom/polychrom; klein/groß. Häufig finden Decor-Formen Verwendung, um räumliche Übergänge (Schwellen, Türrahmen, Niveauwechsel) zu markieren, prominente Räume herauszuheben oder auch Raumgruppen durch gemeinsame Decor-Formen (z.B. einen einheitlichen Boden oder ein gleichartiges Wandschema ${ }^{75}$ ) zusammenzuschließen ${ }^{76}$.

Eine systematische Analyse der genannten architektonischen Gestaltungsformen und der darauf bezogenen Decor-Formationen hat für römische Wohnhäuser Carol Martin Watts vorgelegt. Sie bezieht sich in ihrer Untersuchung auf die von Christopher Alexander eingeführte ,Pattern Language ' und leistet damit einen systematischen Zugriff auf Raum-Decor-Relationen ${ }^{77}$. Sie belegt die Wirksamkeit der Strukturmerkmale mit zahlreichen Beispielen. Die Studie stellt damit einen wichtigen Ausgangspunkt für die folgenden Überlegungen dar, und doch bleiben bei Watts einige zentrale Aspekte unberücksichtigt: das konkrete Zusammenspiel der Strukturelemente; die Spezifika der einzelnen Decor-Formen (etwa der verschiedenen Wandmalerei-Stile); die Funktion und Bedeutung von Bildern; der Wandel von Architektur- und Decor-Schemata; das Verhältnis von menschlichem Akteur und Decor-Raum.

74 Zanker 1994, bes. $285 f$.

75 Zu einheitlichen Farbschemata und Böden etwa Watts 1987, 153-159.

76 Watts 1987, 220: „Ornament serves to tie parts together into a whole, particularly at boundaries between things. This use of ornament to emphasize boundaries is of special importance at the scale of the individual space.“

77 Watts 1987, Bezug nehmend auf die normativ konzipierte Architektursprache bei Alexander 1977. Indem die Prinzipien der Architektursprache auf antike Gebäude angewendet werden, werden die normativen Parameter Alexanders bei Watts zu analytischen Kategorien. 
Formale Gestaltungsprinzipien sind für die Wahrnehmung besonders wirkmächtig, da sie auf Prinzipien rekurrieren, die den Wahrnehmungsprozess organisieren. So hat die Gestaltpsychologie Grundprinzipien nachweisen können, die dem Betrachter helfen, in sensualistisch überdeterminierten Settings das wahrnehmbare ,Material' ${ }^{`}$ u strukturieren und zu selektieren ${ }^{78}$. Sie bestätigt, dass der architektonischen Disposition des Raumes eine zentrale Ordnungsfunktion zukommt. Seine Wahrnehmung bestimmt sich durch seine Zugänglichkeit und Beleuchtung. Die Perspektive, die der Betrachter einnehmen kann und ggf. muss, wird zu einer zentralen Kategorie der Ordnung von Wahrnehmung. Darüber hinaus unterliegen die Architektur und ihr Decor Wahrnehmungsprinzipien, die sich an Größe, Material (Oberflächentextur), Farbe, Kontrast mit dem Hintergrund, Komplexität, Redundanz/Überraschung (Regel/Abweichung), Ordnung/Unordnung (insbesondere Symmetrie und Axialität), Balance/Instabilität, Ruhe/Bewegung sowie Qualität und Quantität des Decors orientieren $^{79}$. Diese Prinzipien wirken in die Wahrnehmung inhaltlicher Qualitäten hinein, sie organisieren das visuelle Feld. Sie tragen dazu bei, dass sich bestimmte Bildelemente und Bilder zusammenschließen oder unterscheiden, sie organisieren die Bewegung im Raum - etwa durch Motive bzw. Bilder, die zum Verweilen einladen, und solchen, die Bewegung nahelegen ${ }^{80}$.

Decor-Räume entfalten ihre Wirkung folglich maßgeblich auf ästhetischer Ebene. Formalen Gliederungsprinzipien kommt eine besonders große Bedeutung zu, da sie durch Wahrnehmungsprinzipien verstärkt werden.

\subsection{Die semantische Ordnung des Decor-Raums}

Der Betrachter belegt seiner Umwelt immer schon mit Sinnzuschreibungen. Treten in einem DecorSetting jedoch figürlich-gegenständliche Gestaltungselemente hinzu, so intensiviert sich die Deutungsleistung. Für antike Decor-Räume ist charakteristisch, dass häufig mehrere Bildelemente in einem Raum nebeneinander treten und auf diese Weise komplexe Bild-Ensembles erzeugen. Diese lassen sich ihrerseits auf ihre Bezüge und die damit einhergehenden Wahrnehmungsmodi hin untersuchen.

Wir haben bereits gesehen, dass schon das Einzelbild polyvalent ausfallen und in verschiedene Diskurse eingebunden sein kann. Durch seine visuelle Korrespondenz mit anderen figürlichen Elementen werden jedoch zusätzliche Sinnpotenziale aktiviert, die über das jeweilige Einzelbild hinausgreifen. Für deren Erschließung ist eine besondere Abstraktionsleistung notwendig, der Betrachter ist als „struktureller Betrachter“ gefragt, der Ordnungsstrukturen nachspürt ${ }^{81}$. Je nach Art der Bildzusammenstellung kann die Vielzahl von Bildern zu einer Kontextualisierung des Einzelbildes, zu einer Fokussierung auf bestimmte Wahrnehmungsaspekte und damit zu einer Vereindeutigung der Bildaussage beitragen. Durch die Vielzahl von in sich polyvalenten Bildern kann die Bedeutungsvielfalt aber auch zusätzlich gesteigert werden ${ }^{82}$.

Grundlegend für die Frage der Intentionalität von Bildbezügen sind die Entstehungsbedingungen von Decor-Räumen. Jüngst haben David Ganz und Felix Thürlemann ${ }^{83}$ eine Unterscheidung

78 Explizit Gombrich 2002, 95f.; kritisch zur Übertragbarkeit der Ergebnisse der Gestaltpsychologie auf historische Kontexte Horrocks 2000, bes. 28-30. Zu Recht kritisiert er die einseitige Fokussierung kunsthistorischer Studien auf Symmetrie, Axialität und Rhythmus, die die Existenz einer Universalästhetik suggerieren. Dies ist jedoch auf eine verkürzende Perspektive auf die Wahrnehmungspsychologie, nicht auf die Methode selbst zurückzuführen. Tatsächlich eignen sich gestaltpsychologische Wahrnehmungsprinzipien als Ausgangspunkt, um danach zu fragen, wie Architektur- und Decor-Prinzipien und mit ihnen auch Sehgewohnheiten kulturspezifisch entwickelt werden.

79 Gombrich 2002, 117-148; s. auch Trilling 2001, 11; Haug 2014, 230 f.

80 Erstmals systematisch beobachtet bei Muth 1998, 61-63.

81 Zum Terminus Kemp 1994, $17 \mathrm{f}$.

82 Diese Option von Zanker 2000, 216 nicht in Rechnung gestellt.

83 Ganz - Thürlemann 2010, 16: „So soll von pluralen Bildern immer dann die Rede sein, wenn die Bildstruktur einen doppelten Produktions- und einen doppelten Rezeptionsakt impliziert.“ 
von „pluralen Bildern“ nach dem Modus ihrer Zusammenstellung vorgenommen und unterscheiden auf dieser Grundlage Bild-Ensembles, hyperimages und summierende Bilder ${ }^{84}$. Als Bild-Ensembles bezeichnen sie „Gefüge aus mehreren Bildeinheiten, die koordiniert geplant und hergestellt wurden“. Unter hyperimages werden autonome Bilder verstanden, die „unabhängig voneinander entstanden sind und nur temporär zu räumlichen Anordnungen zusammengefasst sind“. Von summierenden Bildern sprechen sie dort, „wo moderne Verfahren wie Überblendung, Collage oder Montage aus anderweitig hergestellten Materialien zum Einsatz kommen, deren additive Fügung im Werk erkennbar bleibt.“

So aufschlussreich diese Unterscheidungen für die Analyse visueller Zusammenhänge auch für antike Bildräume ist: Die inhaltlichen Bezüge, die einerseits der Auftraggeber/die Handwerker in Decor-Räume intentional einschreiben und die andererseits der Betrachter herstellt, sind damit nicht ausreichend differenziert erfasst. Dies gilt bereits für zusammenhängende Bild-Ensembles, für die sich mit Wolfgang Kemp nach der ratio relationis, dem ,Beziehungsgrund', fragen lässt, der die Darstellungen verbindet ${ }^{85}$. Ob für die verschiedenen Decor-Elemente eines Raumes von den Produzenten ein Tertium comparationis mitgedacht wurde, inwiefern dieses für die Betrachter nachvollziehbar war oder ob die Bildbeziehungen gänzlich offen angelegt waren, lässt sich nur konkret am jeweiligen Decor-Raum diskutieren. Noch komplexer nimmt sich die Diskussion für hyperimages aus. So sind die Skulpturenbestände eines Hauses zumeist nach und nach angeschafft worden $^{86}$. Dennoch können Neuanschaffungen mit Blick auf die bereits vorhandene Ausstattung gezielt geplant und zu bestimmten räumlichen Arrangements zusammengeführt worden sein. Gerade für solche semimobilen Objekte sind die Kategorien durchlässig ${ }^{87}$. Besonders dringlich stellt sich die Frage nach intentionalen Decor-Bezügen dann, wenn Decor-Räume im Laufe der Zeit verändert wurden, Altes neben Neues trat. Ob und in welcher Weise auf bestehende Ausstattungselemente intentional Bezug genommen wurde, kann auch dann nur im Einzelfall entschieden werden ${ }^{88}$.

Bei aller Vielfalt an Beziehungsoptionen sind architektonisch fixierte Decor-Elemente aber auf einen konkreten Ort innerhalb eines Raumes festgelegt, durch den ,Bild'- und ,Ornament'-Folgen eine räumliche und damit auch sinnstiftende Struktur erhalten ${ }^{89}$. Ihre Positionierung setzt sie in ein Verhältnis zueinander. Bei gleichzeitig in einem Raum wahrnehmbaren Decor-Elementen wird ihre Wahrnehmung durch ihre Platzierung organisiert ${ }^{90}$; das räumliche Arrangement leitet das Bildverständnis an. Formen der Raumaneignung wirken in die Bildrezeption hinein.

Für pompejanische Räume bedeutet dies, dass sich ein komplexes Beziehungsgeflecht zwischen den Gestaltelementen auf ein und derselben Wand, dann aber auch im Vergleich der Elemente in einem Raum ergibt, das durch das Wandsystem vorstrukturiert wird. Diese Bezüge sind auf einer formalen Ebene nach Entsprechungen (similitudo), Ähnlichkeiten/Variationen (vicinitas)

84 Zu den folgenden Zitaten: Ganz - Thürlemann 2010, $14 \mathrm{f}$.

85 Kemp 1994, 18, der hier auf scholastisches Vokabular zurückgreift. Kemp 1994, 17 entlehnt den Begriff des Syntagmatischen von Roman Jakobson, um gezielt nach „Relationsmustern“ zu fragen: „Die große Gemeinsamkeit der christlichen Kunstepoche, die von 400 bis 1400 reicht, ist die Dominanz der Bilder über das ,Bild‘ (im emphatischen Sinn, den ihm die Neuzeit gibt) und der Kontexte über den Text.“

86 Mayer 2012, 191.

87 Es sind insbesondere die mobilen Ausstattungselemente (die im Rahmen der vorliegenden Untersuchung nicht berücksichtigt werden), die sich zu immer neuen, ephemeren hyperimages fügen.

88 Ehrhardt 2012.

89 Kemp 1995, bes. 103.

90 Ein solch aktiver Beitrag des Raumes zur Bedeutungsgenerierung wird besonders gut dann greifbar, wenn die räumliche Bildanordnung einer narrativen Sequenz zuwiderläuft, s. Brilliant 1984, 67 für die literarische Fiktion des Arrangements der Achillbilder in der Domus Ubobi. 
und Unterschieden (contrarium) strukturiert, auf inhaltlich-narrativer Ebene lassen sich affirmative, komplementäre, kontrastierende und konsekutive Verknüpfungen unterscheiden ${ }^{91}$.

Im Fall von Ausstattungselementen, die auf verschiedene Räume verteilt und daher nicht gleichzeitig sichtbar sind, ist es nicht der visuelle Zusammenhang, der ein Ensemble konstituiert, sondern die Erinnerung des Betrachters ${ }^{92}$. Er vermag sich den Zusammenhang erst durch die Bewegung zu erschließen ${ }^{93}$. Solche assoziativen Bezugnahmen, die sich zwischen verschiedenen Räumen eines Hauses einstellen, sind methodisch noch einmal schwerer zu plausibilisieren.

\section{Raum, Architektur und Handlung}

Das Wechselspiel von Decor und Raum führt uns zum Betrachter sowie den ,Haltungen“ und Handlungen, die für spezifische Decor-Räume vorauszusetzen sind. Die Forschung hat sich dabei 1) kritisch mit den Raum-,Funktionen' auseinandergesetzt, 2) statische und peripatetische Wahrnehmungshaltungen unterschieden und 3) die Form der Raumaneignung an eine Gegenüberstellung von öffentlich und privat geknüpft. Diese drei Zugangsweisen sollen im Folgenden diskutiert werden.

\subsection{Das Problem der Raum-,Funktionen`}

Raum-,Funktionen“ im Sinne stabiler Handlungsmuster, die sich mit bestimmten architektonischen Konstellationen verbinden, sind für die Bestimmung der Interdependenz von Architektur, Decor und Handlung von großer Relevanz. Die traditionellen Forschungsansätze sind jedoch einer kritischen Diskussion zu unterziehen.

Seit dem 19.Jh. hat die Forschung einzelne Raumtypen des römischen Wohnhauses im Lichte der Wohnerfahrungen ihrer eigenen Zeit mit aus der antiken Literatur bekannten Raumbegriffen verknüpft ${ }^{94}$, diese mit konkreten Handlungsoptionen verbunden und daraus die vermeintlich kontextspezifische Rezeption des Decors erschlossen ${ }^{95}$. Speisezimmer wurden so zu Räumen, deren Decor Bacchus feiert, während Cubicula mit „Symbole[n] und Mythen der Liebe“ geschmückt seien $^{96}$.

Bereits Andrew Wallace-Hadrill erkannte die Problematik dieses Dreischritts und beschränkte sich in seiner Untersuchung darauf, den Zusammenhang von Ausstattung und Raumtypen, die er mit konventionellen Namen ansprach, zu diskutieren. Nur im Fall des Atriums stellte er eine konkretere Verbindung zwischen Raumtypus und sozialer Aneignung her. Wie die Forschung vor ihm bezog er den Terminus atrium auf den durch Compluvium und Impluvium gekennzeichneten Hofbereich im vorderen Hausteil, um hier den Morgenempfang (salutatio) der Klienten zu lokalisie-

91 Siehe dazu Bergmann 1994; Lorenz 2008 - ausführlich u. S. 454-465. Jüngst werden solche ,Bild‘-Beziehungen unter dem Schlagwort der ,Interpiktorialität‘ untersucht. Isekenmeier 2013, bes. 76 unterscheidet verschiedene ,Grade“ an „Abweichung“, die sich durch eine Varianz im Material, in der Form und im Stil kennzeichnen. Er ordnet diesen Transformationen verschiedene Termini zu (z. B. Transposition, Paraphrase, Anspielung). Für den Umgang mit antiker Wandmalerei sind diese jedoch letztlich nicht hilfreich, weil sie sich auf das gesamte Feld an Interpiktorialitätsoptionen beziehen. Vor allem aber ist der Terminus für das antike Phänomen zu eng und zu weit zugleich: zu eng, weil er die räumliche Gegenüberstellung von thematisch unterschiedlichen Bildern nicht beschreibbar macht, zu weit, weil er auch den Rekurs auf Bildschemata mit einschließt, deren ,Ursprung' sich kaum einmal fassen lässt (hier als ,Decoscapes'). Auf den Gebrauch des Terminus wird hier daher verzichtet.

92 So explizit Brilliant 1984; Bergmann 1994; jüngst Elsner - Squire 2016, bes. $191 \mathrm{f}$.

93 So auch Ganz - Thürlemann 2010, 18-21.

94 Kritisch Dickmann 1999, 23f.; Lorenz 2008, 16-18; erneut Dickmann 2011, 54.

95 So bereits Mau 1908, bes. 250-289, der die Begriffe auf ein ,typisches‘ römisches Atriumhaus (später sog. StandardAtriumhaus) bezieht.

96 Schefold 1952, $34 \mathrm{f}$. 
ren. Selbst dieser Zusammenhang ist jüngst jedoch kritisch hinterfragt worden. So wird der Terminus atrium allein bei Vitruv typologisch definiert, sonst aber heterogen gebraucht. Selbiges trifft auf die Bezeichnung tablinum zu, sodass diese Begriffe kaum auf spezifische Raumkonstellationen bezogen werden können ${ }^{97}$.

Eine umfassende kritische Diskussion von Raumtypen und ihren aus der antiken Literatur abgeleiteten Termini haben Eleanor Leach, Andrew Riggsby und Jens-Arne Dickmann unternommen $^{98}$. Sie zeigen, dass antiken Raumbezeichnungen verschiedene Benennungsprinzipien zugrunde liegen. Cubicula und Triclinia sind etwa durch ihre Ausstattung mit Klinen als ,Liegeräume“ charakterisiert, die aber in ausgesprochen vielfältiger Weise nutzbar sind ${ }^{99}$. Schon diese Liegefunktion ist jedoch archäologisch schwer zu greifen. Anna Anguissola bezieht in ihre Untersuchung zu Cubicula daher nur jene Räume ein, für die aufgrund spezifischer Ausstattungselemente - insbesondere Alkoven, Wandvertiefungen, aber auch Spezifika im Decor - die Aufstellung von Klinen plausibel gemacht werden kann ${ }^{100}$. Diese enge Definition hat allerdings zur Folge, dass in einem großen Haus wie der Casa del Fauno nur ein einziger Raum als Cubiculum angesprochen werden kann, obwohl das Haus über zahlreiche weitere ,kleine' Räume verfügt. Dies dürfte kaum den Nutzungsgepflogenheiten entsprochen haben. Noch restriktiver geht Laura Nissin vor, die für Herculaneum nur jene Räume als Schlafräume begreift, in denen ein hölzernes Bett nachweisbar war ${ }^{101}$. Schon die Erhaltungs- und Dokumentationsbedingungen sind problematisch, weiterhin können Betten vielfältig genutzt und innerhalb eines Hauses immer wieder an neue Orte verbracht worden sein.

Die Verwendung des Begriffs triclinium zur Bezeichnung von Gelageräumen ist erstmals im 2.Jh.v. Chr. greifbar, er wird bei Lucilius und im 1.Jh.v.Chr. bei Varro sowohl für den Raum selbst als auch für das Mobiliar verwendet ${ }^{102}$. Trotz dieser Ambivalenz ist der Terminus insofern verhältnismäßig konkret, als er sich auf die Aufstellung von drei lecti bezieht. Archäologisch steht die Existenz von Speiseliegen nur dann außer Zweifel, wenn sie in Mauerwerk ausgeführt sind, durch eine Einlassung in der Wand oder durch einen T- oder U-förmigen Boden-Decor bezeugt sind ${ }^{103}$. Schon bei Cubicula und Triclinia, deren Nutzung literarisch gut bezeugt ist, ergeben sich somit erhebliche Schwierigkeiten.

Anders nimmt sich die Situation im Falle der Exedren aus. Sie sind bei Vitruv architektonisch als Räume mit weiter Öffnung definiert, ohne dass dies eine spezifische Form der Nutzung mit sich gebracht hätte. In ähnlicher Weise stehen Peristyle, die (nach moderner Konvention) bautypologisch als von Portiken umgebener Garten definiert sind, sehr unterschiedlichen Nutzungsformen offen ${ }^{104}$. Kaum mit einer spezifischen Raumgruppe zu verbinden ist schließlich der in der antiken Literatur ohnehin nur sporadisch verwendete Terminus la $^{105}$.

97 Zum tablinum etwa Leach 1997, 52f.; Trimble 2002, 242 mit dem Hinweis, dass die Schriftquellen keine Verbindung von tablinum und salutatio herstellen - ein Aspekt, der später noch relevant wird.

98 Leach 1997; Riggsby 1997 (zum Cubiculum); Dickmann 1999; 2011.

99 Riggsby 1997 benennt folgende „patterns of association“: rest, sex, adultery, controlled display of art, murder and suicide, reception. Er geht von einem - verglichen mit anderen Räumen - privateren Charakter des Raumes aus; eine umfangreiche Diskussion erneut bei Nissinen 2009, die darauf hinweist, dass die Räume unter besonderen Umständen auch dem Gästeempfang dienen konnten; zuletzt Platts 2020, $133 \mathrm{f}$.

100 Zuvor bereits Elia 1932, bes. 394; Anguissola 2010.

101 Nissin 2016, $22 \mathrm{f}$.

102 Lucil. 1237f. [Christes/Garburgino]; im 1.Jh.v.Chr. gebraucht Varro den Begriff mehrfach; vgl. Schnurbusch 2011, 66 mit Verweisen.

103 Gemauerte Speiseliegen etwa in der Casa del Moralista (III 4,2) und der Casa del Criptoportico (I 6,2-4); Wandöffnungen in der Casa dei Dioscuri (VI 9,6) und der Casa dell'Efebo (I 7,11).

104 Simelius 2018, bes. 33-40 zu Schwierigkeiten der Peristyldefinition; sein Vorschlag: ,an open space with a garden that featured, at least on one side, a portico, defined by at least one free-standing column or pier, and the garden and the portico must be more-or-less on the same level, so that the garden can be accessed immediately from the portico." 105 Vitruv spricht in Bezug auf den Tempelbau von Seitenräumen $(4,7,2)$, bisweilen wird aliae in alae geändert, kritisch C. Fensterbusch; vgl. Cova 2015, 73f. 
Diese Schwierigkeiten reflektieren den Umstand, dass die Räume des römischen Wohnhauses keine festgeschriebenen Funktionen besaßen. Anders formuliert sind Architekturen keine Container für spezifische Handlungen, vielmehr können sie je nach Bedarf in unterschiedlicher Weise in Anspruch genommen werden ${ }^{106}$.

Dies gilt allerdings für manche Räume mehr als für andere. $\mathrm{Zu}$ einer stärkeren funktionalen Festlegung trugen dauerhafte Installationen bei. Insbesondere Küchen und Latrinen waren durch Installationen auf spezifischere Nutzungsformen festgelegt ${ }^{107}$. Entschied man sich dafür, in eine Ala einen Schrank einzubauen, so war die ,freie‘ Nutzung des Raumes erheblich eingeschränkt ${ }^{108}$. In anderen Raumkonstellationen beanspruchen Installationen weniger Platz, sodass sie zwar bestimmte Nutzungsmöglichkeiten schaffen ${ }^{109}$, ohne jedoch Räume in ihrer Funktion zu determinieren. So ermöglichten Zisternen in den Höfen des Hauses die Entnahme von Wasser, gemauerte Sockel waren in den Atrien für die Aufstellung von Arcae vorgesehen. Waren Webstühle im Atrium aufgestellt ${ }^{110}$, so wird es von ihrer Größe abhängig gewesen sein, ob man diese ,ad hoc' in einen anderen räumlichen Bereich versetzen konnte.

Üblicherweise nutzte man leichte Möbel, die in den Dienst einer flexiblen Raumnutzung treten konnten. Insbesondere die repräsentativ ausgestatteten Räume, in denen dauerhafte Installationen oft fehlen, waren vielfältig bespielbar. Wenn die Gäste das Haus verlassen haben, mögen die Prunkräume von spielenden Kindern in Beschlag genommen worden sein ${ }^{111}$. Unterschiedliche Nutzungen dürften sich in Abhängigkeit von Tages- und Jahreszeiten, von Wind- und Wetterverhältnissen sowie von Alltag und Fest ergeben haben ${ }^{112}$.

Besonders ,frei' einsetzbar waren im römischen Wohnhaus die mobilen Objekte. In der älteren Forschung hat man Fundverteilungen häufig dazu genutzt, um Aussagen zu bestimmten Raumfunktionen zu treffen. Allerdings wurde die Fundsituation von Objekten nur sehr unpräzise dokumentiert, wertvolle Objekte können im Moment des Ausbruchs mitgenommen und auch noch danach ,geraubt' worden sein, verschiedene postdepositionale Prozesse stören das Auffindungsmuster. Hinzu kommt, dass der Aufbewahrungsort und Nutzungsort keineswegs zusammenfallen müssen. So findet sich Geschirr meist an seinem Aufbewahrungsort und nicht am Ort, wo gespeist wurde $^{113}$. Auf der Seite der Objekte ist zu bedenken, dass auch sie nicht auf spezifische Funktionen

106 Zur Frage der funktionalen Festgelegtheit bzw. Offenheit von Wohnräumen im hellenistischen Sizilien, s. Dickmann 2011; Haug - Steuernagel 2014.

107 Mit dieser Argumentation auch Dickmann 2011, 54; zur tageszeitspezifischen Nutzung von Räumen allgemein Laurence 1994, 122-132; Nissin 2016, 16.

108 Ausführlich Cova 2015, allerdings lassen sich die Eingriffe meist nicht datieren.

109 Um den Angebotscharakter von Objekten (und hier: Räumen) zu beschreiben, wurde von dem Gestaltpsychologen James J. Gibson der Terminus ,affordance“ eingeführt; vgl. Gibson 1986, 127: „Perhaps the composition and layout of surfaces constitute what [things] afford. If so, to perceive them is to perceive what they afford. This is a radical hypothesis, for it implies that the 'values' and 'meanings' of things in the environment can be directly perceived."; aufgegriffen bei Norman 1990, bes. 9: „The term affordance refers to the perceived and actual properties of the thing, primarily those fundamental properties that determine just how the thing could possibly be used." Norman unterstellt den Objekten (etwa auch Türen etc.) kommunikative Qualitäten, die ihre Benutzung regulieren: „Affordances provide strong clues to the operations of things.“

110 Zum Arbeiten mit Wolle im Atrium (bei Nacht!): Liv. 1,57,9.

$111 \mathrm{Zu}$ spielenden Kindern im Hof: Verg. Aen. 7,379; Tib. 1,10,15f. spricht von den Laren, vor deren Füßen (ante pedes) die Kinder herumlaufen.

112 Zur tageszeitspezifischen Nutzung von Cubicula: Nissinen 2009; zum Atrium Dickmann 2011, 61. 71.

113 Allison 2006, bes. 12-15. 389. Sie reflektiert einige Probleme, die ihr in ihren älteren Arbeiten zur Artefaktdistribution (Allison 1994; Allison 1997; Allison 2004) vorgeworfen worden waren. Insbesondere stellt diese Monographie eine systematische Analyse eines Hauszusammenhangs dar, während ihre älteren Publikationen den kontextuellen Zusammenhang unberücksichtigt ließen (dazu Flohr 2005, 590; Dickmann 2006, 290). Durch diesen Fokus auf ein Haus werden jedoch andere problematische Implikationen der älteren Arbeiten nicht ausgeräumt. Dies gilt insbesondere für den Fokus auf Atriumhäuser, die daran anschließende Annahme einer standardisierten, normierten Form der Fundverteilung (über soziale Unterschiede hinweg), für den problematischen Umgang mit Statistik und insbesondere für eine methodische Schwäche im Umgang mit verlorenem Material (Flohr 2005; Dickmann 2006). Mit Kritik an einer 
festgelegt, sondern vielfältig nutzbar waren ${ }^{114}$. Schon die Frage, ob es sich um ein Repräsentationsoder ein Aufbewahrungsgefäß handelt, kann nicht immer eindeutig bestimmt werden ${ }^{115}$. Entscheidet man sich dennoch für eine Analyse der Verteilungsmuster von Fundobjekten, so sind diese nur bedingt aussagekräftig. In der Casa del Menandro (I 10,4) stammen Webgewichte etwa aus den unterschiedlichsten räumlichen Zusammenhängen ${ }^{116}$, für einige Häuser lassen sich überhaupt keine signifikanten Verteilungsmuster erkennen ${ }^{117}$.

Diese Überlegungen führen zu dem Ergebnis, dass man in antiken Wohnhäusern von flexiblen, akzidentiellen Nutzungsformen ausgehen muss. Auf die terminologische Festschreibung von Raumfunktionen, wie sie die Verwendung spezifischer Raumbezeichnungen nahelegt, wäre folglich zu verzichten ${ }^{118}$. Moderne Benennungen, die stabile Nutzungszusammenhänge anzeigen (z.B. ,Schlafzimmer` oder ,Empfangszimmer'), sind nicht weniger problematisch. Stattdessen dürften konsequenterweise allein Raumnummern zur Bezeichnung von Räumen genutzt werden. Damit würde jedoch jede schnelle räumliche Orientierung verloren gehen, weshalb in der vorliegenden Studie an dem in der Forschung eingebürgerten konventionellen Gebrauch der Termini festgehalten wird $^{119}$. Damit geht einher, dass Raumbezeichnungen pauschal verwendet werden: Kleine, von einer Tür verschlossene Räume werden als Cubicula bezeichnet, größere Räume, die wenigstens theoretisch für die Aufstellung von mehreren Klinen genutzt werden konnten, als Triclinia oder Oeci. Alae und Tablina werden entsprechend ihrer Platzierung innerhalb des Hauses benannt, offene Räume als Exedrae. Die genannten Termini dienen nur als Orientierungshilfen, um die Räume im Grundriss rasch auffinden zu können. Für die Frage der konkreten Nutzung müssen weitere Kriterien (Installationen, Größe, Zugänglichkeit, Einbindung in den Hausgrundriss etc.) herangezogen werden.

\section{2 Öffentlich und privat im römischen Wohnhaus}

Die Diskussion von Nutzungsformationen im römischen Haus gab Anlass zu einer strukturalistischen Perspektive auf Wohnhäuser: die Gliederung in (stärker) öffentliche und (stärker) private Bereiche. Das Haus habe als domus frequentata einerseits einer quasi öffentlichen Nutzung offengestanden, andererseits habe es als privater Rückzugsort, als sanctum refugium, fungiert. Die Überlegungen basieren einerseits auf der Nähe einzelner Räume zur Straße und auf ihrer Verschließbarkeit, andererseits auf den für die Räume angenommenen Handlungen. Architekturformen und Ausstattungselemente hätten - so etwa Lise Bek und Filippo Coarelli - auf die privaten und öffentlichen Nutzungsformen Bezug genommen und so eine Differenzierung des Hauses in stärker privat und stärker öffentlich genutzte Areale hergestellt ${ }^{120}$. Eine solche räumliche Gliederung würde die antithetisch aufeinander bezogenen Lebensformen - Otium und Negotium ,abbilden'.

fehlenden Kartierung der Objekte Dubouloz 2005, 415; Berry 1997 mit einer kritischen Diskussion der Belastbarkeit und Interpretierbarkeit von Kleinfunden (insbesondere in Bezug auf die Dokumentationssituation).

114 Allison begegnet diesen Schwierigkeiten, indem sie aus der Objektanalyse zunächst verschiedene Tätigkeitsbereiche erschließt: Aufbewahrung von Nahrungsmitteln, Essenszubereitung, Nahrungsaufnahme, Beleuchtung, Schlafen, Körperpflege, Religion, Spiele, Wiegen, Spinnen, Landwirtschaft; s. Allison 2006, 387-398.

115 Zu entsprechenden Schwierigkeiten der Funktionsdefinition auch Dubouloz 2005, 415.

116 Allison 2006, 387-398.

117 Berry 1997, 194.

118 Mit diesem Vorschlag Allison 2004, 8-12. 43-47.

$119 \mathrm{Zu}$ dieser Lösung etwa Dickmann 2006, 288, der sich kritisch mit Penelope Allisons Verzicht auf solche Termini auseinandersetzt.

120 Bek 1980; Coarelli 1983. Ähnliche Beobachtungen fließen in die von Strocka 1984 publizierte Auswertung der Wandmalereien vierten Stils in der Casa del Principe di Napoli ein. Dickmann 1999 wählt domus frequentata als Titel seines Buches. 
Wallace-Hadrill entwickelt auf dieser Basis seine Überlegungen zur sozialhierarchischen Strukturierung des Wohnraums ${ }^{121}$. Architektur und Decor, Zugänglichkeit und Repräsentativität, tragen in seinem Modell gleichermaßen zur sozialen und ästhetischen ,Ordnung des Hauses bei. Er ergänzt die Achse public/private um die Dimension grand/humble, die in seinem Modell gerade nicht zusammenfallen, sondern ein Achsenkreuz bilden. Die von ihm postulierten Akteursgruppen werden diesen Achsen zugeordnet: pater familias: grand/private; amici: grand/public; servi: humble/private; clientes: humble/public. Einzelne Raumtypen (Atrium, Tablinum, Triclinium, Cubiculum, Serviceräume) im Haus werden auf diese Achsenstruktur bezogen, wobei die ,vorderen', nahe des Eingangs gelegenen Räume am Atrium üblicherweise als public, die im hinteren Hausteil am Peristyl gelegenen als private angesprochen werden ${ }^{122}$. An dieser Stelle sind einige grundsätzliche Annahmen Wallace-Hadrills zu diskutieren. Die Kritik an diesem Modell setzt bei seiner Auffassung der Hausarchitektur, bei seinem Decor-Verständnis und den von ihm postulierten Praxen an.

1) Das Modell Wallace-Hadrills wurde in der Altertumswissenschaft intensiv rezipiert, etwa von Susanne Muth, Rolf Tybout, Eleanor Leach, Bettina Bergmann und Katharina Lorenz ${ }^{123}$. Diese Arbeiten gehen von einem speziellen Decor-Phänomen (bei Lorenz etwa Mythenbilder) aus und betrachten es in seinem räumlichen Kontext. Bei Muth und Lorenz wird Decor jedoch nicht allein als Anzeiger für Raumfunktionen und für die sozialhierarchische Bedeutung von Räumen aufgefass ${ }^{124}$. Sie erweitern Wallace-Hadrills Konzept um die Vorstellung, dass Decor eine ambientale Funktion besitzt, d.h. zur Schaffung spezifischer, für ein Ambiente ,passender Raumatmosphären eingesetzt wird ${ }^{125}$. Muth und Lorenz argumentieren daher zu Recht, dass Handlungsszenarien, die man für Räume annimmt, nicht darauf reduziert werden können, was die Bilder ,atmosphärisch` nahelegen, und auch umgekehrt können die Bilder nicht im Hinblick auf die erwarteten Handlungsszenarien gedeutet werden ${ }^{126}$. Die ,Passung von Decor und Handlung - und damit die Modi der Erzeugung von Atmosphäre - können sich damit sehr unterschiedlich ausnehmen. Decor kann spezifische Atmosphären stimulieren, die durch Handlungen intensiviert, aber auch negiert werden können ${ }^{127}$.

2) Eine grundsätzliche Schwierigkeit besteht in dem Versuch, die soziale Wertigkeit von DecorElementen a priori festzulegen. In einigen Fällen wird man Decor-Formen zwar als verschieden beschreiben, nicht aber in ein klares hierarchisches Verhältnis zueinander setzen können. Dies gilt etwa für Opera sectilia und aufwendige Bildmosaiken, wie sie in der Casa del Fauno nebeneinander auftreten ${ }^{128}$. Ausstattungsensembles können folglich verschiedenartige, aber potenziell gleichwertige Gestaltungsoptionen umfassen. Damit sei nicht in Abrede gestellt, dass sich in anderen Fällen Decor-Formen hinsichtlich ihres Aufwands und ihrer Qualität unterscheiden können. Hier ist aus methodischer Hinsicht eine besonders differenzierte Argu-

121 Wallace-Hadrill 1988, 50-58; 1994, bes. 38-61.

122 Simplifizierend rezipiert bei Tybout 2001, 42f. Zapheiropoulou 2006, 148f.; von Stackelberg 2009, 62; ausführlicher diskutiert bei Grassigli 1998, 41-54.

123 Muth 1998, 49-53; Tybout 1993; 2001; Hales 2003, bes. 101-122; Leach 2004, 18-54; Bergmann 1994, 231; Lorenz 2008, 21-26.

124 So etwa Corlàita Scagliarini 1974, 3: „,...] connotare a livello culturale, sociale, psicologico l'attività prevalente a cui l'ambiente è destinato.“; ähnlich Barbet 2009, 57 für den zweiten Stil mit der Annahme „[...] que chaque type de pièce peut recevoir une décoration appropriée qui diffère selon sa destination et ses dimensions“; kritisiert bei Strocka 1991, 115f.; Dickmann 1999, 241; kritisch für spätere Stilphasen auch Tybout 2001, 53 mit Verweis auf die statistische Auswertung von Bildthemen in Triclinia bei Ling 1995.

125 Muth 1998, bes. 55f.; Lorenz 2008, 23-25. 431-442, die unter dem Stichwort der Atmosphäre thematische Schwerpunktsetzungen in bestimmten Raumgruppen versteht.

126 In Bezug auf die ,dionysische‘ Ausstattung von Triclinia bereits hinterfragt bei Ling 1995.

127 Muth 1998, 68.

128 s. u. S. $188-191$. 
mentation notwendig. Die von Wallace-Hadrill vorgenommene Differenzierung in grand/humble greift sicherlich zu kurz.

3) Mit Blick auf die Definition von Raumhierarchien wurde Wallace-Hadrills einseitiger Fokus auf Wandmalerei als das einzige zur Analyse von visuellen Hierarchien herangezogene Element kritisiert ${ }^{129}$. Fasst man die Gesamtheit decorativer Elemente ins Auge, so ergeben sich komplexe Ausstattungssamples, deren Position auf der Achse grand/humble noch einmal schwerer $\mathrm{zu}$ bestimmen ist. Mit sehr aufwendigen Böden können einfache Formen der Wandgestaltung einhergehen, und umgekehrt. Noch viel weniger wissen wir über die Decken, die seit der späten Republik auch in Wohnhäusern mitunter vergoldet wurden und im Aufwand die Böden und Wände um ein Vielfaches übertreffen konnten ${ }^{130}$. Die Wechselwirkungen zwischen verschiedenen Ausstattungselementen können intendiert sein: Die Wirkung eines Decor-Elements kann dadurch gesteigert werden, dass andere Decor-Elemente dahinter zurücktreten. Wenn nur einzelne Elemente eines Decor-Raums erhalten sind, lassen sich Decor-Hierarchien letztlich nicht zuverlässig greifen.

4) In Bezug auf die Architekturanalyse wurde von Mark Grahame kritisiert, dass die Achse public/ private vom ,Hauptzugang، aus konzipiert ist (der durch die Fauces auf das Atrium führt), eventuelle ,Nebeneingänge“ einen solch linearen Zuschnitt aber durchkreuzen können ${ }^{131}$. Diese theoretisch formulierte Kritik erhält besonderes Gewicht, wenn man sich beispielhaft die Casa dei Capitelli colorati (VII 4,31.51) in ihrem Zustand um 100 v. Chr. vor Augen hält. Das Haus besaß zu diesem Zeitpunkt nicht nur einen Zugang (VII 4,31) über die Fauces (1), von wo aus man in das Atrium (2), Tablinum (13) und in die rückwärtigen Peristyle $(18 ; 40)$ gelangte. Ein zweiter Eingang (VII 4,51) lag auf der gegenüberliegenden Hausseite und führte über tiefe Fauces (50) direkt in das große Nordperistyl (40). Es ist dieser ,hintere‘ Eingang, der zur Straße hin durch prunkvolle Figuralkapitelle hervorgehoben war. Betrat man das Haus von hier aus, so war die Raumsequenz , auf den Kopf' gestellit ${ }^{132}$.

5) Für die strukturelle Differenzierung des Hauses entlang der Achsen von privat und öffentlich geht Wallace-Hadrill von zwei weiteren, problematischen Grundannahmen aus: die vermeintlich ,freie‘ Zugänglichkeit und Transparenz des römischen Wohnhauses, die seine öffentliche Wahrnehmung determinieren, und die relativ starre Festlegung einzelner Räume auf eine eher ,private، oder eher ,öffentliche“ Nutzung ${ }^{133}$. Eine zentrale Quelle stellen in diesem Zusammenhang Vitruvs Ausführungen zum römischen Wohnhaus dar (Vitr. 6,5,1). Sie wurden als Beleg für die freie Zugänglichkeit, den öffentlichen Charakter des Hauses und seine Gliederung in öffentliche und private Bereiche gelesen ${ }^{134}$. Aus diesem Grund soll der Text eingehender betrachtet werden.

Cum ad regiones caeli ita ea fuerint disposita, tunc etiam animadvertendum est, quibus rationibus privatis aedificiis propria loca patribus familiarum et quemadmodum communia cum extraneis aedificari debeant. Namque ex his | quae propria sunt, in ea non est potestas omnibus introeundi nisi invitatis, quemadmodum sunt cubicula, triclinia, balneae ceteraque, que easdem habent usus rationes. Communia autem sunt, quibus etiam invocati suo iure de populo possunt venire, id est vestibula, cava aedium, peristylia quae|que eundem habere

129 Grahame 1997, 139-142; Lorenz 2008, 22.

130 Lipps 2018.

131 Grahame 1997, $140 \mathrm{f}$.

132 PPM VI (1996) 996-1107 s. v. VII 4,31.51, Casa dei Capitelli colorati (J.-P. Descoeudres) 996f.

133 Wallace-Hadrill 1988, 46; 1994, 5; ihm folgend Zanker 1995, 16-20; Flower 1996, 92; erneut Wallace-Hadrill 2010, 194; jüngst kritisch in Bezug auf die Termini public/private - Platts 2020, 16f. $80 \mathrm{f}$.

134 Wallace-Hadrill 1994, 10 f.; aufgegriffen bei Zevi 1998, 32; Zevi 2000, 121; Flower 1996, 188. 199; George 1997, 300; Muth 1998, bes. 50; Dickmann 1999; Winterling 2005, 229 geht in Bezug auf die Vitruvpassage davon aus, dass in privata aedificia zwei verschiedene Bereiche existieren - communia loca (also öffentlich zugängliche Bereiche) und propria loca (für geladene Gäste); ebenso Schnurbusch 2011, 20; jüngst Tuori 2015, bes. 7 f. 
possunt usum. Igitur is, qui communi sunt fortuna, non necessaria magnifica vestibula nec tabulina neque atria, quod aliis officia praestant ambiundo neque ab aliis ambiuntur ${ }^{135}$.

Zunächst ist festzuhalten, dass Vitruv die präskriptive und deskriptive Ebene nicht trennt ${ }^{136}$. Er führt zwei miteinander gekoppelte Aspekte ein: den Gästestatus (eingeladen/nicht eingeladen) und die Zugänglichkeit von Räumen. Der Einlass von nicht eingeladenen Gästen in die zentralen Hofbereiche bedeutet jedoch nicht, dass das Haus allen Leuten der Stadt offengestanden, d.h. frei zugänglich gewesen wäre ${ }^{137}$. Vielmehr legen geschlossene Fassaden, kleine Außenfenster und komplex gestaffelte Zugangslösungen nahe, dass die Häuser als geschlossene Einheiten konzipiert waren und auch schriftliche Quellen lassen sich in diesem Sinn verstehen. Auf diese Frage nach der Offenheit bzw. Geschlossenheit von Häusern wird am Ende der Untersuchung noch einmal zurückzukommen $\operatorname{sein}^{138}$.

Im Hausinneren werden Besucher je nachdem, ob sie geladen oder ungeladen in das Haus kommen, unterschiedlich behandelt. An dieser Stelle führt Vitruv eine Differenzierung in Räume der Zirkulation (Vestibula, Atria, Peristylia) und Aufenthaltsräume (Cubicula, Triclinia, Balnea) ein. Tatsächlich gilt auch Seneca ein häufig besuchtes Atrium (frequens atrium) als Ausweis menschlichen Glücks (bonum), zeugt doch die Vielzahl der Besucher von sozialer Anerkennung ${ }^{139}$. Gerade bei Vitruv wird aber deutlich, dass es nicht um eine Differenzierung in ein öffentliches Atrium und ein stärker privates Peristyl oder ein öffentliches Triclinium und ein privates Cubiculum geht, sondern um einen pragmatischen Umgang mit ungeladenen Gästen: Man trifft sie in den Knotenpunkten des Hauses. Tatsächlich wird sich zeigen, dass auch innerhalb eines Hauses zahlreiche Optionen zur Verfügung standen, um Zugänglichkeiten und Sichtbarkeiten zu regulieren, verschiedene Grade an ,Öffentlichkeit' und ,Privatheit' zu erzeugen.

6) Weiterhin ist - im Gegensatz zu Wallace-Hadrills statischem Modell - in Rechnung zu stellen, dass die räumliche Organisation und soziale Aneignung des Wohnraums im Laufe der Zeit einem Wandel unterlagen. Während die vierseitigen Peristyle als regelrechte Wandelgänge konzipiert waren, die einen Hortus ${ }^{140}$ umgaben, legte man hier ab dem späten 2.Jh.v.Chr., dann aber vor allem im Verlauf des 1.Jhs.v.Chr. prunkvolle, für den Gästeempfang genutzte Räume $\mathrm{an}^{141}$. Dickmann verweist zu Recht darauf, dass diese nur erreichbar waren, wenn der

135 Übersetzung Fensterbusch: „Wenn die Räume in Hinsicht auf die Himmelsrichtungen so verteilt sind, dann muß man seine Aufmerksamkeit auch darauf richten, in welcher Weise in Privatgebäuden die Zimmer gebaut werden müssen, die allein den Hausherren gehören, und wie die, die auch Leuten, die nicht zur Familie gehören, zugänglich sind. Denn in die Privaträume haben nicht alle Zutritt, sondern nur geladene Gäste, z.B. in die Schlafräume, Speisezimmer, Baderäume und die übrigen Räume, die gleichen Gebrauchszwecken dienen. Allgemein zugängliche Räume aber sind die, in die auch uneingeladen Leute aus dem Volk mit Fug und Recht kommen können, d.h. Vorhallen, Höfe, Peristyle und solche Räume, die in derselben Weise benutzt werden können. Daher sind für Leute, die nur durchschnittliches Vermögen besitzen, prächtige Vorhallen, Empfangssäle, Atrien nicht notwendig, weil diese Leute anderen durch ihren Besuch ihre Aufwartung machen, aber nicht von anderen besucht werden.“

136 So auch Tybout 2001, 43.

137 Dickmann 1999, 117 im Zusammenhang mit den im Atrium gestifteten Tischen: „Monument und Aufstellungsort verwandelten die Halle in einen kleinen, den Bewohnern der Stadt zugänglichen Platz“; Heinrich 2002, 66: „Die Räume am Atrium sind vielleicht dem von Vitruv beschriebenen Bereich zuzurechnen, der der Allgemeinheit zugänglich war.“ Mit Blick auf Vitruv führt Grassigli 1998, 44 jedoch eine Trennung der Vorstellung von Privatheit und der Frage der Einladung/Nicht-Einladung ein; erneut eine freie Zugänglichkeit voraussetzend Balch 2008, $4 \mathrm{f}$.

138 s. u. S. 521-527.

139 Sen. epist. 76,12.

140 Hortus wird hier als Terminus für den Garten gebraucht, ausführlich zur Begrifflichkeit, s. von Stackelberg 2009, 9-16. Auf den in der Forschung ebenfalls etablierten Begriff Viridarium - meist für einen kleinen Garten gebraucht wird jedoch verzichtet, da er in der lateinischen Literatur Spezifischeres, nämlich einen besonders elitären Garten meint; s. von Stackelberg 2009; Marzano 2014, 196; etwas anders jedoch Piscitelli 2019, 2, die hortus als Bezeichnung für einen Nutzgarten, viridarium für einen Schaugarten auffasst.

141 Dickmann 1999, bes. 43-46. 
Gast das gesamte Haus durchschritt ${ }^{142}$. Die Vorführung der Hausarchitektur wurde zu einem zentralen Element der Wohnkultur. Auch vor diesem Hintergrund ist eine Gliederung des Hauses entlang der Achse von public/private kaum haltbar.

7) Weiterhin konstatiert Dickmann zu Recht, dass der Empfang verschiedener sozialer Gruppen (clientes, amici) nicht stereotyp auf die Achsen public und private verteilt werden könne. Eine relationale Differenzierung zwischen dem Triclinium als public und dem Cubiculum als private $^{143}$ wird vor diesem Hintergrund hinfällig, beide mögen - je nach Anlass und Zusammensetzung der Gäste - für Empfänge genutzt worden $\operatorname{sein}^{144}$.

8) Diese Überlegungen gewinnen an zusätzlichem Gewicht, wenn man die jüngsten Ergebnisse zur Salutatio berücksichtigt. Es ist jener genuin ,öffentliche“ Handlungszusammenhang, der in Wallace-Hadrills Argumentation für die auf Öffentlichkeit ausgelegte Konzeption des Atriums (und damit des Atriumhauses im Ganzen) eine besondere Rolle spielt ${ }^{145}$. Der Hausherr habe sich den Klienten in der Blickachse des Hauses, im Tablinum, präsentiert ${ }^{146}$. Das Atrium wird aus dieser Perspektive zum zentralen Kulminationspunkt, zum eigentlichen Showroom ${ }^{147}$. Tatsächlich korrelierte die Ausbildung des Atriumhaustyps jedoch nicht mit der Entstehung der Salutatio. In ihrer differenzierten Form scheint sich die Salutatio erst im 2.Jh.v.Chr., und damit lange nach dem Auftreten der ersten Atriumhäuser, entwickelt zu haben. Als das Atrium im späten 2.Jh.n.Chr. an Bedeutung verlor, existierte die Praxis der Salutatio noch immer ${ }^{148}$. Auch Details, die einen Zusammenhang von Salutatio und Atriumhaus stützen sollen, sind nicht haltbar. Das Tablinum als Ort, wo das Ehebett aufgestellt und sich der Dominus seinen Gästen präsentierte, ist den Quellen so nicht zu entnehmen ${ }^{149}$. Das Tablinum ist damit nur sehr allgemein als großzügiger, multifunktionaler Raum anzusprechen ${ }^{150}$.

Noch schwerwiegender sind die Argumente, die nahelegen, dass diese ritualisierte Form des Gästeempfangs in Pompeji nicht stattgefunden hat. Fabian Goldbeck hat jüngst gezeigt ${ }^{151}$, dass diese Praxis allein für Rom bezeugt ist. Hier waren es Senatoren und Volkstribunen, die ihre Klienten empfingen, seit der Kaiserzeit dann auch Ritter und Freigelassene. In allen Fällen handelt es sich jedoch um politisch einflussreiche oder zumindest um finanziell potente Personen. Salutationes bei ,normalen' Equites sind auch in der Kaiserzeit nicht bezeugt. Wenn Salutationes ausnahmsweise außerhalb Roms stattfanden, so handelt es sich um römische

142 Zanker 2000, 208; in Bezug auf die Casa del Labirinto Dickmann 2011, 62.

143 Wallace-Hadrill 1994, 17: „The triclinium will be private relative to the main circulation and open reception areas; yet the cubiculum is private relative to the triclinium [...].“

144 Dickmann 1999, 43; 2011, 55.

145 Etwa Wallace-Hadrill 1989a, 63f.; Wallace-Hadrill 1994, 12: „[...] the vestibulum-atrium-alae-tablinum complex lends itself to the salutatio, the traditional ritual of morning greeting“; ähnlich Flower 1996, 188f.; Zevi 1998, 33; Dickmann 1999, 20.

146 Explizit etwa Clarke 1991, 4; Wallace-Hadrill 1994, 120.

147 Wallace-Hadrill 1994, 52.

148 Dickmann 1999, 135 zur Tendenz der Abwertung des Atriums bereits zu Beginn des 1.Jhs.v. Chr.; zur Salutatio Badel 2007; Goldbeck 2010.

149 Ein in drei Textstellen erwähnter lectu(lu)s adversus wird aufgrund seiner Benennung gegenüber - d.h. gegenüber dem Haupteingang - lokalisiert; s. etwa Marquardt 1980, 56 Anm. 5. Es handelt sich um folgende Quellen: Prop. 4,11,85: seu timida aduersum mutarit domina lectum sederit et nostro cauta nouerca toro [...]; Laberius bei Gell. 16,9,4: [...] mater familias tua in lecto aduerso sedet [...]; Ascon. in Milon. 43C: deinde omni vi ianua expugnata et imagines maiorum deiecerunt et lectulum adversum uxoris eius Corneliae [...] fregerunt, itemque telas, quae ex vetere more in atrio texebantur, diruerunt. Der Rückschluss, das genannte Bett sei deshalb im Tablinum zu lokalisieren, geht so aus den Quellen nicht hervor. Ebenso wenig klar ist die Annahme, es handle sich dabei um das Ehebett; s. Goldbeck 2010, 138 bes. Anm. 4. Dass der lectus genialis im Tablinum stünde, ist wiederum ebenfalls nicht belegt.

150 Non. p. 117,11 = Varro, vita pop. Rom. frag. 308 [Salvadore]: ad focum hieme ac frigoribus cenitabant; aestivo tempore in propatulo; rure in chorte; in urbe in tabulino, quod maenianum possumus intellegere tabulis fabricatum. Für das Tablinum wird eine Funktion als Sommertriclinium suggeriert.

151 Goldbeck 2010, 60-73, bes. 67; in Bezug auf die Disposition von Vestibula bereits angedeutet bei Leach 1997, 55 f. 
Senatoren, die ihre Gäste auf einem Landsitz empfingen ${ }^{152}$. Gerade im vorrömischen Italien, etwa im oskischen Pompeji, darf man an der Existenz dieser Praxis zweifeln ${ }^{153}$. Dies bedeutet, dass Architektur und Decor des Atriums nicht auf die Salutatio bezogen werden können - und zwar weder allgemein im Sinne der Schaffung einer repräsentativen Bühne noch konkret in Bezug auf ein spezifisches Bildverständnis ${ }^{154}$.

9) Wallace-Hadrills sozialhierarchische Differenzierung der Nutzergruppen in pater familias, amici, clientes und servi basiert zwar auf antiken Rechtsvorstellungen. Allerdings werden dadurch andere soziale Formationen vernachlässigt. Der pater familias ist immer auch Teil der familia, die in diesem Modell unter dem Hausherrn subsumiert wird. Innerhalb der familia wären wiederum verschiedenste Differenzierungen (nach Alter, Geschlecht oder Erbfolge) möglich. Mit der Kategorie der amici sind im Sinne Wallace-Hadrills Standesgenossen gemeint, allerdings liegt der Begriff - als emotionale Kategorie verstanden - quer zu den anderen Kategorien. Innerhalb der amici und clientes können sich die sozialen Bindungen, je nach emotionaler Nähe, sehr unterschiedlich ausnehmen. Letzteres gilt auch für die Gruppe der Sklaven. Noch entscheidender ist, dass ein und derselbe Besucher den Hausherrn oder Teile seiner Familie in unterschiedlichen Angelegenheiten aufsuchen konnte - etwa geschäftlich oder auch freundschaftlich. Seine juristische Stellung muss folglich nicht die alleinige oder auch nur entscheidende Rolle für seine Behandlung innerhalb des Hauses gespielt haben.

10) Einen letzten Anhaltspunkt für die Frage nach dem Besucherverkehr, nach ,öffentlichem ‘ und ,privatem` Verhalten liefert Polly Lohmanns Analyse der Graffiti in einzelnen Häusern. Prinzipiell kommen als Schreiber Bewohner wie Besucher des Hauses infrage. Im Atrium handelt es sich jedoch um unauffällig in den Sockelzonen oder Randzonen angebrachte „Zahlen, Daten und Strichlisten“, die sie eher mit den Bewohnern des Hauses in Verbindung bringt, während die Peristyle „eine größere Bandbreite an Texten und meist auch einige Zeichnungen“ aufweisen, die sich neben Bewohnern auch auf Besucher beziehen ließen ${ }^{155}$. Daraus ließe sich schlussfolgern, dass Besucher ihren Aufenthalt im Atrium nicht zur Anbringung von Graffiti nutzten, von dieser Option aber im Peristyl Gebrauch machten, wo sie möglicherweise länger verweilten.

Diese umfängliche Diskussion von Wallace-Hadrills Position führt zu dem Ergebnis, dass die Gliederung ,des' römischen Wohnhauses entlang der Achse public/private für die nachfolgenden Überlegungen verworfen wird. Gegen eine solch statische Struktur sprechen sowohl die architektonische Gliederung, die verwendeten Decor-Formen als auch die flexiblen Modi sozialen Handelns. Insbesondere die Salutatio wird man nicht als Argument für den öffentlichen Charakter des Hauses (bzw. des Atriums) heranziehen können.

An die Stelle von Wallace-Hadrills strukturalistischem Architektur-Decor-Modell soll hier eine stärker akzidentielle Auffassung von Raum, Architektur, Decor und Handlung treten. Der durch Architektur und Decor gestaltete Raum und der wahrnehmende Betrachter wirken nicht nur aufeinander zurück, vielmehr verändert sich die Qualität dieser Wechselbeziehung in Abhängigkeit von spezifischen Handlungsanlässen und -konstellationen: Es ist die Einbindung in Handlungen, die Formen der Wahrnehmung und Aufmerksamkeit strukturiert ${ }^{156}$. Dieser stärker auf das Akzidentielle Bezug nehmende Interpretationsansatz stellt dennoch in Rechnung, dass sich wiederholende kulturelle Praktiken auf spezifische Raumkonstellationen bezogen sein können.

152 Goldbeck 2010, 128.

153 Für nicht-römische, italische Gesellschaften (ohne Argumente) postuliert von Pesando 1996, 215.

154 Eine solch konkrete Lesweise hatte Trimble 2002, 243-245 vorgeschlagen.

155 Lohmann 2018, 364.

156 Gombrich 2002, 105-110. 


\section{Handlungsformationen und Wahrnehmungskonstellationen}

Bislang ist menschliches Handeln ausgehend von Raumkonstellationen diskutiert worden. Im Folgenden wird die Betrachtung umgekehrt und nach Handlungsmodi in Bezug auf bestimmte Kontexte gefragt. Dazu wird einerseits eine basale Unterscheidung von statischer und mobiler Wahrnehmung eingeführt, andererseits kommen verschiedene, für das antike Haus zentrale Handlungsformationen zur Sprache.

\subsection{Statische und mobile Wahrnehmung von Decor-Räumen}

Zugänglichkeit, Größe und Beleuchtung eines Raumes erlauben basale Aussagen zu Betrachterhaltungen (bzw. Modi der Bewegung), die für die räumliche Anbringung von Decor ebenso wie für dessen Wahrnehmung bedeutsam sind. Durch die Raumdisposition wird der Betrachter bis zu einem gewissen Grad auf eine bestimmte Form der körperlichen Präsenz und zugleich auf eine Perspektive festgelegt, die er in Bezug auf die ,Welt' einnimmt ${ }^{157}$. Der Architektur und dem Decor ist somit eine menschlich-körperliche Dimension eingeschrieben. Ein grundsätzlicher Unterschied ergibt sich dadurch, ob Decor-Räume einen statischen oder einen dynamischen Betrachter vorsehen. David Ganz und Stefan Neuner haben sich für eine Historisierung dieser Frage ausgesprochen. Sie begreifen die peripatetische Raumerschließung als Konzept der Moderne, verweisen aber darauf, dass Raum-Decor schon zuvor mehr oder minder explizit auf ,Raumpraxen“ Bezug nehmen konnte ${ }^{158}$. Tatsächlich erzeugen architektonische Räume immer schon bestimmte Zugänglichkeiten und Sichtbarkeiten, die körperliche Handlungen und Betrachtungsoptionen vorstrukturieren. Auch antike Wohnhäuser lassen sich daher darauf befragen, inwieweit ein statischer oder ein mobiler Wahrnehmungsmodus durch die architektonische und decorative Gestaltung privilegiert wird ${ }^{159}$.

Voraussetzung für die Schaffung von statischen Betrachtungssituationen ist die gezielte Gestaltung von Blickachsen. Möglicherweise stellt die Wertschätzung von (Aus-)Blicken eine anthropologische Konstante dar ${ }^{160}$, in jedem Fall aber ist die gestalterische Organisation von Blickoptionen ein hochgradig kulturelles Produkt. In der Antike existierte ein ausgeprägtes Bewusstsein für Fragen der Sichtbarkeit und Platzierung. Vitruv etwa empfiehlt, bei der Errichtung von Tempeln auf ihre Aussicht und Ansichtigkeit, bzw. auf den konkreten Charakter und Zuschnitt des Raumes (natura) zu achten ${ }^{161}$. Auch in der konkreten Baupraxis spielen solche Aspekte eine große Rolle man denke an die Lokalisierung von Kultstätten auf Hügel- oder Bergkuppen oder die symmetrische Organisation von Platzanlagen. Sichtbarkeiten und Zugänglichkeiten, Zugangs- und Sichtbeschränkungen, werden zu einem zentralen Gestaltungsmittel ${ }^{162}$.

In Bezug auf die Villen- und Hausarchitektur hat Heinrich Drerup Blickachsen und im Besonderen den Ausblick auf die Landschaft als ein bedeutsames Phänomen charakterisiert ${ }^{163}$. In der

157 In Bezug auf Michel de Certeau: Ganz - Neuner 2013.

158 Ganz - Neuner 2013, bes. 14.

159 Zum weltlichen Hofzeremoniell der Renaissance Weddigen 2006, 37: „Räumlichkeiten werden mittels exklusiver und privilegierender Verhaltensnormen und Zugänglichkeitsregulierungen voneinander abgegrenzt und hierarchisiert.“

160 Deinsberger-Deinsweger 2018, 59.

161 Vitr. 4,5,2.

162 Mit besonders hoher sozialer Relevanz geschieht dies im kultischen Bereich, der häufig durch die Trennung von sakral/profan strukturiert ist; s. Weddigen 2006, bes. $30 \mathrm{f}$.

163 Drerup 1959, 147f. verweist auf Tac. ann. 15,42, der freie Flächen (aperta spatia) und Ausblick (prospectus) als besondere Qualitäten der Domus Aurea bezeichnet; umgekehrt entwertet laut Cicero (dom. 115; har. resp. 33) eine verstellte Aussicht ein Gebäude; erneut Wesenberg 1985, 479; Horrocks 2000, bes. 34-36. 
iustinianischen Gesetzgebung zählt der prospectus, die freie Aussicht, zum einklagbaren Besitz eines Grundstücks ${ }^{164}$. Ein Brief Ciceros an seinen Freund Atticus belegt, dass die Qualität eines Durchblicks unter Bezugnahme auf theoretische Überlegungen diskutiert wurde (Cic. Att. 2,3,2). Auf den Vorwurf, sein Fenster sei für den gewünschten Durchblick zu klein, entgegnet er, dass dies nur zuträfe, sofern man die epikureische Sehtheorie zugrunde legte. Diese geht von einem Sehbild als gleichschenkligem Dreieck aus, von dem aus das Auge getroffen würde. Cicero setzt indes eine betrachterorientierte Organisation der Umwelt voraus. Vom sehenden Subjekt aus sei der Fensterdurchblick in seinen Garten folglich angemessen:

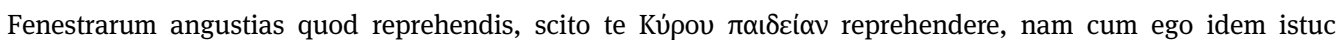

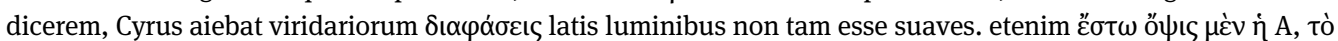

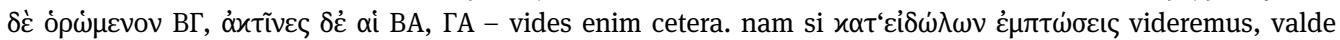

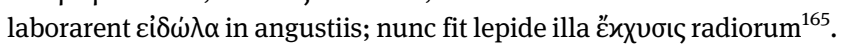

Cicero geht damit von einer durch eine optische Theorie abgestützten Orientierung der Architektur an der Betrachterperspektive aus. Daran schließt Drerup die Annahme an, dass solche Blickachsen mit einem statischen und nicht mit einem mobilen Betrachter rechnen. Und tatsächlich finden solche Ausblicke in der antiken Literatur insbesondere im Zusammenhang mit statischen Betrachtungssituationen Erwähnung ${ }^{166}$. Es sei der auf eine bestimmte statische Betrachterposition ausgerichtete, gerahmte Blick, der in besonderer Weise geschätzt und damit auch gestaltet worden sei: Erst „[die Rahmung] verwandelt den Ausblick in einen Durchblick“, die Architektur wird zum Bild $^{167}$. Und tatsächlich reflektieren auch antike Quellen die architektonisch hergestellte Zergliederung eines Ausblicks in verschiedene Durchblicke. Plinius etwa spricht in Bezug auf sein Laurentinum von einem Durchblick auf drei Meere ${ }^{168}$. An diese Analyse literarischer und bildlicher Quellen schließt Drerup Beobachtungen zu Befunden an, konzentriert sich jedoch ausschließlich auf die Hauptblickachse, die von den Fauces über das Atrium in den Peristylgarten führt. Für die Casa del Menandro (I 10,4) geht er so weit, den ,idealen' Blickpunkt konkret zu benennen ${ }^{169}$ : „Bezogen aber ist der Durchblick auf einen ganz bestimmten Betrachterstandpunkt: auf die Stelle unmittelbar hinter der Innenkante der Türschwelle, also jenseits der Eingangstür zu Anfang der Fauces“. Zu diesem Schluss kann er allerdings nur kommen, indem er bestimmte Bewertungskriterien (Seitenwände des Atriums in genauer Deckung mit den Ecken der inneren Fauces-Öffnung) a priori voraussetzt. Tatsächlich würde dieses Ergebnis Drerups These, dass das römische Haus mit einem statischen Betrachter rechne, infrage stellen: Der von ihm kalkulierte Bereich ist ein klassischer Durchgangsbereich ${ }^{170}$. Überhaupt ergaben sich nicht nur am Eingang, sondern entlang der gesamten, symmetrisch organisierten Blickachse attraktive Aus- und Durchblicke. Die nachfolgende Forschung hat sich Drerups Position zu Eigen gemacht, gleichzeitig aber auch

\footnotetext{
164 Ulp. Dig. 8,2,3.12.15.

165 Übersetzung Kasten: „Du tadelst die engen Fenster; damit tadelst Du aber gleichzeitig die Cyropädie, denn als ich mich genauso äußerte, erwiderte Cyrus, bei breiten Fenstern sei das Bild des Gartens nicht so lieblich: angenommen, der Blickpunkt sei A, das Wahrgenommene BC, die Strahlen BA, CA - Du verstehst schon, worauf das hinaus soll. Wenn das Sehen so vor sich ginge, daß von dem Gegenstande ausgestrahlte Bilder auf unsere Netzhaut fielen, dann hätten diese Bilder allerdings ihre liebe Not mit den engen Fensteröffnungen; aber so ist es nun ja nicht, vielmehr beruht das Sehen auf der bekannten Ausstrahlung der Augen; da geht es dann ja ganz vorzüglich.“

166 Beim Lesen: Cic. fam. 7,1,1; beim Schreiben: Cic. ad Q. fr. 2,13,1; bei der Mahlzeit/auf einer Kline ruhend: Plin. epist. 2,17; 5,6,19-32; in der Piscina/beim Bad: Sen. epist. 86,8; Plin. epist. 2,17,11; zu den Quellen Drerup 1959, $149 \mathrm{f}$.

167 Drerup 1959, 150.

168 Plin. epist. 2,17,5.

169 Drerup 1959, 156.

170 Drerup 1959, 158f. versucht, dafür Begründungen beizubringen. Zum einen charakterisiert er das Vestibulum als Ort, an dem sich die Klientel zur Salutatio versammelt habe, zum anderen erkläre sich seine „baukünstlerische Funktion“ durch seine Bedeutung für den Hauskult. Beides darf man, mit Gründen, die in Teil II zu erörtern sind, als problematisch erachten.
} 
weitere ,Standpunkte، und die mit ihnen korrelierenden Perspektiven berücksichtigt. So wurden innerhalb des Hauses verschiedene Symmetrieachsen beobachtet, etwa die einander gegenüberliegenden Alae ${ }^{171}$. Darüber hinausgehend hat man Blickachsen untersucht, die sich von bestimmten, relevanten Blickpunkten ergaben - etwa für das Gelage beim Convivium ${ }^{172}$. Ausgehend von einer solchen Bedeutung von Blickachsen und Perspektiven lässt sich danach fragen, inwieweit Decor-Elemente auf Nähe/Entfernung des Betrachters, auf seine Körpergröße, auf seine vorauszusetzende Haltung oder auf spezifische Lichtverhältnisse hin kalkuliert $\operatorname{sind}^{173}$. Eine besondere Bedeutung besitzt für diese Fragen der zweite pompejanische Stil, der bei der Darstellung von Architektur mit Perspektiven und imaginierten Betrachterstandpunkten arbeitet. Gerade hier spielen imaginierte Standorte, potenzielle Blickachsen und Größenverhältnisse eine entscheidende Rolle.

Bereits der Umstand, dass sich antike Bewohner in ihrem Haus bewegen mussten, legt aber die Frage nahe, ob antike Decor-Räume auch gezielt auf einen mobilen Betrachter hin gestaltet wurden. Diesen Ansatz wählt Susanne Muth für die Analyse spätantiker Hausinnenräume. Mosaiken, so ihre Annahme, erzeugen eine visuelle Struktur, die den Betrachter durch das Haus ,leiten ${ }^{\text {‘174}}$. Decor wird zu einem Prinzip der Bewegungsorganisation; in der Bewegung wird der Raum als Raum erfahrbar. Drerup selbst hat die Konsequenzen für die Wahrnehmung bereits beschrieben. Der mobile Betrachter erschließt sich ein von Schritt zu Schritt neu konfigurierendes visuelles Ensemble, „das sich nicht dem ,außerhalb“ verweilenden Betrachterauge, sondern dem sich im Atrium Bewegenden, gewissermaßen dem Hausbewohner mitteilt ${ }^{\text {“175 }}$. Architektur wird in der Bewegung weniger bildhaft, sondern stärker räumlich wahrgenommen. Auch wenn dieser peripatetische Wahrnehmungsmodus in antiken Quellen nicht explizit reflektiert wurde, so erhellt Muths Auseinandersetzung mit spätantiken Befunden, dass er bei der Raumgestaltung in Rechnung gestellt wurde.

Es wird daher im Folgenden danach zu fragen sein, inwieweit in pompejanischen Häusern statisch-skopische oder mobil-haptische Modi der Raumerschließung zum Tragen kommen, sich ggf. verändern und inwieweit sie auch ineinander verflochten Wirkung entfalten ${ }^{176}$. Denn gerade dem Akteur, der sich im Haus bewegt, haben sich sukzessiv neue Durchblicke erschlossen.

\subsection{Handlungsfelder}

Will man über grundsätzliche ,Haltungen', die ein Betrachter im Raum annimmt, hinausgehen, so sind literarische Quellen auf Handlungsszenarien im Haus hin zu befragen. Das akzidentielle Alltagshandeln fand darin zwar kaum einen Niederschlag, sie schildern jedoch ausführlich routinisierte, insbesondere ritualisierte Formen sozialen Handelns ${ }^{177}$. Zumeist gilt das Interesse den Handlungen selbst, insbesondere häuslichen Riten, während ihre konkrete räumliche Verortung keine oder nur am Rande Erwähnung findet. Im Folgenden sollen einige signifikante Handlungskontexte, für die wenigstens eine ungefähre räumliche Kontextualisierung möglich ist, zur Sprache kommen, um sie später als Wahrnehmungskontexte von Decor voraussetzen zu können.

171 Explizit Watts 1987, 110-113 für die Casa del Poeta Tragico.

172 Bek 1980, bes. 189f. berücksichtigt; vgl. Clarke 1991, 14-17; Clarke 2003, 223.

173 Perry 2005, 50-53 konstatiert für den Titusbogen, dass für dasselbe Bildthema (einen Triumphzug) in Abhängigkeit von der Platzierung am Bogen (Attika, Durchgang) unterschiedliche Darstellungsweisen gewählt wurden.

174 Muth 1998, 61-63; 2018, bes. 412-419.

175 Drerup 1959, 159.

176 Zu historischen Optionen der Verflechtung Ganz - Neuner 2013.

177 Soziale Praxis lässt sich im Sinne der Praxistheorie definieren als ,a routinized type of behavior which consists of several elements, interconnected to one other: forms of bodily activities, forms of mental activities, 'things' and their use, a background knowledge in the form of understanding, know-how, states of emotion and motivational knowledge“; s. Reckwitz 2002, 249. 
Auch wenn in Pompeji keine förmliche Salutatio stattgefunden hat, so darf man dennoch den Empfang von Klienten voraussetzen. Dies führt zu der Frage, ab wann man in Pompeji mit Sklaven, Freigelassenen und Klienten rechnen darf. Da sich Freigelassene im epigraphischen Befund des 2. und 1.Jhs.v. Chr. nicht fassen lassen, bleibt ihre Rolle im samnitischen Pompeji vor 89 v.Chr. unklar ${ }^{178}$. Mit Einrichtung der Kolonie 80 v.Chr. wird in den Inschriften das Cognomen genannt, sodass nun Freigelassene greifbar werden ${ }^{179}$, erst in augusteischer Zeit verdichtet sich jedoch die Quellenlage ${ }^{180}$. Dann treten Freigelassene auf, die ein Grab für ihren Patronus stiften ${ }^{181}$ oder ihren Patronus in dessen Atrium mit einem Porträt ehren ${ }^{182}$. Darin zeichnen sich Formen der Interaktion zwischen Patronus und Freigelassenen/Klienten ab, die ihren Ort wenigstens teilweise im Atrium hatten ${ }^{183}$.

Darüber hinaus fungierte das Haus als Ort für die Klärung juristischer Angelegenheiten. Diese ergaben sich aus verschiedenen Funktionen, welche die Eliten einer Stadt übernahmen. Bei Gerichtsverhandlungen fand der zweite Schritt des Verfahrens, der auf das Klagefeststellungsverfahren folgte, d.h. die Klärung der eigentlichen Sachfragen, nach Auskunft Vitruvs in der frühen Kaiserzeit häufig apud iudicem statt, d.h. in einem Privathaus ${ }^{184}$. Daneben konnte der pater familias laut Vitruv auch selbst als arbiter eines Verfahrens bestellt werden ${ }^{185}$. Für die Wahr-

178 Nicht gemeint ist hier der Umstand, dass verbündete Gemeinden ihrerseits mit der römischen Oberschicht über Klientelbeziehungen verbunden waren, s. Badian 1958; kritisch dazu Jehne - Polo 2015.

179 Bei dem Magistrat N. Veius Barcha mag es sich um einen Freigelassenen gehandelt haben, wie Castrén 1975, 86 aus einem Cognomen schließt.

180 Mouritsen 1988, 75f.; Freigelassene sind nun insbesondere in Grabinschriften greifbar. Mouritsen 1988, 62f. verweist darauf, dass über 80 \% der Grabinschriften Freigelassenen zuzurechnen sind; für Zahlen zu Rom und Ostia, s. Mouritsen 2005, 38f. Er erklärt diesen hohen Prozentsatz als Ergebnis eines sozial konditionierten epigraphic habit, sodass sich Rückschlüsse auf die Bevölkerungszusammensetzung verbieten. Freigelassene und Sklaven bekleideten in Pompeji Priesterämter der magistri vici und magistri pagi sowie der ministri Augusti, ministri pagi und ministri Fortunae Augustae; diese sind seit augusteischer Zeit belegt; s. Castrén 1975, 72-75; Mouritsen 1988, 92-106.

181 Campbell 2015, 111-114 mit einer sieben Fälle umfassenden Liste.

182 Dies gilt für den Freigelassenen Felix, der im Atrium der Casa di Caecilius Iucundus (V 1,26) zwei Hermen mit bronzener Einsatzbüste aufstellen ließ. Die Inschrift auf der Basis beider Hermen nennt Stifter und Empfänger: Genio $L$ (ucii) nostri / Felix L(ibertus) - s. Neapel, NM 110663; CIL X, 860. Die Identifizierung des Lucius, dem die Stiftung galt, bereitet Schwierigkeiten, könnte sie sich doch einerseits auf einen Bankier mit dem vollen Namen L. Caecilius Iucundus beziehen, dessen Wirken in die Jahre zwischen 52 und 62 n. Chr. fällt (Lahusen - Formigli 2007, 134f.), andererseits aber auch auf den früheren Hausbesitzer L. Caecilius Felix, der im Jahr 1 v. Chr. als minister Augusti inschriftlich erwähnt ist, folglich Freigelassener war. Im Jahr 15 n. Chr. tritt dieser Name im Wachstafelarchiv des Hauses in Erscheinung (Eckert 2011, 178f.). Eine wichtige Rolle für eine Identifikation spielt dabei die stilistische Datierung des erhaltenen Bronzeporträts. Hier wird sowohl eine frühe Datierung in augusteische Zeit als auch eine späte Datierung in neronische Zeit diskutiert (mit augusteischer Datierung De Franciscis 1951, 31-34; Dexter 1979, 180183; Döhl - Zanker 1979, 197; Bonifacio 1997, 92f.; Eckert 2011, 179; mit flavischer Datierung Lahusen - Formigli 2007, 135). Die späthellenistischen Züge scheinen m. E. tatsächlich eher für eine frühe Datierung in augusteische Zeit zu sprechen, gestützt würde die Datierung durch die Buchstabenformen der Hermeninschriften. Immer noch kämen aber verschiedene Optionen infrage. So könnte der augusteische Hausbesitzer, der Freigelassene Lucius [Caecilius Felix], als Stifter für den Genius eines (unbekannten) Lucius auftreten. Wahrscheinlicher ist jedoch, dass ein nicht näher bekannter Freigelassener mit Namen Felix Hermen für seinen Patronus, den Lucius [Caecilius Felix] stiftete. In jedem Fall haben wir es hier mit einer Form der statuarischen Interaktion zu tun, in die ein Freigelassener involviert war.

183 Sen. epist. 22,9 spricht beim Ausbleiben der Klienten vom atrium uacuum; für Sen. epist. 76,12 gehört das von Klienten frequentierte Atrium (frequens atrium) zu den Vorzügen des Lebens; vgl. Goldbeck 2010, 135.

184 Bablitz 2015.

185 Bablitz 2016, 242 führt diese Unterscheidung für die späte Republik ein - der Unterschied zwischen iudex und arbiter habe sich in der Kaiserzeit verloren. Vitr. 6,5,2: Item feneratoribus et publicanis commodiora et speciosiora et ab insidiis tuta, forensibus autem et disertis elegantiora et spatiosiora ad conventus excipiundos, nobilibus vero, qui hono/res magistratusque gerundo praestare debent officia civibus, faciunda sunt vestibula regalia alta, atria et peristylia amplissi$\mathrm{ma}$, silvae ambulationesque laxiores ad decorem maiestatis perfectae; praeterea bybliothecas, pinacothecas, basilicas non dissimili modo quam publicorum operum magnificentia / comparatas, quod in domibus eorum saepius et publica consilia et privata iudicia arbitriaque conficiuntur. Übersetzung Fensterbusch: „Ferner muß man für die Geldverleiher und Steuerpächter den Verhältnissen angemessene, ansehnliche und gegen Diebstahl gesicherte Wohnhäuser bauen, 
nehmung solch repräsentativer Aufgaben bedürfe es eines entsprechend aufwendigen häuslichen Rahmens. Leanne Bablitz nimmt für solche Ereignisse im Durchschnitt etwa zehn Teilnehmer an, wobei für die Platzierung der Gäste ein U-förmiges Arrangement gewählt worden sei ${ }^{186}$. Dass die Klinen, wie Bablitz annimmt, im Atrium oder im Peristyl aufgestellt wurden, lässt sich weder auf literarische noch auf architektonische Befunde stützen. Besonders gut vorstellbar wäre ein Uförmiges Platzarrangement in den auf ganzer Front zu den Höfen geöffneten Räumen - den Tablina, Alae und Exedrae.

Aus Vitruvs Text lassen sich darüber hinaus für den häuslichen Kontext halb-offizielle Treffen politischen Charakters erschließen ${ }^{187}$. Rechtsanwälte mögen im Haus ihre Besprechungen mit Klienten abgehalten haben, auch politische Treffen und private Beratungen haben hier stattgefunden (Vitr. 6,5,1). In Pompeji liefern Programmata für die Zeit nach $62 \mathrm{n}$. Chr. einen positiven Beleg für solche geschäftlichen Verbindungen ${ }^{188}$. Aus ihnen geht hervor, dass verschiedene soziale Gruppierungen (etwa Berufsgruppen, sodales, Nachbarn) als Unterstützer eines Kandidaten auftraten ${ }^{189}$. Als Voraussetzung für eine solche Unterstützung mag man sich einen engeren Kontakt mit den politischen Führern vorstellen, der durchaus im häuslichen Rahmen gepflegt worden sein mag.

Eine besonders wichtige Rolle muss der Empfang von Gästen im Rahmen des abendlichen Conviviums gespielt haben, der in verschiedensten Quellen bezeugt ist ${ }^{190}$. Die Partizipation an diesem Ereignis wurde vom Hausherrn kontrolliert. Der Zugang zum Haus war reglementiert, Selbsteinladungen waren unmöglich ${ }^{191}$. Der Conviviums-Kontext bot somit die Gelegenheit für eine ostentative Zurschaustellung von luxuria - der servierten Speisen, aber auch des räumlichen Settings ${ }^{192}$. Zum Convivium wurden zumeist zwischen drei und neun Teilnehmer erwartet ${ }^{193}$, die

für Rechtsanwälte und Redner elegantere und geräumigere, damit in ihnen Zusammenkünfte stattfinden können. Für hochstehende Personen aber, die, weil sie Ehrenstellen und Staatsämter bekleiden müssen, den Bürgern gegenüber Verpflichtungen erfüllen müssen, müssen fürstliche, hohe Vorhallen, sehr weiträumige Atrien und Peristyle gebaut werden, Gartenanlagen und geräumige Spazierwege, die der Würde angemessen angelegt sind; außerdem Bibliotheken, Räume für Gemäldesammlungen und basilikaähnliche Hallen, die in ähnlicher Weise prunkvoll ausgestattet sind wie die staatlichen Gebäude, weil in den Häusern dieser Männer öfter politische Beratungen abgehalten und Urteile und Entscheidungen in privaten Angelegenheiten gefällt werden.“

186 Bablitz 2015, 65.

187 Einige knappe Überlegungen dazu bei Dickmann 2011, $60 \mathrm{f}$.

188 Für die Programmata recentiora, den zahlenmäßig besonders dicht überlieferten Programmata der Zeit nach 62 n. Chr., konstatiert Mouritsen 1988, 63 einen hohen Anteil an Namen, die er mit Sklaven beziehungsweise Freigelassenen verbindet.

189 So wurden etwa M. Holconius Priscus, M. Cerennius und Vettius Firmus von den pomari unterstützt (CIL IV 202; CIL IV 149; CIL IV 183), mit denen diese offenkundig in Beziehung standen; s. Wallace 2006, xiii. 2. 4; hier weitere Beispiele für Berufsgruppen, die einen Kandidaten unterstützen. Auch ein gewisser Phoebus unterstützt, zusammen mit seinen emptores, die sich offenbar als Gruppe empfanden und dementsprechend gemeinsam votierten, den Kandidaten M. Holconius Priscus (CIL IV 103), s. mit Übersetzung Wallace 2006, xiii. 2. Bisweilen schlagen auch Kaufleute (?) Kandidaten cum discentes vor, s. CIL IV 275; CIL IV 698; bei Wallace 2006, 9 als „apprentices“ verstanden. Andernorts unterstützt man Kandidaten cum sodales, s. CIL IV 7665; Wallace 2006, 18. Auch die Nachbarn (vicini) konnten für die Wahlwerbung eintreten, s. Castrén 1975, 114f., der auf eine besonders intensive Praxis solch ,privater Wahlwerbung in den letzten Jahren von Pompeji verweist.

190 Daneben wurden auch die Begriffe cena, epulum, epulari verwendet; zur Quellendiskussion Vössing 2004, 187196; Schnurbusch 2011, 135-137. Die übrigen Mahlzeiten in der Frühe des Morgens (ientaculum) und am späteren Vormittag (prandium) fielen meist bescheidener aus, v.a. aber besaßen sie nicht die soziale Relevanz des abendlichen Mahls und sind in den Quellen entsprechend schlechter bezeugt. Zu den Termini Vössing 2004, 187-196.

191 Vössing 2004, 223f.; zur Selbsteinladung cenam condicere alicui Vössing 2000, 90-92.

192 Vössing 2004, 236f. mit der Diskussion des auf Repräsentation ausgerichteten Charakters des Convivium.

193 Gell. 13,11,2: Dicit autem conuiuarum numerum incipere oportere a Gratiarum numero et progredi ad Musarum ut, cum paucissimi conuiuae sunt non pauciores sint quam tres, cum plurumi non plures quam nouem. 
üblicherweise auf drei Speiseliegen verteilt wurden ${ }^{194}$. Vereinzelt sind aber deutlich mehr Besucher bezeugt. Plinius suggeriert eine riesige Cenatio mit 30 Onyxsäulen; Plutarch kennt Gelage mit 30 Speiseliegen ${ }^{195}$. Seneca verweist auf den Raumluxus von Speiseräumen (cenationes), in denen sich ein ganzes Volk (populus) versammeln könne ${ }^{196}$. Die Gäste wurden nach sozialem Rang ${ }^{197}$, bzw. nach ihrem privaten Verhältnis (amici) und ihrem sozialen Verhältnis (pari) zum Gastgeber ausgewählt ${ }^{198}$, auch Familienangehörige (Frauen und Jugendliche ${ }^{199}$ ) sowie Klienten konnten zur Tischgemeinschaft hinzugebeten werden ${ }^{200}$.

Als Ort des Conviviums werden Triclinium, Conclave, Oecus und Cenatio genannt ${ }^{201}$. Den Gästen wurde in Abhängigkeit von ihrer sozialen Stellung und von ihrem Verhältnis zum Hausherrn ein Platz zugewiesen ${ }^{202}$. Von diesem hingen die Bedienfolge und sogar die servierten Speisen ab. Auf der links des Eingangs befindlichen Kline nahm der Gastgeber den Platz summus in imo ein, gewissermaßen ein Beobachterplatz im Zentrum der Runde ${ }^{203}$. Auf der dem Eingang gegenüberstehenden Kline kam dem Ehrengast der Platz imus in medio zu, sodass Gastgeber und Ehrengast Kopf an Kopf lagen und sich bequem unterhalten konnten. Auch die anderen Liegeplätze unterschieden sich in ihrem sozialen Prestige. Mit dem Convivium greifen wir folglich eine Handlungsformation, die sich nicht nur recht konkret in einem Raum verorten lässt, sondern für die eine sozialräumliche Ordnung überliefert ist. Fühlten sich die Gäste in ihrem Status nicht angemessen behandelt, konnte dies zu Unmut und Rangstreitigkeiten führen ${ }^{204}$. Gerade daran wird einmal mehr deutlich, dass sozialräumliche Ordnungsprozesse ein Ergebnis von Aushandlungsprozessen sind.

Nicht nur der soziale und räumliche Rahmen, sondern auch der Ablauf des Conviviums und die involvierten Handlungen sind gut bezeugt. Die Unterhaltung bei Tisch konnte vielfältige Themen berühren. Intellektuelle Gespräche über populäre Themen wie Gladiatorenspiele waren ebenso Gegenstand wie Klatsch und derbe Trinksprüche. Die Unterhaltung sollte sich jedoch nicht auf ernste (etwa politische) Themen, sondern auf Gelehrtes beziehen ${ }^{205}$. Der Kontakt zwischen den

194 Im kaiserlichen Kontext ist bisweilen von sehr viel größeren Gelagen die Rede. Cic. Att. 13,52,1f. überliefert für die Domus Caesars 2000 Personen; s. Schnurbusch 2011, 187.

195 Plut. mor. 678C-D; Plin. nat. 36,60 erwähnt die riesigen Onyx-Säulen in der Cenatio des Freigelassenen Callistus, die eine entsprechende Raumgröße nahelegen; vgl. Schnurbusch 2011, 69. 73. Bei Plin. epist. 2,17,10 kann ein Raum allerdings cubiculum grande und modica cenatio zugleich sein - ein Hinweis darauf, dass Räume entsprechend multifunktional besetzt sein können und dass cenatio auch auf kleinere Räume bezogen werden kann.

196 Sen. epist. 115,8.

197 Suet. Aug. 74 in Bezug auf das kaiserliche Mahl, das förmlich organisiert ist und bei dem der soziale Status (ordo) der Gäste bedeutsam ist; Freigelassene werden üblicherweise nicht eingeladen.

198 Anlässlich des Geburtstags Caesars lädt Horaz Manlius Torquatus zu einem Mahl unter gleichgestellten Freunden - Hor. epist. 1,5,24-26: ne fidos inter amicos sit qui dicta foras eliminet, ut coëat par jungaturque pari.

199 Nach Nep. praef. 1,6f. ist es in Rom üblich, dass Frauen ihre Männer zum Convivium begleiten: quem enim Romanorum pudet uxorem ducere in convivium? Val. Max. 2,1,2 mit dem Verweis, dass die Frauen dabei ursprünglich saßen, während die Männer lagen, man auf diesen sittlichen Abstand nun aber außer bei Göttermahlen verzichten würde. Auch in Plutarchs Gastmahl der sieben Weisen nehmen zwei Frauen am Mahl teil, eine sitzend, eine stehend; beide partizipieren jedoch nicht an der Konversation; vgl. Plut. mor. 150 B-E. Frauen können wie Terentia auch als Gastgeberinnen auftreten - Cic. Att. 2,3; zur Anwesenheit von Jugendlichen (iuventus) beim Gastmahl Val. Max. 2,1,9f.; vgl. Foss 1994, 45-50; Schnurbusch 2011, 192-196.

$200 \mathrm{Zu}$ den Quellen Schnurbusch 2011, $190 \mathrm{f}$.

201 Die Termini wurden weitgehend austauschbar verwendet und zeigen keine Raumtypen an, s. o. S. 22.

202 So auch bei dem von Horaz geschilderten Gastmahl des Nasidienus, dessen Ehrengast Maecenas auf der ehrenvollsten Liege Platz nahm, dabei jedoch seine eigenen Unterhalter, Balatro und Vibidius, gegen Langeweile mitbrachte, vgl. Hor. sat. 2,8,18-24.

203 Clarke 1991, 17; 2003, 235.

204 Etwa Plut. mor. 148F. 149F; Plut. mor. 619 B-C; satirisch reflektiert bei Petron. 66-67; vgl. Clarke 2003, 223-225; eine ausführliche Quellendiskussion bei Vössing 2004, 227-234; Schnurbusch 2011, 197-200.

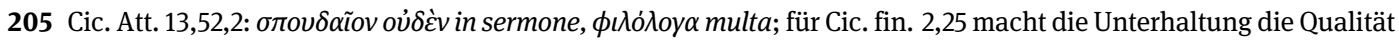
des Mahls aus; zum sozialen Rahmen des Mahls und zur Qualität der Unterhaltung auch Plut. symp. (Mor. 697C-E); s. Vössing 2004, 220. 239. 
Geschlechtern konnte vom Flirten ${ }^{206}$ über versteckte Zeichen unter Liebenden ${ }^{207}$ bis hin zu freizügiger Sexualität reichen ${ }^{208}$. Nicht weniger vielfältig nahm sich das Unterhaltungsprogramm aus. Es mochte das Rezitieren griechischer Klassiker wie Homer ebenso einschließen wie musikalischtänzerische Darbietungen und Späße (scurrae) ${ }^{209}$. Raumgreifendere Aufführungen haben deshalb vielleicht in den Hofarealen stattgefunden, zu denen sich die Speiseräume öffneten (d.h. Atrium oder Peristyl). Ausgehend von der großen Vielfalt an Handlungen und Diskursen, die im Rahmen des Conviviums zum Tragen kamen, wird man für die Rezeption des Decors von Gelageräumen eine Vielzahl an möglichen Kontextualisierungen in Rechnung stellen müssen.

Kulthandlungen waren für die häusliche Gesellschaft zentral. Gemauerte Altäre, mobiles Kultgerät und rituell aufgeladene Wandmalereien zeugen davon, dass sie zumeist in Hofbereichen, aber auch in Küchenarealen stattfanden ${ }^{210}$. Aus Schriftquellen sind Informationen zu Kultteilnehmern, Kultanlässen und Opfergaben zu gewinnen. An den häuslichen Kulten partizipierte zuvorderst die Hausgemeinschaft selbst, die damit als eigentlicher Adressat der kultischen Ikonographien gelten darf. Bei zentralen häuslichen Festen opferte der pater familias ${ }^{211}$, dabei war die Hausgemeinschaft (familia) zugegen. Allein zum Compitalienfest sollte der Verwalter (vilicus) an den Compita oder am häuslichen Herd (in foco) opfern ${ }^{212}$.

Bei den Hausgöttern handelt es sich um die den Ort und die Familie beschützenden Laren ${ }^{213}$ sowie die Penaten, d.h. Götter, denen die Familie besonders verbunden $\operatorname{war}^{214}$ und die zu ganz unterschiedlichen Ritual- und Kultanlässen verehrt wurden. Sie wurden beim Eintritt in ein Haus begrüßt und beim Verlassen verabschiedet ${ }^{215}$. Wurde Mahl gehalten, so waren sie an der Tafel anwesend $^{216}$, auch sie erhielten Gaben ${ }^{217}$. Cato schreibt vor, dass anlässlich eines Opfermahls (dapis) Iuppiter einen Weinbecher sowie Opfergaben für ein As erhalten solle. Besondere Opfer sind nach Cato anlässlich der Ernte zu tätigen, hier sind Ceres, Ianus, Iuppiter und Iuno zu bedenken ${ }^{218}$. Hinzu kommen Opfer anlässlich der Kalenden, Nonen und Iden eines Monats ${ }^{219}$. Tibull erwähnt monatliche Opfer für die Lares ${ }^{220}$. Besondere Kulthandlungen fanden darüber hinaus an den Caristia, zum Geburtstag von Dominus und Domina sowie anlässlich von Familien-

206 Ein Graffito im Triclinium der Casa del Moralista (III 4,3) CIL IV 7698, fordert die Gäste auf, ihre Augen von den Frauen anderer Männer zu lassen: lascivos voltus et blandos aufer ocellos coniuge ab alterius: sit tibi in ore pudor; vgl. dazu Ov. epist. 17,75-92.

207 So Prop. 3,8,23-26 (nicht konkret auf den Kontext der Mahlzeit bezogen), s. Yardley 1991, 151.

208 Plut. am. 16 (Mor. 760A): Gabba stellt sich beim Convivium schlafend, um mitzubekommen, ob Maecenas mit seiner Frau Ehebruch begeht; vgl. Festus 173 M.; das Thema Liebhaber, Hetäre und Rivale beim Symposion ist ein griechischer Topos, der aber auch in der römischen Komödie auftaucht und von den Elegikern aufgegriffen wird, s. Yardley 1991, 152.

209 Zum Programm, mit Quellenverweisen Vössing 2004, 214-219; zum Zusammenhang von Convivium und Theater, s. Jones 1991, 185.

210 Für die einzelnen Phasen werden die archäologischen Zeugnisse ausführlicher zu besprechen sein.

211 Cato agr. 2,1 benennt das Opfer für die Laren als erste Pflicht des Hausherrn; Cato agr. 152,1: scito dominum pro tota familia rem divinam facere; Cato agr. 141 zum rituellen Ablauf des häuslichen Opfermahls für Iuppiter Dapalis und Vesta; Cato agr. 143 zum Ernteopfer für Ceres, Ianus, Iuppiter, Iuno.

212 Cato agr. 7,3.

213 Zum Verständnis der Lares, s. Flower 2017, 6-17.

214 Bodel 2008, bes. 252f.

215 Plaut. Stich. 534f.; Cato agr. 2,1 (Betreten des Hauses); Plaut. Mil. 1339; Opfer der Bulla bei Annahme der Toga virilis - Pers. 5,30f.

216 So bei Petron. 60,8-9; nicht nur beim Gastmahl, sondern auch bei gewöhnlichen Mahlzeiten erstrebenswert, s. Colum. 11,1,19.

217 Hor. carm. 4,5,29-35 (Trankspende); Serv. Aen. 1,730f.; Ov. fast. 2,631-634; Petron. 60,8-9; Fröhlich 1991, 24; Flower 2017, 10.

218 Cato agr. 143,1-2.

219 Prop. 4,3,55f.; zu den Lares-Festivitäten, die die Zeit strukturieren, s. Flower 2017, 44f.

220 Tib. 1,3,33f.: at mihi contingat patrios celebrare Penates / reddereque antiquo menstrua tura Lari. 
festen statt ${ }^{221}$. So wurden die Laren auch anlässlich einer Hochzeit mit Weihrauch und Blumenkränzen geehrt ${ }^{222}$ und der Hausherr opferte dem Genius an seinem Geburtstag Weihrauch und Kuchen $^{223}$. Die Quellen erlauben den Rückschluss, dass die Kulthandlungen zu unterschiedlichen Anlässen und Jahreszeiten stattfanden, unterschiedliche Formen annahmen und damit jeweils unterschiedliche atmosphärische Konstellationen erzeugt haben.

Die Unterschiede werden mit Blick auf die Opfergaben noch konkreter greifbar. Literarische Zeugnisse, bildliche Darstellungen und archäologische Befunde lassen sich nicht exakt zur Deckung bringen. Literarische Quellen überliefern, dass zum Opfer eine Gebetsformel gehörte, die von entsprechenden Kulthandlungen begleitet wurde ${ }^{224}$. Bei den Opfergaben handelte es sich nach Auskunft der Schriftzeugnisse um Weihrauch, Wein und Girlanden, weiterhin bezeugt sind Kränze, Obst und Opferkuchen bzw. Fladenbrote. Diese wurden sowohl dem Genius und den Laren ${ }^{225}$ als auch anderen Göttern dargebracht ${ }^{226}$. In einzelnen Fällen ist in den Quellen von blutigen Opfern die Rede, für die man voraussetzen darf, dass sie entsprechend raumfüllend gewesen sein müssen. Cato fordert im Zusammenhang mit der Ernte ein Schweineopfer (Eingeweide) für Ceres ${ }^{227}$; Horaz, Plautus und Tibull sprechen von Tieropfern im Zusammenhang mit der Verehrung des Genius und der Laren ${ }^{228}$. Bildliche Opferdarstellungen sind vor allem aus dem vierten Stil erhalten. Als Opfergaben auf den Larenaltären sind Pinienzapfen, Feigen, Datteln und Eier erkennbar, Tieropfer sind üblicherweise nicht dargestellt.

In jüngster Zeit sind von Mark Robinson Holz- und Speisereste, die im Peristyl niedergelegt wurden, als Hinweise auf Opfer ausgewertet worden ${ }^{229}$. Knochen gehören regelhaft zu den Deponierungen, auch wenn es sich meist nicht um vollständige Tiere handelt. Eine Ausnahme stellt die Casa degli Epigrammi Greci (V 1,18.11.12) dar; hier wurden zwei ganze Hennen verbrannt. Andernorts kommen Getreidekörner, selten gebackene Brote hinzu; weiterhin Früchte und Nüsse, Pflanzen. Zu den flüssigen Opfern haben Wein und Milch gezählt. Die archäologischen Befunde zeugen von den konkret vor Ort vollzogenen Handlungen, die sich durch eine große Vielfalt auszeichnen.

Neben Kulthandlungen im engeren Sinn sind für das Haus eine Vielzahl von Riten und Zeremonien bezeugt, über deren konkreten räumlichen Kontext sich die Quellen jedoch weitgehend ausschweigen. Nach seiner Geburt wurde das Kind auf den Boden des Hauses gelegt und

221 Caristia - Weihrauchopfer für Götter, Speiseopfer für Laren: Ov. fast. 2,631f.; anlässlich des Geburtstags erwähnt Prop. 3,10 eine Zeremonie für Venus; bei Tib. 2,2,1-8 kommt der Genius anlässlich des Geburtstags zum (häuslichen) Altar, wo er Weihrauch und Gewürze empfängt. Er soll mit Girlanden geschmückt, mit Öl gesalbt sowie mit Fladenbrot und Wein gesättigt werden; ähnlich Tib. 1,7,49-54; Ov. trist. 3,13,13-18; 5,5,1-14; Pers. 2,3; Mart. 10,24,4f.; Cens. 2,2 ff.; vgl. Fröhlich 1991, 24 f.

222 Plaut. Aul. 385 f.

223 Mart. 10,24,4f.

224 Ausführlich Cato agr. 141. 143.

225 Cens. 2,2 (Wein an Genius); Hor. carm. 3,17,14f. (Wein und zwei Monate altes Ferkel an Genius); Hor. sat. 2,5,10-12 (Obst und Feldfrüchte an Laren); Iuv. 9,137f. (Weihrauch und Kran an Laren); Macr. Sat. 1,24,22 (Weihrauch an Penaten); Mart. 10,24,4 (Kuchen und Weihrauch an Genius); Ov. fast. 2,631f. (Speiseopfer an Laren); Ov. trist. 3,13,1318 (Kränze, Weihrauch und Kuchen an Genius); Plaut. Aul. 23-25 (Weihrauch, Wein und Girlanden an Lar); Plaut. Aul. 385f. (Weihrauch und Kränze an die Laren); Plaut. Trin. 39 (Kranz an Lar); Prop. 3,10,19f. (Weihrauch, Altar bekränzt); Tib. 1,3,33f. (Weihrauch für Penaten und Laren); Tib. 1,10,21-24 (Weintraube, Ährenkranz, Fladenbrot, Wabenhonig für die Laren); Tib. 2,1,59f. (Kranz für Laren); Tib. 2,2,1-8 (Weihrauch, Gewürze, Girlanden, Öl, Wein und Fladenbrote für den Genius); Tib. 4,6,1f. (Weihrauch, Brot und Wein an Iuno). Die Quellen gesammelt bei Fröhlich 1991, 25 Anm. 91. 226 Cato agr. 143 empfiehlt anlässlich des Ernteopfers eine stark repetitive Sequenz von Opfern und Gebeten: ein von Weihrauch und Wein begleitetes Gebet für Ianus, Iuppiter und Iuno; sodann einen Opferkuchen für Ianus, einen Opferfladen für Iuppiter; Wein für Ianus; einen Opferkuchen und Wein für Iuppiter; einen Opferkuchen für Ianus; einen Opferfladen für Iuppiter; Wein für Ianus und Iuppiter.

227 Cato agr. 143,1.

228 Hor. carm. 3,17,14f. (Wein und zwei Monate altes Ferkel an Genius); Plaut. Rud. 1206f.; Tib. 1,10,27f. (im Kontext von Opfergebräuchen für die Laren).

229 Robinson 2019, 239-241. 
dann durch denjenigen, der die Versorgungstätigkeit ausübte, aufgehoben ${ }^{230}$. Verschiedene Quellen berichten von Möbeln, die im Haus für die Götter aufgestellt wurden. Bei dem Ritus des lectisternium handelt es sich um das rituelle Aufstellen einer Liege für die Geburtsgötter Pilumnus und Picumnus. Sie erhielten im Haus ein Speisebett (evtl. mit einem Speisetisch), in das wohl ein pilum gelegt wurde ${ }^{231}$. Das In-die-Wiege-Legen und Füttern des Neugeborenen mag durch diesen Ritus magisch verdoppelt worden $\operatorname{sein}^{232}$. Eine weitere Liege wurde für Iuno zusammen mit einem Tisch für Hercules aufgestellt ${ }^{233}$, eine andere Quelle berichtet von einem Tisch für Iuno ${ }^{234}$. Zur Geburtszeremonie gehört ferner eine Mensa, auf der die Freundinnen der Mutter Geschenke für die Götter niederlegen ${ }^{235}$. Vieles bleibt in den Quellen unklar: Ob es sich bei den genannten Speiseliegen und Tischen immer wieder um dieselben Möbel oder um verschiedene handelt ${ }^{236}$, ist ebenso ungewiss wie deren genaue Lokalisierung. In jedem Fall fungierten die Tische, wie aus den Quellen hervorgeht, als Opfertische ${ }^{237}$. Der Übergang vom Knaben- zum Mannesalter fand seinen rituellen Ausdruck im Wechsel der Kleidung ${ }^{238}$. Die Bulla wurde abgelegt und im Lararium aufgehängt ${ }^{239}$, der Bart den Laren geweiht ${ }^{240}$, die Toga virilis angelegt. Cicero spricht von togam puram dare bzw. togam virilem sumere, Tertiullian von sollemnitas togae purae ${ }^{241}$. Dieser Übergangsritus hatte seinen Ort ganz offensichtlich im Atrium. Im Rahmen der Hochzeitsriten wurde die Braut zunächst aus dem Haus der Eltern entführt ${ }^{242}$ und dann in einem Festzug zum Haus des Bräutigams geleitet. Dort bestrich die Braut die Türpfosten mit Fett oder Öl und schmückte sie mit Wollbinden $^{243}$. Dann wurde sie über die Schwelle des Hauses gehoben ${ }^{244}$ bzw. überschritt diese ${ }^{245}$. In limine, wo sich Bräutigam und Braut begegneten, wurden Feuer und Wasser ,gebraucht ${ }^{\text {` }}$ die Symbole für Mann und Frau ${ }^{246}$. Das Empfangen von Feuer und Wasser als Zeichen der Aufnahme in den Hausstand mag im Atrium stattgefunden haben ${ }^{247}$. Der Aufstellungsort des lectus genialis

230 Die Quellen sind in ihrer Interpretation umstritten, s. Köves-Zulauf 1990.

231 Non. p. 848,11 = Varro, pop. Rom. frag. 390 [Salvadore]: natus si erat vitalis ac sublatus ab ostetrice, statuebatur in terra, ut aspiceretur rectus esse; dis coniugalibus Pilumno et Picumno in aedibus lectus sternebatur; s. Köves-Zulauf 1990, 179-182.

232 Köves-Zulauf 1990, 179f.

233 Serv. ecl. 4,62: Proinde (sc. ut Veneri ac Libero possent operari) nobilibus pueris editis in atrio domus Iununi lectus, Herculi mensa ponebatur; vgl. Köves-Zulauf 1990, 182.

234 Tert. anim 39.2: per totam hebdomadem Junoni mensa proponitur.

235 Non. p. 487,9 = Varro, pop. Rom. frag. 391 [Salvadore]: mensa anteponebatur cum culia aucuno, [in] quo quae veniebant ad fetam amicae gratulatum, dis mactabant; vgl. Köves-Zulauf 1990, 182.

236 Mit der Annahme einer ,multifunktionellen` Nutzung der Möbel für verschiedene rituelle Zwecke - Köves-Zulauf 1990, $182 \mathrm{f}$.

237 Köves-Zulauf 1990, 184 f.

238 Zum Folgenden Clarke 1991, 9f.

239 Pers. 5,30f.; Prop. 4,1,131-132; Orr 1978, 1567 Anm. 59.

240 Orr 1978, 16.

241 Cic. Phil. 2,44; vgl. auch togam accipere bei Liv. per. 26; togam mutare bei Gell. 18,4,1; Hor. carm. 1,36,9; und sollemnitas togae purae bei Tert. idol. 16,1; zu den Quellen Dolansky 2008, Anm. 1.

242 Festus p. 289a; Macrob. Sat 1,15,21; Catull. 61,3.

243 Don. 1,2,60: cum puellae nuberent, maritorium postes ungebant ibique lanam figebant; Isid. orig. 9, 7, 12; Serv. Aen. 4, 458; laut Plin. nat. 28,135 berührt die Braut beim Eintritt in das Haus die Türpfosten mit Schweinefett; Serv. Aen. 1,1; Öl: Isid. orig. 1,1; vgl. Marquardt 1980, 55; bei Lucan. 2,354f. Verweis auf Kränze und Girlanden, die den Eingang schmücken, und Binden an den Türpfosten.

244 Plut. qu. R. 29 (mor. 271D); Isid. orig. 9,7,12; Plaut. Cas. 4,4,1; Lucan. 2,359.

245 Catull. 61,166f.

246 Varro ling. 5,61: Igitur causa nascendi duplex: ignis et aqua. Ideo ea nuptiis in limine adhibentur [...]; vgl. Garani 2014, 149.

247 Scaev. Dig. 24,1,66; Novius bei Nonius p. 516; Varro bei Serv. Aen. 4, 167; Ov. fast. 4,792 (zu Feuer und Wasser als Eheritus); Plut. qu. r. 1 (mor. 263E) zum Berühren von Feuer und Wasser; Marquardt 1980, 55 f. 
lässt sich nicht mit Bestimmtheit lokalisieren ${ }^{248}$. Für die Frage der decorativen Gestaltung des Hauses sind diese Übergangsriten insofern relevant, weil sie einerseits die Bedeutung des Eingangs als Grenze betonen, andererseits zeigen, dass das Atrium im Zentrum häuslicher Aktivitäten stand.

Aufgrund der geringen Quellendichte lässt sich nicht mehr nachzeichnen, ob die Handlungen zwischen dem 2.Jh.v. Chr. und dem 1.Jh.n. Chr. einem Wandel unterlagen, oder ob sich zumindest die Qualität des Handelns - das Maß an Performativität oder Religiosität etwa - veränderte. Ebenso entzieht sich unserer Kenntnis, ob sich die Handlungen in Bezug auf verschiedene soziale Gruppen unterschieden.

\subsection{Wahrnehmungshaltungen und Handlungsformationen im räumlichen Kontext}

Ausgehend von den verschiedenen möglichen Wahrnehmungshaltungen (mobil/statisch) und Handlungsformationen lassen sich einzelne Bereiche des Hauses kontrastierend beschreiben.

Atrium und Peristyl wird man zuvorderst als Knotenpunkte auffassen, an denen man sich begegnete und auch förmlich Besucher empfing. Die Hofbereiche wurden dadurch zu Orten der gemeinschaftlichen Aktion und sozialen Repräsentation ${ }^{249}$, hier fanden zentrale kultische Handlungen für die Lares und den Genius statt, hier waren die Arcae aufgestellt ${ }^{250}$, hier konnte man Objekte präsentieren, die auf besondere biographische Leistungen verwiesen ${ }^{251}$ und sich über die Imagines maiorum der eigenen Vergangenheit vergewissern ${ }^{252}$. Die Höfe stehen damit im Schnittpunkt verschiedenster Rezipientengruppen, ihr Decor vermittelt zwischen den Wahrnehmungserwartungen der Bewohner und der intendierten Wirkung auf den Besucher. Atrium und Peristyl unterscheiden sich nur graduell - und zwar dadurch, dass das Atrium üblicherweise nahe dem (Haupt-)Eingang, das Peristyl im rückwärtigen Teil des Hauses lag. Die ganz auf die Hofbereiche geöffneten Räume (Tablinum, Alae, Exedrae) wird man auf diese Kommunikations- und Handlungszusammenhänge beziehen dürfen.

Triclinia und Cubicula, d.h. ,Liegeräume', die für den Empfang von geladenen Gästen infrage kommen, zeichneten sich im Unterschied zu den Höfen durch eine ,statische‘ Wahrnehmung aus. Schon im Moment des Gästeempfangs konnten sich die Wahrnehmungsszenarien jedoch erheblich unterscheiden, abseits des festlichen Conviviums standen die Räume ganz unterschiedlichen Nutzungen offen.

Davon kategorial verschieden sind Räume, die als ,Servicebereiche‘ genutzt wurden. Installationen wie der Einbau eines Herdes oder einer Latrine spezifizierten ihre Nutzung. Darüber hinaus waren sie nicht selten auch architektonisch von den ,Wohnbereichen' getrennt. Auch wenn die

248 s. o. S. 20. 26. Optimistischer allerdings Lorenz 2008, 383, die die Mythenbilder der Tablina entsprechend deutet. 249 Cic. orat. 1,161f.; vgl. Goldbeck 2010, 135.

250 Brothers 1996, 41.

251 Plin. nat. 35,6f. berichtet von einem Triumphator, der im Vestibulum seines Hauses Schiffsschnäbel anbringen ließ; so über Pompeius auch Cic. Phil. 2,68.

252 Zur Platzierung der Imagines im Atrium: Pol. 6,53,4 (Aufstellung des Bildes des Toten an dem am besten sichtbaren Ort im Haus); Ov. fast. 1,591 (Wachsbilder - ceras - im Atrium); Val. Max. 5,8,3, Sen. benef. 3,28,2; Sen. epist. 44,5; 76,12 (erwähnt Ahnenporträts ohne direkten Nexus zum Atrium); Mart. 2,90,5-8 (auf die Vielzahl der Ahnenbilder Bezug nehmend); Iuv. 8,1-5. 19-20. Zur Aufbewahrung in einem Holzschrein: Pol. 6,53,4. Von dem repräsentativen Wert dieser imagines zeugt der Überfall auf das Haus des Marcus Aemilius Lepidus, in dessen Zuge die imagines maiorum zusammen mit den Waffen, die das Atrium schmückten, zerstört wurden, wie Asconius in Milon. 43C wissen lässt: deinde omni vi ianua expugnata et imagines maiorum deiecerunt et lectulum adversum uxoris eius Corneliae [...] fregerunt, itemque telas, quae ex vetere more in atrio texebantur, diruerunt. Da diese imagines der Überlieferung nach aus Wachs waren, verwundert es nicht, dass sie sich nicht erhalten haben. Polybios lässt uns jedoch wissen, dass das Bild (eikon) eine Maske (prosopon) ist, die in Form und Farbe dem Toten ähnelt. Die Bilder würden anlässlich staatlicher Opferfeste geschmückt; s. Pol. 6,53,5f. 
Servicebereiche großer Häuser vornehmlich von Sklaven bespielt worden sein dürften und sich durch eine besonders dichte Nutzung auszeichneten ${ }^{253}$, so korrelierte mit der architektonischen Separierung keine strikte Ausgliederung der Nutzergruppen: Sklaven erfüllten einige ihrer Funktionen in Interaktion mit den Hausbewohnern. In kleineren Häusern fielen die räumlichen (und wohl auch personellen) Trennungen ohnehin nicht so scharf aus.

Die Wahrnehmung von Decor unterliegt verschiedenen Framings, die sich gegenseitig bedingen. Der räumliche Kontext ermöglicht, rahmt und stimuliert spezifische Körperhaltungen und Handlungsformen. Aus diesen wiederum ergeben sich spezifische Betrachterhaltungen. Eine Skulptur wird folglich in einem Heiligtum anders als im Haus wahrgenommen ${ }^{254}$, weil sich das Gesamtsetting, die dadurch bedingten Formen der Inszenierung ${ }^{255}$, vor allem aber die Handlungsformen und die mit diesen einhergehenden Wahrnehmungshaltungen unterscheiden.

\section{Akteure und Decor}

Die Wahrnehmung des Betrachters wird nicht nur durch dessen Einbindung in räumlich verortete Handlungskonstellationen geprägt, sondern auch durch dessen sozialen Habitus. Damit rückt das Verhältnis von spezifischen Akteursgruppen und Decor-Formen in den Blick. Konkret geht es darum, dem Geschmack und Repräsentationsbedürfnis der Bewohner nachzuspüren, um davon ausgehend die Frage nach der sozialen Aufladung von Decor-Formen zu stellen. Dabei bewegt sich die Forschung zwischen zwei Deutungsoptionen: einerseits dem Postulat eines individuellen Geschmacks des Hausherrn, der in den Wohnausstattungen zum Ausdruck komme, andererseits der Annahme eines sozial durchwirkten Kollektiv-Geschmacks bzw. Habitus.

\subsection{Auftraggeber und ihr individueller Wohngeschmack}

Die decorative Qualität von Ausstattungselementen wurde wiederholt als Ausdruck des individuellen Geschmacks und der persönlichen Aussageintentionen des Hausbesitzers aufgefasst ${ }^{256}$, etwa

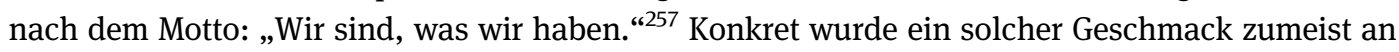
der Auswahl spezifischer Bildinhalte festgemacht. Beide Aspekte - die Rekonstruktion eines individuellen Auftraggebergeschmacks und das Postulat spezifischer Botschaften, die kommuniziert werden sollten - sind aber nicht unproblematisch.

Zwar lassen sich einzelne antike Quellen beibringen, welche die Auswahl von Bildwerken auf den Habitus des Hausbesitzers zurückführen. Cato etwa behielt unter den Bildwerken, die er auf Zypern verkaufte, nur eine Skulptur des Zenon für sich, nicht ihres Preises wegen, sondern weil es sich um ein Philosophenbildnis handelte ${ }^{258}$. Gerade das Bild des Stoikers fügt sich in das Selbstbild Catos $^{259}$. Allerdings sind uns andernorts auch andere Auswahlkriterien für den Ankauf von Skulpturen überliefert. Cicero etwa ,bestellt' für die Academia in seiner Villa in Tusculum eine Aus-

253 Dickmann 2011, 65.

254 So etwa auch Zanker 2000, 216.

255 So auch Perry 2005, etwa 62f.

256 Perry 2005, 65f. argumentiert mit der Empfehlung Ciceros (Cic. off. 1,110-114), das eigene Verhalten solle mit der eigenen natura konsistent sein. Den Zusammenhang zur Hausausstattung stellt Cicero selbst aber nicht her. Leach 1982, bes. 140 f. postuliert, dass der erste und zweite Stil von den Handwerkern realisiert worden sei und erst im dritten und vierten Stil der explizite Geschmack des Hausherrn zum Tragen käme. Methodisch ist dies problematisch, lässt sich eine solche ,Wahl' doch entweder für alle oder eben für keines der Bildelemente postulieren.

257 So der Buchtitel von Schäfer 2012, der Konzepte aus der Psychologie diskutiert, die den Zusammenhang von Besitz bzw. materialisiertem Habitus und ,Identität‘ ins Auge fassen.

258 Plin. nat. 34,92.

259 Perry 2005, 65. 
stattung, die für eine Palästra oder ein Gymnasium passend ist ${ }^{260}$. Atticus verspricht daraufhin die Lieferung megarischer Statuen und Hermen, konkret ist die Rede von einer Hermathena ${ }^{261}$. Da sich die Statuen nicht erhalten haben, braucht nicht weiter diskutiert zu werden, inwieweit die gewählte Ausstattung für ein intellektuelles Ambiente ,passend' war. Entscheidend ist, dass Cicero die Auswahl Atticus überlässt und sich als Auswahlkriterium nur sehr allgemein auf die in seiner Zeit gängige Vorstellung von Adäquatheit bezieht.

Dieser Umstand ist methodisch insofern relevant, als die Besitzer konkret erhaltener Häuser meist noch nicht einmal namentlich bekannt sind, in keinem Fall aber Selbstäußerungen bezüglich der Auswahl spezifischer Decor-Elemente vorliegen. Gerade dann, wenn die Hausausstattungen dem gängigen Repertoire der Zeit entsprechen, liegt es nahe, sie im Kontext allgemein anerkannter Decor-Prinzipien zu erklären - auch dann, wenn die Hausbesitzer selbst sie als Ausdruck ihres individuellen Habitus verstanden haben mögen. Spezifik wird in diesen Fällen durch die räumliche Kontextualisierung und die Kombination von bekannten Versatzstücken erzeugt. Der Geschmack der Hausbewohner wird also zuvorderst in Decor-Ensembles greifbar. Von der intentionalen Auswahl eines Ausstattungselements wird man erst ausgehen, wenn es die Konventionen der Zeit sprengt ${ }^{262}$. Selbst im Fall des exzeptionellen Alexandermosaiks bleiben allerdings zahlreiche ,individuelle‘ Rezeptionsoptionen denkbar ${ }^{263}$. Dem individuellen, psychosozial motivierten Ausstattungsgeschmack des Dominus ist also kaum auf die Spur zu kommen.

\subsection{Auftraggeber und ihr soziokultureller Geltungsanspruch}

Auch wenn man die individuellen Motivationen, die hinter der Gestaltung eines Hauses stehen, kaum greifen kann, so hat die Forschung doch versucht, spezifische Architektur- und DecorFormen auf den soziokulturellen Geltungsanspruch des Hausherrn zu beziehen. Kritisch ist zunächst anzumerken, dass Architektur und Ausstattung von Häusern kaum allein vom Dominus, sondern bis zu einem gewissen Grad sicher auch von Familienmitgliedern, von der Bauleitung und den Werkstätten mitbestimmt wurden. Trotz dieser Einwände bleibt die Frage, inwieweit der Decor einen sozialen Aussagewert besaß, der es der Familie erlaubte, sich ihres sozialen Ranges zu versichern und nach außen darzustellen.

Hier kommen in der Forschung zwei verschiedene Zugriffsweisen zum Tragen. Auf der einen Seite stehen Studien, die von einer a priori vorgenommenen sozialen Verortung spezifischer Stilformen und damit auch eines spezifischen, sozial determinierten Geschmacks ausgehen (als elitär oder volkstümlich). Auf der anderen Seite stehen Untersuchungen, die den sozialen Status des Auftraggebers zum Ausgangspunkt für die soziale Klassifikation des Geschmacks nehmen ${ }^{264}$. In Bezug auf die Pompeji-Forschung bedeutet dies, dass der soziale Parameter der Hausgröße zum Ausgangspunkt für eine soziale Klassifikation der in den jeweiligen Häusern vorkommenden Ausstattungsformen gewählt wird.

Stil und soziale Zugehörigkeit. Die soziale Klassifikation von Gestaltungsmerkmalen - die Unterscheidung von Staatskunst und populärer Kunst - ist von Gerhard Rodenwaldt in die Klassische Archäologie eingeführt ${ }^{265}$ und durch Ranuccio Bianchi Bandinelli prominent gemacht wor-

260 Cic. Att. 1,5,2; 1,6,2; vgl. Neudecker 1988, 12-14; Newby 2005, 90f.; Squire 2015, 591-593.

261 Cic. Att. 1,5,2; 1,9,3.

262 Auch hier ist wiederum die Spezifik von Medien in Rechnung zu stellen: Ehrenstatuen und auch Sarkophage sind als repräsentative Medien konkreter auf ein Individuum zu beziehen als ganze Hausausstattungen.

263 s. u. S. 87-90. 116.

264 Etwa Clarke 2003 nimmt, imperiale‘ Kunst zum Ausgangspunkt. Seine Überlegungen zur sozialen Kontextualisierung von Wahrnehmungen sind entweder hypothetisch oder unterscheiden sich nicht von gängigen Überlegungen (etwa zu den augusteischen Monumenten - S. 19-28).

265 Rodenwaldt 1940, 12. 
den. In Bezug auf die pompejanische Wandmalerei rechnete Bianchi Bandinelli Alltagsszenen der ,arte popolaresche‘ zu, die sich durch ein Fehlen eines kompositorischen Gestaltungswillens (z.B. Beziehungslosigkeit der Einzelfiguren) auszeichne ${ }^{266}$. Solche Züge hat man insbesondere in den Lararien- und Fassadenbildern anzutreffen geglaubt, die man auch in Bezug auf die Auftraggeberschaft mit dem ,einfachen Volk' verbunden hat ${ }^{267}$. Thomas Fröhlich interpretiert die thematischen und kompositorischen Besonderheiten indes als Ausdruck eines Gattungsstils. Er beobachtet bei Fassaden- und Lararienbildern klassizistische Formen und kompositorische Merkmale ${ }^{268}$, sieht aber dennoch Spezifika: „der neutrale Hintergrund, die flächenparallele Anlage der einzelnen Figuren und Bildelemente, die parataktische oder symmetrische Kompositionsweise und die Vorliebe für strenge Frontal- und Profilansichten“269. Ihre Verbindung mit einer spezifischen sozialen Gruppe weist er mit dem Hinweis zurück, dass solche Bilder auch in großen Häusern auftreten ${ }^{270}$. Lauren Hackworth Petersen verwirft das Konzept einer ,Freigelassenen-Kunst` grundsätzlich, da nicht nur die soziale Schicht inhomogen, sondern auch die Stilformen nicht monolithisch zu begreifen seien und daher soziale Zugehörigkeit und Stilformen kaum aufeinander bezogen werden könnten ${ }^{271}$. Ebenso tritt Tonio Hölscher einer sozialen Aufladung vermeintlich populärer Elemente (Bedeutungsgröße, frontale Wiedergabe, axialsymmetrische Komposition, additive Reihung, Detailrealismus) entgegen. Da diese in sich heterogenen Merkmale auch auf Staatsmonumenten auftreten, interpretiert er sie als mediale Phänomene: „[Die Phänomene der Volkskunst] sind [...] Teil eines generativen Systems von Stilkonzepten, die nicht habituell, als sozio-kulturelle Distinktive, sondern medial, als System der Kommunikation zu verstehen sind.“272 Es handle sich um eine „präsentative“ Stilform, die für den Verweis auf individuelle Leistung und Aufstieg genutzt worden $\mathrm{sei}^{273}$. Spezifische Stilformen lassen sich damit zwar mit spezifischen Kommunikationsabsichten, nicht aber mit spezifischen sozialen Gruppen (und erst recht nicht mit der sozialen Zugehörigkeit des Hausbesitzers) in Verbindung bringen. Darüber hinaus wäre auch der Rezeptionsrahmen in Rechnung zu stellen: Fassadenbilder und Bilder an Schreinen setzen eine andere Aufmerksamkeitslage (und Rezeptionsbedingungen) voraus als etwa Bilder in Gelageräumen.

Hausgrößen und soziale Zugehörigkeit. Mit Bezug auf Vitruv (6,5,1-2) wird der soziale Status eines Hausbesitzers an der Größe seines Hauses (laxitas) bemessen. Wallace-Hadrill benennt vier Kategorien, die sich nicht nur hinsichtlich ihrer Grundfläche, sondern dadurch bedingt auch hinsichtlich ihrer architektonischen Merkmale unterscheiden ${ }^{274}$. Besonders große Häuser mit einer Grundfläche von $3000 \mathrm{~m}^{2}$ bis $350 \mathrm{~m}^{2}$ sind üblicherweise (in $64 \%$ der Fälle) mit Atrium und Peristyl ausgestattet. Die größten Häuser besitzen sogar ein zweites Atrium und/oder ein zweites Peristyl, wenigstens aber fällt die Peristylfläche oft besonders groß aus ${ }^{275}$. Die folgende Gruppe von Häusern markiert mit 345 bis $175 \mathrm{~m}^{2}$ den pompejanischen Standard. Die Mehrzahl (60 \%) besitzt ein Atrium,

266 Bianchi Bandinelli 1941, bes. 12. Eine ähnliche Vorstellung vom, realistischen`Charakter der Alltagsszenen bereits bei Helbig 1873, bes. 68-79 und Rizzo 1929, bes. 88-90; Baldassarre 2012, bes. 17f. interpretiert Bianchi Bandinellis Auffassung von der ,arte plebea‘ aber gerade nicht als Rückbindung von Stilformen an ein spezifisches soziales Milieu, sondern als Benennung einer spezifischen Bildsprache.

267 Zuletzt etwa Clarke 2003, 73f.

268 Fröhlich 1991, 14-20 mit ausführlicher Forschungsgeschichte. Er weist darauf hin, dass die Opposition von Volkskunst und Hochkunst üblicherweise parallelisiert wird mit der Gegenüberstellung von griechischer Kunst und italischer Tradition. Fröhlich 1991, 189-210.

269 Fröhlich 1991, 194.

270 Fröhlich 1991, 197 f.; kritisiert bei Tybout 1996, 365f., der daran festhält, dass sich diese Bilder grundsätzlich an die untersten Gesellschaftsschichten richten, und der deshalb dafür eintritt, den sozialen Kontext zumindest als einen möglichen „constituent in the generation of the ,popular“ painting“ im Auge zu behalten.

271 Petersen 2006 verweist darauf, dass die Vorstellung von einer Freigelassenenkunst auf Topoi der antiken Literatur zurückgeht.

272 Hölscher 2012, 29.

273 Hölscher 2012, bes. 32-44; ähnlich von Hesberg 2012.

274 Wallace-Hadrill 1990, 156-164; Wallace-Hadrill 1994, 72-82.

275 Zur Peristylgröße als Indikator für sozialen Status, s. Simelius 2018, 77-83. 
einige weitere auch einen Garten mit Säulenstellung (28\%), selten handelt es sich um ein volles Peristyl. Mehrheitlich (60 \%) verfügen diese Häuser über Läden. Die Häuser mit einer Grundfläche von $170 \mathrm{~m}^{2}$ bis $50 \mathrm{~m}^{2}$ besitzen zwischen zwei und sieben Räumen, wobei es sich zumeist um merkantile Räume handelt (61\%). Die Mehrzahl verfügt über einen zentralen Verteilerraum (medianum). Bei der Gruppe mit der geringsten Grundfläche von $45 \mathrm{~m}^{2}$ bis $10 \mathrm{~m}^{2}$ handelt es sich um Tabernae oder Officinae, bisweilen mit einem rückwärtigen Raum oder einem Raum im Obergeschoss, der zum Aufenthalt genutzt werden konnte (pergula). Diese verschiedenen Hausgrößen wurden mit verschiedenen sozialen Gruppen in Verbindung gebracht: die großen Häuser mit der Elite, die kleineren Atrium- und Hofhäuser mit Handwerkern, Geschäftsläuten und Freigelassenen, die kleinen Tabernae und Officinae mit den ärmsten Bevölkerungsteilen. Das Modell WallaceHadrills ist jüngst verschiedentlich aufgegriffen und modifiziert worden ${ }^{276}$. Die grundsätzliche Vorstellung von einer Korrelation von Hausgrößen und sozialem Status blieb jedoch unhinterfragt. An dieser Stelle ist auf einige Schwierigkeiten dieser Klassifikation hinzuweisen.

1) Unberücksichtigt bleiben etwaige Ober- und Untergeschosse, die für die zur Verfügung stehende Nutzungsfläche aber durchaus relevant sind.

2) Unberücksichtigt bleibt weiterhin, dass der Wert von Wohnraum nicht nur von der schieren Hausgröße, sondern auch von der Lage des Grundstücks abhängt. Die Grundstückspreise im Osten Pompejis, wo sich agrarisch genutzte Flächen befinden, dürften deutlich niedriger gewesen sein als westlich der Via Stabiana ${ }^{277}$.

3) Weiterhin unberücksichtigt bleiben sich ändernde Besitzverhältnisse, die im Laufe der Zeit annähernd jedes Haus betrafen.

4) Einzuwenden ist zudem, dass sich der Wohnluxus nicht allein an der schieren Hausgröße oder der Zahl der Räume in einem Haus bemisst, sondern an den pro Kopf zur Verfügung stehenden Quadratmetern. Es ist gerade nicht möglich, a priori anzunehmen, dass jeder Haushalt mithin jede separate Wohneinheit - von derselben Zahl an Personen bewohnt gewesen sei, und ebenso wenig lässt sich voraussetzen, dass mit jedem im Haus verfügbaren Raum eine bestimmte Zahl an Bewohnern korrelierte ${ }^{278}$. Bei solchen Standardkalkulationen bleibt unberücksichtigt, dass sich Luxus im Verfügen über besonders viel Platz, Armut in der besonders dichten Nutzung von Wohnraum zeigen kann. Der Hausbefund allein kann somit nicht als Indikator für die Zahl der Bewohner herangezogen werden.

5) Die Hausgröße muss per se nicht zwingend mit dem sozialen Status des Besitzers korrelieren, sondern kann auch anders motiviert sein. Bei den Besitzern mittelgroßer Häuser kann es sich prinzipiell auch um Reiche gehandelt haben, die außerhalb der Stadt eine große Villa besaßen und in der Stadt nur ein kleines Haus unterhielten; um Söhne, denen durch Erbe nur der Teil eines Hauses oder ein kleineres Haus zufiel; oder um kleine Familien, für die ein kleineres Haus ausreichend war.

6) Prestige und Reichtum lässt sich nicht allein über Hausgrößen, sondern auch über andere Marker artikulieren - etwa eine besonders aufwendige Architektur und/oder Ausstattung. Und hier ergibt sich ein Zirkelschluss: Wird der soziale Wert der Ausstattung an der Hausgröße bemessen, so müsste sie sich bei kleinen Hausgrößen grundsätzlich einfach ausnehmen. Dies

276 Mit etwas anderen Hausgrößen La Rocca u.a. 1990, 46-48; Heinrich 2002, bes. 65-67 unterscheidet drei Größenkategorien, die er mit bestimmten Decor-Phänomenen verbindet; diese Kategorien werden dann auf Oberschicht, Handwerker, Landarbeiter und Tagelöhner bezogen; eine Gliederung nach (etwas anderen) Hausgrößen auch bei Romizzi 2006, 13-70; mit Blick auf Peristyle Simelius 2018, bes. 13-18. 31; demnächst Christian Beck; zur sozialen Differenzierung des Wohnens, ausgehend von Vitruv, auch De Albentiis 2007/2008, 16f.; Packer 1975 diskutiert einige Häuser Pompejis und Herculaneums mit kleiner Grundfläche im Detail; Zanker 1979, bes. 514-517 mit einem maßstäblichen Grundrissvergleich; das Modell aufgegriffen und angewendet bei Lorenz 2008, 329, die Mythenbilder der obersten Hausgruppe Wallace-Hadrills zuweist. Einen etwas anderen quantifizierenden Ansatz wählt Flohr 2017, 5662, der seine Kategorien nicht auf die Grundstücksgröße, sondern auf die Raumzahl stützt.

277 Flohr 2017, 57.

278 Anders Flohr 2017, 62-64, der die beiden Optionen vergleichend diskutiert und optimistischer Stellung bezieht. 
ist, wie Wallace-Hadrill belegen kann, wenigstens tendenziell der Fall. Auffällig und besonders aussagekräftig sind aber die von ihm vernachlässigten Ausnahmen: reich ausgestattete, kleine Häuser $^{279}$. Dies gilt im ersten Stil etwa für die Casa Sannitica in Herculaneum, im vierten Stil für die Casa dei Vettii (VI 15,1) in Pompeji. Hier greift man nicht notwendigerweise eine Mittelschicht, die sich an Wohnstandards der Oberschicht orientierte.

An der sozialen Bewertung großer Luxusbauten wie der Casa del Fauno am einen Ende der Skala und kleiner Pergulae am anderen Ende ändert dies nichts. Die enormen Größenunterschiede strukturieren bei beiden Extremen die Handlungsmöglichkeiten. Dies gilt insbesondere für die Möglichkeiten, Gäste zu empfangen. Während die größten Häuser über eine Vielzahl unterschiedlicher Räume für den Gästeempfang verfügten, war es - wie Cicero ausführt - den Ärmsten verwehrt, überhaupt Gäste einzuladen ${ }^{280}$. Sehr viel schwieriger zu interpretieren ist die überwiegende Mehrzahl der Häuser von mittlerer Größe, die sich durch eine große Vielfalt an architektonischen Lösungen und Ausstattungsformen auszeichnen. Man darf die Hausgröße folglich als wichtigen, jedoch nicht als alleinigen Statusanzeiger in Rechnung stellen.

Hausgrößen, finanzielle Möglichkeiten und ,Geschmack`. Auf der Basis einer sozialen Differenzierung von Wohnformen entlang von Hausgrößen wurde zunächst von Paul Zanker, jüngst erneut von Emanuel Mayer, die Vorstellung formuliert, dass sich der Wohngeschmack je nach sozialer Zugehörigkeit (implizit: des Hausbesitzers) unterscheide. Für Zanker waren es die Eliten, die geschmacksbildend wirkten, während die Mittelschicht ihre Wohnformen mit bescheideneren Mitteln imitiert habe ${ }^{281}$. Emanuel Mayer geht noch weiter, indem er für die römische „middle class“ ein Klassenbewusstsein postuliert und auf dieser Grundlage einen spezifischen Klassengeschmack annimmt ${ }^{282}$. Dieser konstituiere sich nicht allein über spezifische ökonomische Möglichkeiten, sondern auch über einen spezifischen Umgang mit materieller Kultur ${ }^{283}$. Eine solch zugespitzte Position ist mit Blick auf die problematische Definition von ,Mittelklasse ${ }^{6}$ kritisiert worden, dürfte diese doch als kohärentes Konzept in der römischen Antike nicht existiert haben ${ }^{284}$. Vielmehr darf man die römische Gesellschaft als eine durchlässige, sich konstant veränderte Formation begreifen, in der vielfältige, sich überschneidende Prozesse sozialer Formierung (ökonomisch, politisch, juristisch, kulturell) am Werk waren ${ }^{285}$.

Auch wenn man die Vorstellung eines Klassengeschmacks mit guten Gründen verwerfen darf und die Identifizierung spezifischer Stilformen als ,volkstümlich' problematisch ist, so stellt sich dennoch die Frage nach einer sozial differenzierten Form der Decor-Produktion und Decor-Rezeption $^{286}$. Doch hier treten weitere methodische Schwierigkeiten auf. Pierre Bourdieu und in seiner Folge auch Wallace-Hadrill und Zanker setzen eine von allen Akteuren geteilte, gewissermaßen konventionelle, soziale Semantisierung von decor voraus. Gerade dies darf aber als fraglich gelten: Unterschiedliche Zeiten (Republik/Kaiserzeit), Regionen (Nord-/Süditalien), soziale Gruppen und selbst Individuen können spezifische Ausstattungsformen jeweils mit eigenen Konnotationen

279 Wallace-Hadrill 1990 möchte die Korrelation von Hausgröße und Decor-Aufwand statistisch belegen, indem er das Auftreten bestimmter Decor-Elemente nach Hausgrößen untersucht. Unberücksichtigt bleibt hier aber, dass gerade in kleineren Häusern der Decor kaum geschützt wurde, sich damit selten erhalten hat und einer Auswertung letztlich nicht zur Verfügung steht. Sinnvoller als eine statistische Auswertung sind m. E. in dieser Hinsicht ausführliche Case Studies.

280 Cic. Mur. 71.

281 Zanker 1979, bes. 514-519; Zanker 1995, bes. 204f.; Simelius 2018, 16 f.

282 Mayer 2012, 6f. postuliert, die Mittelklasse habe ihre eigenen „forms of cultural expression“ besessen, sowie (S. 14) ihre „class-specific social values and lifestyles“. Kritisch Petersen 2013.

283 Mayer 2012, 7.

284 Rez. zu Mayer 2012 von Mouritsen 2012; Wallace-Hadrill 2013; Squire 2013; Newby 2016, $22 f$.

285 Etwa Wallace-Hadrill 1994, 173; und Mayer 2012, bes. 9-11 selbst; Mouritsen 2012; Wallace-Hadrill 2013.

286 Als Frage formuliert auch bei De Angelis u. a. 2012a, bes. 8 . 
belegt haben ${ }^{287}$. Man wird daher kaum einen sozialen Konsens zur sozialen Bedeutung von DecorFormen erwarten können ${ }^{288}$.

Wenn die soziale und kulturelle Semantisierung von Decor-Formen infrage steht, so gilt es, das von Georg Simmel formulierte ${ }^{289}$, von Bourdieu weiterentwickelte und von Wallace-Hadrill und Zanker aufgegriffene Movens für die Veränderung der Artefakt-Welt zu hinterfragen: das Streben nach Distinktion ${ }^{290}$. Aus Bourdieus Perspektive beanspruchen Eliten für sich die ästhetisch, semantisch oder etwa auch technisch avancierteste Form der Ausstattung, die von den anderen sozialen Schichten imitiert wird. Tatsächlich wird die Vorbildfunktion der Elite und das damit verbundene Prinzip des Wetteiferns (aemulatio) schon von Cicero erkannt ${ }^{291}$. Da es zu einer immer weiteren Ausbreitung des Luxus führt, setzt hier seine Kritik an: cupiditatibus principum et vitiis infici solet tota civitas. Entsprechende Quellen haben dazu Anlass gegeben, spezifische Kulturphänomene als Ergebnis solcher Imitationsprozesse aufzufassen. So hat Zanker die Ausbildung der römischen (Mittelschicht-)Wohnkultur als Imitation der elitären Villenkultur erklärt ${ }^{292}$, es ließen sich jedoch zahlreiche andere Artefakt-Konstellationen in dieses Erklärungsmuster einbinden. Nicht-Eliten würden dadurch ihre Zugehörigkeit zum kulturellen System zum Ausdruck bringen ${ }^{293}$. Sobald ein kulturelles Phänomen in verschiedenen Schichten Verbreitung gefunden habe, hätte die Elite nach neuen Modi der Distinktion gesucht ${ }^{294}$. Auf diesem Wege ließe sich die enorme Steigerung des häuslichen Luxus in der späten Republik erklären, die von antiken Autoren hinreichend kommentiert und kritisiert wurde.

Dieses Modell der Imitation vermag somit, eine erhellende Perspektive auf antike Phänomene zu werfen, und doch lässt es sich auch hinterfragen. Wenn kein gesellschaftlicher Konsens über die soziale Wertigkeit von decorativen Einzelformen existiert, so wird man die Imitation ,höherer Kulturgüter nicht als ausschließliches Movens für kulturelle Produktion begreifen können. Es wäre zunächst einmal auszuhandeln, welchen sozialen Stellenwert einzelne Kulturformen überhaupt besitzen. Die Cena Trimalchionis lässt sich als satirisch verfasster, kritischer Kommentar auf solche Aushandlungsprozesse lesen. Petron beschreibt etwa eine ausgefallene Kuppelkonstruktion wie sie für die Domus aurea des Kaisers auch tatsächlich bekannt ist. Sind damit exzeptionelle Luxusformen Ausdruck einer ,falschen' Aneignung kultureller Formen? ${ }^{295}$ Seine Brisanz mag dieses Werk dadurch erhalten haben, dass das, was ,guter Geschmack ‘ ist, immer wieder infrage gestellt wird.

Hinzu kommt, dass nicht nur Angleichung, sondern auch die positiv besetzte Abgrenzung ,nach oben` als Movens für die Ausbildung von Decor-Formen denkbar ist ${ }^{296}$. Soziale Konkurrenz

287 Ullrich 2014, bes. 57 f. zu den unterschiedlichen sozialen Semantisierungen von Objekten am Beispiel von Kaviar. 288 Obwohl Mayer 2012, bes. 170-178 von der Vielfältigkeit der Bildbedeutungen in Abhängigkeit vom sozialen Hintergrund des Rezipienten ausgeht, stellt er die Existenz eines von allen geteilten und damit auch für alle signifikanten, sozial definierten Systems von Kulturformen nicht infrage. Für ihn gibt es einen klar zu konturierenden Mittelklassegeschmack. Letztlich folgt er darin wiederum Bourdieu.

289 Simmel [1905] 1995, 7-37 in Bezug auf die Mode, die er als Elitephänomen begreift. Schon Simmel allerdings sieht die „eigentliche Variabilität des geschichtlichen Lebens [...] im Mittelstand“; vgl. Veblen [1925] 1987. Gerade auch Veblen wird jedoch dafür kritisiert, dass dem luxuriös-verschwenderischen Güterkonsum eine soziale Intention, nämlich das Streben nach Distinktion, unkritisch unterstellt wird, s. Campbell 1995.

290 Bourdieu 1979; vgl. Wallace-Hadrill 1994, 143-147.

291 Cic. leg. 3,30-31. Er kritisiert den Villenluxus des Lucullus, der von Nachbarn niedereren Standes imitiert wird (imitatores); weiterhin Varro rust. 1,2,10; 1,13,7; 1,59,2; Plin. nat. 35,118; 36,110.

292 Zanker 1979.

293 Etwa Wallace-Hadrill 1994, 14; Newby 2016, $22 \mathrm{f}$.

294 Wallace-Hadrill 1994, 145f. 173f.; auch für Zanker 1995, 200-205 orientiert sich die antike Mittelklasse an der elitären Wertewelt.

295 Ausführlich zu diesen komplexen Verschränkungen Stein-Hölkeskamp 2005, 63-67. 125-127.

296 Kritisch zu diesem Modell auch Wallace-Hadrill 2010, 36f., der kulturellen Wandel nicht als top-down-Prozess, auch nicht im engeren Sinn als bottom-up-Prozess begreift, aber davon ausgeht, dass neue kulturelle Formen Ergebnis von Aushandlungsprozessen sind. Auch Mayer 2012, 5 positioniert sich gegen Bourdieus „trickle-down“ Distinktionsmodell, auch wenn er letztlich nur einen anderen Modus der Distinktion voraussetzt, der nicht auf Nachahmung 
kann ihren Ausdruck also nicht nur in Adaption, sondern auch in Abgrenzung und Differenzierung finden ${ }^{297}$. Kleine Atriumhäuser ahmen auch dann, wenn der Platz eigentlich zur Verfügung stünde, keineswegs immer die strenge symmetrische Struktur der reichen Häuser nach ${ }^{298}$.

Folglich muss man damit rechnen, dass verschiedene Gruppen einer Gesellschaft einzelnen Architektur- und Ausstattungsformen jeweils unterschiedliche soziale und kulturelle Bedeutungen zugeschrieben haben können. Dies wiederum bedeutet auch, dass sich die Auftraggeberperspektive in einer möglichen Betrachterperspektive auflöst. Wie aber nähert man sich hermeneutisch überhaupt sozialen und kulturellen Bedeutungen, wenn diese potenziell von Betrachter zu Betrachter variieren können? Freilich ist es müßig, über individuelle Wahrnehmungen antiker Betrachter zu spekulieren. Der Schlüssel liegt vielmehr in den soziokulturell angeeigneten Decor-Prinzipien. „Was sichtbar wird und was unsichtbar bleibt, welche Gestalten in Erscheinung treten und welche aus dem Sichtfeld ausgeklammert werden, hängt also [...] von dem ,historischen“ oder ,konkreten Apriori ‘ der jeweiligen Körper-, Praxis- und Artefaktkonstellationen ab.“299 Dieser bei Maurice Merleau-Ponty entwickelte Gedanke wird bei Michel Foucault weiter zugespitzt. Bei ihm sind es die Sprach- und Artefaktanordnungen, die „den handelnden und wahrnehmenden Leib allererst her-

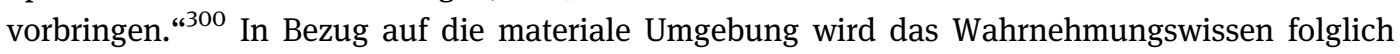
durch spezifische Formen des Objektarrangements hergestellt - d.h. durch kulturspezifische Raum- und Gestaltungsprinzipien ${ }^{301}$. So darf man mit Wolfgang Ullrich annehmen, dass „das einzelne Objekt seine Bedeutung [...] erst innerhalb einer Gesamtinszenierung [erhält].“302

Im Unterschied zu den Studien von Bianchi Bandinelli, Fröhlich oder auch Mayer geht die Frage nach dem sozialen Sinn folglich nicht von der Einzelform, sondern von der kontextuellen Verortung von Decor aus ${ }^{303}$, im Unterschied zu Wallace-Hadrill und Zanker nicht primär von der Hausgröße, sondern auch von den Decor-Formen. Hausgrößen, Hausarchitekturen und die Modi der Ausstattung sind folglich in ihrer Beziehung zueinander zu verstehen, ohne dass einzelne Analysekategorien a priori als konstitutives Element für eine soziale Differenzierung der Wohnund Ausstattungskultur herangezogen werden.

\footnotetext{
(allein) beruht. Eine ausführliche und kritische Diskussion des Ortes von Innovation (Elite: trickle-down; Mittelschicht: Spiralmodell; Unterschicht: trickle-up), s. Jäckel 2006, 221-225.

297 Als ,opting in' und ,opting out‘ beschrieben bei Assmann 1986; vlg. Wallace-Hadrill 2010, 436.

298 Jung 1984, 80f.; s. u. S. 132 f.

299 Prinz 2016, $193 f$.

300 Prinz 2016, 194.

301 In der Denkweise des mittleren 20.Jhs. ist es der ,Geist‘, der materiell konkretisiert wird - Merleau-Ponty 2000, 179: „Der Geist einer Gesellschaft verwirklicht sich, überliefert sich und wird wahrnehmbar in den kulturellen Objekten, die sie sich gibt und mitten unter denen sie lebt. Ihre praktischen Kategorien sedimentieren sich darin, und umgekehrt legen sie den Menschen eine Seins- und Denkweise nahe.“ Deleuze 1987, 82 in Bezug auf Foucault: „Die Bedingung, auf die die Sichtbarkeit sich beruft, ist nicht die Sichtweise eines Subjekts: das sehende Subjekt ist seinerseits eine Stelle innerhalb der Sichtbarkeit, eine abgeleitete Funktion der Sichtbarkeit [...]. Wenn beispielsweise Architekturen Sichtbarkeiten sind, Orte der Sichtbarkeit, so deshalb, weil sie nicht nur Steinformen sind, das heißt Anordnungen von Dingen und Verbindungen von Qualitäten, sondern zunächst Formen des Lichts, die Helligkeit und Dunkelheit verteilen, das Opake und das Transparente, das Gesehene und das Ungesehene usw. “ Prinz 2016, 187 spricht von der „empirischen Topologie der kulturellen Formen“, aus der sich das „historisch spezifische Apperzeptionsvermögen“ ableitet.

302 Ullrich 2014, 57. Er hält dies für eine spezifisch moderne Ausprägung des Konsumverhaltens, einige Grundzüge dieser Strategien sind m. E. allerdings bereits in der Antike greifbar.

303 Für Einzelphänomene, s. von Hesberg 1990; Haug - Kobusch, im Druck.
} 


\section{Eine Zusammenführung der Ansätze: Raumatmosphären und Gefühlsräume}

Die vorausgegangene Diskussion der Forschungsansätze vermochte zu zeigen, dass Decor-Räume ausgehend von den Wirkqualitäten von Architektur und Decor einerseits, und den Betrachtern, ihrer Einbindung in Handlungskonstellationen und ihrem spezifischen soziokulturellen Hintergrund andererseits, betrachtet werden können. Der gestaltete Raum und die Akteure sind immer schon aufeinander bezogen: 1) Kulturelle Praxen korrelieren häufig mit spezifischen räumlichen Konstellationen, wodurch sich stabile Erlebnisarrangements ergeben. 2) Die Nutzung von Räumen schreibt sich ebenso wie der Umgang mit Objekten als soziales Wissen in die Körper ein und verdichtet sich so zu einer „perzeptiven Syntax“304. 3) Das Bekannte strukturiert den Wahrnehmungsprozess, erlaubt kulturspezifische Deutungsmuster, während das Unbekannte, Ungewöhnliche und Überraschende die besondere Aufmerksamkeit auf sich zieht.

Diese inhärente Verschränkung lässt sich im Folgenden noch einmal systematischer mit Bezug auf das Konzept der Atmosphäre fassen. Mit Gernot Böhme wird Atmosphäre als eine Stimmung und Gestimmtheit verstanden, die zwischen Architektur bzw. Decor und Nutzer entsteht. Atmosphären sind weder reine Projektionen noch objektiv gegeben ${ }^{305}$ : „Atmosphären sind so konzipiert weder als etwas Objektives, nämlich Eigenschaften, die die Dinge haben, und doch sind sie etwas Dinghaftes, zum Ding Gehöriges, insofern nämlich die Dinge durch ihre Eigenschaften - als Ekstasen gedacht - die Sphären ihrer Anwesenheit artikulieren. Noch sind die Atmosphären etwas Subjektives, etwa Bestimmungen eines Seelenzustandes. Und doch sind sie subjekthaft, gehören zu Subjekten, insofern sie in leiblicher Anwesenheit durch Menschen gespürt werden und dieses Spüren zugleich ein leibliches Sich-Befinden der Subjekte im Raum ist“. Atmosphären ereignen sich folglich zwischen Menschen und Objekten in Räumen und sind damit als historisch-kulturelle Produkte interpretierbar ${ }^{306}$. Daran schließen sich einige grundsätzliche, für die folgende Arbeit relevante Überlegungen zur Verfasstheit von Atmosphären an.

(1) Bei Böhme konstituiert sich Atmosphäre wesentlich durch die formale, ästhetische Gestaltung des Ambiente, eine semantische Aufladung ist irrelevant. Konträr dazu angelegt ist das Atmosphärenverständnis von Muth, Zanker und Lorenz, die ausschließlich semantische Elemente für die Entstehung von Atmosphären geltend machen ${ }^{307}$. Hier indes wird angenommen, dass ästhetische und semantische Kategorien, wie sie sich als Gestalt- und Wahrnehmungsprinzipien greifen lassen, an der Schaffung von Atmosphären beteiligt sind. Atmosphären entstehen, so ließe sich mit Hans Ulrich Gumbrecht formulieren, in einem Oszillieren zwischen Präsenzund Sinneffekten ${ }^{308}$. Für die Untersuchung bedeutet dies, dass die Räume sowohl im Hinblick auf ihre formalästhetischen Qualitäten als auch im Hinblick auf die Sinnwelten, die sie vorführen, befragt werden.

(2) Böhme verortet die Entstehung von Atmosphären aus theoretischer Perspektive zwar im Dazwischen von Objekt und Subjekt, in der konkreten Anwendung setzt er aber eine starke

304 Prinz 2016, 195.

305 Böhme 1995, 33f.; Böhme 2005, 14. Damit unterscheidet er sich von dem essentialistischen Atmosphären-Konzept bei Hermann Schmitz (Schmitz 1967; 1969) und Norberg-Schulz 1982, 11. 14f., der vom ,Charakter‘ der Dinge spricht: „Der Charakter ist durch die materielle und formelle Beschaffenheit des Ortes determiniert“. Individuelle Rezipienten werden hier in das Konzept der Entstehung von Atmosphäre nicht einbezogen.

306 In dieser Weise das Sphären-Konzept von Sloterdijk 1999.

307 Böhme 1995; Muth 1998, 54: „Raumausstattung macht Raum in bestimmter Weise erlebbar, definiert ihn als Lebensatmosphäre.“ Bei Lorenz 2008, 6 entsteht Atmosphäre letztlich unabhängig vom wahrnehmenden Menschen: „Die Ausstattung setzt sich aus unterschiedlichen Elementen, beispielsweise der Schmückung der Wände und Böden, sowie auch aus Gegenständen im Raum zusammen, beispielsweise dem Mobiliar. Gemeinsam generieren sie eine bestimmte Atmosphäre“; vgl. Zanker 2000, 209. 213.

308 Gumbrecht 2004, bes. 128-132; vgl. Haug 2014, 235. 
,Macht' gestalteter Räume bei der Erzeugung von räumlich verankerten Stimmungen voraus ${ }^{309}$. Und tatsächlich sind Räume nicht selten gezielt gestaltet, um spezifische Atmosphären zu erzeugen, d.h. „um auf bestimmte Weise affizierend zu wirken“310. Solche atmosphärischen Räume werden durch Decor-Elemente verdichtet, mithin semiotisch-imaginären Artefakten, „die als Affektgeneratoren wirken“‘311. Räume (und Objekte) besitzen aus dieser Perspektive eine Wirkung nach außen ${ }^{312}$. Dabei wird jedoch die Rolle, die den anwesenden Menschen ${ }^{313}$ und der Wahrnehmungshaltung des jeweiligen Individuums bei der Entstehung von Atmosphären zukommt, zu gering veranschlagt.

(3) Dass die Betrachterhaltung für den Prozess der Wahrnehmung zentral ist, wurde wahrnehmungspsychologisch ausführlich begründet. Der Wahrnehmungsprozess setzt immer schon eine Selektion der überkomplexen Erfahrungssituation voraus. Schon im Prozess der Wahrnehmung kommt dem Betrachter eine aktive Rolle $\mathrm{zu}^{314}$. Martina Löw begreift Wahrnehmung daher zu Recht als "simultaneous process of emanation by social goods and people and the perceptual activity of bodily sensing" 315 . Nicht nur die gestalteten Räume, sondern auch die Wahrnehmungsdisposition des Betrachters hat an der Entstehung von Atmosphären entscheidenden Anteil. „[...] Rezeptionspraktiken sind daher mit entsprechenden Produktionspraktiken verbunden. “316

(4) Solche unterschiedlichen Betrachterhaltungen ergeben sich maßgeblich aus unterschiedlichen Modi der Aufmerksamkeit. Für die Antike ist die Quellenlage zu schlecht, um verschiedene Aufmerksamkeitsregimes einer Historisierung zuzuführen ${ }^{317}$. Stattdessen sollen hier verschiedene, prototypische - und damit potenziell denkbare - Aufmerksamkeitshaltungen heuristisch unterschieden werden.

a) Die interessengeleitete Wahrnehmung eines Betrachters, der in eine Handlung eingebunden ist. Anders als Böhme, der letztlich einen interessenlosen Betrachter voraussetzt ${ }^{318}$, wird hier der große Einfluss in Rechnung gestellt, den Handlungen auf die Lenkung der Aufmerksamkeit ${ }^{319}$ und auch auf die Interpretation der Stimuli haben. Insbesondere praxeologische Ansätze messen dem Menschen, der den Raum, aber auch Artefakte in Gebrauch nimmt, daher großes Gewicht bei. Indem zu den sozialen Praktiken ein Affekt gehört, wird der Ort dieser Praktiken affektiv besetz ${ }^{320}$, Gefühle werden ,auf die Straße gebracht“. Der

\footnotetext{
309 Eine ausführliche Auseinandersetzung mit dem Konzept Böhmes bei Brandl 2016; Haug - Kreuz 2016b, bes. 74f.; Kamleithner 2016.

310 Zur Gestaltbarkeit von Atmosphären, s. Böhme 2005; Böhme 2006, 18; vgl. Reckwitz 2016, 176.

311 Reckwitz 2016, 176.

312 Löw 2008, 43f.: „external effects“.

313 Zur Atmosphäre, die durch die Präsenz mehrerer Menschen im Raum erzeugt wird, s. Brennan 2004.

314 Luhmann 1995, 17: „In der aktuellen Wahrnehmung und ebenso in der durch Imagination reaktualisierten anschaulichen Vorstellung geht es um das Ergebnis eines Simultanprozessierens einer Fülle von Eindrücken mit der Möglichkeit, Schwerpunkte der Aufmerksamkeit zu wählen, ohne anderes ,aus dem Auge zu lassen‘ ““

315 Löw 2008, 41.

316 Reckwitz 2016, 176.

317 Für die frühe Neuzeit Crary 2002.

318 Der Fokus Böhmes auf den ruhenden, nicht involvierten Betrachter kritisiert bei Kamleithner 2016, bes. $56 f$.

319 Goldstein 2008, 131-147, bes. 137.

320 Reckwitz 2012, bes. 41f.; Kamleithner 2016; zum Affekt Reckwitz 2016, 170: „Affekte werden nun nicht - wie es klassischerweise der Begriff der Emotion oder des Gefühls suggeriert - einem Individuum gewissermaßen als eine innere Eigenschaft zugeschrieben, als ein ,tiefes Gefühl', das nur der Introspektion zugänglich ist. Sie müssen vielmehr den sozialen Praktiken selbst zugerechnet werden. Es ist die jeweilige soziale Praktik, zu der eine spezifische affektuelle ,Gestimmtheit‘ gehört.“ Und S. 173: „Dem Affektbegriff [...] entspricht ein Verb, das einen Prozess beschreibt: eben den des Affizierens und Affiziertwerdens.“ Reckwitz 2016, 175 nähert sich dabei allerdings an das Atmosphären-Konzept von Böhme an, indem er konstatiert, dass Räumen das Subjekt affiziert wird: „Das Subjekt wird affiziert durch diese Atmosphäre, die sich aus der relationalen Situierung von Artefakten - im Übrigen auch von anderen Subjekten, Gruppen oder auch Praktiken - ergibt.“ Ausführlich zu verschiedenen Affektdefinitionen Thrift 2004, bes. 60-64. Binder 2016, 34 . 36 spricht von einer emotionalen Kodierung von Räumen.
} 
Handlungszusammenhang führt $\mathrm{zu}$ einer spezifizierten und zudem emotional besetzten Form der Aufmerksamkeit der involvierten Akteure und damit zu einer (situativ hergestellten) Vereindeutigung des Decor-Verständnisses. Indem jedoch in ein und demselben Decor-Raum unterschiedliche Handlungen stattfinden, können dadurch unterschiedliche Wahrnehmungen stimuliert werden: Je nach Handlungszusammenhang werden jeweils unterschiedliche Sinnpotenziale von Decor-Ensembles aktiviert ${ }^{321}$.

b) Das beiläufige Wahrnehmen des Raumes in seiner Gesamtheit, das sich auf die visuell vorgeführten Bezüge einlässt. Es wird durch die Platzierung der Bilder im Raum und das Decor-Arrangement geleitet. Der Decor wird in seiner den Raum organisierenden Qualität wahrgenommen, insbesondere visuelle Kontraste, die in Architektur und Decor angelegt sind, organisieren die Wahrnehmung. Die Aufmerksamkeit für das einzelne Decor-Element bleibt relativ schwach ${ }^{322}$.

c) Die zielgerichtete Aufmerksamkeit für decorative Einzelelemente. Betrachter vermögen ihre Aufmerksamkeit auch gezielt auf einzelne Decor-Elemente zu richten. Die Inszenierung von Decor-Räumen ist auf eine solche Wahrnehmung angelegt, die Platzierung von DecorElementen fordert die Aufmerksamkeit des Betrachters ein. Eine intensive Decor-Wahrnehmung, die sich auf ästhetische Effekte und semantische Aussagen einlässt, ist folglich durch die Decor-Platzierung mit in Rechnung gestellt, sogar intendiert. Und doch dürfte diese Wahrnehmungsform im alltäglichen Lebensvollzug die Ausnahme dargestellt haben. Die differenzierten Aufmerksamkeitsformen sind immer schon aufeinander bezogen, sie unterscheiden sich aber doch graduell. Welche Aufmerksamkeit man für den Decor-Raum voraussetzen darf, hängt von der Gestaltung des Raumes, von der Intensität der Handlungssituation, von der Interessen- und Aufmerksamkeitslage und emotionalen Verfasstheit des Akteurs sowie schließlich von kulturell bedingten Aufmerksamkeitslagen ab ${ }^{323}$. Bei der Analyse der einzelnen Häuser wird aus hermeneutischen Gründen zunächst eine beiläufige Wahrnehmung vorausgesetzt - mithin ein Betrachter, der den Decor auf sich wirken lässt. Von einer solchen ,Grundhaltung، ausgehend wird dann in Bezug auf Einzelphänomene, insbesondere die Bildausstattungen der Häuser, eine intensive, zielgerichtete Aufmerksamkeit in Rechnung gestellt. In Ausblicken werden schließlich die Konsequenzen diskutiert, die eine interessengeleitete Aufmerksamkeit für die Wahrnehmung der Räume gehabt haben mag.

(5) Der Ort der Wahrnehmung ist zwar der individuelle Körper, und doch ist menschliches Erleben immer kulturell gerahmt und sozial kontextualisiert, es wird kommunikativ geteilt ${ }^{324}$. Dies gilt auch und gerade für den Umgang mit Räumen und ihrer Ausstattung. Folglich sind Wahrnehmung und Aneignung von städtischen Räumen „an soziale Positionen geknüpft [...] und [werden] von sozial wirksamen Differenz- und Hierarchiesystemen strukturiert. “325

(6) Die Bestimmung von Atmosphäre im Zusammenspiel von Architektur, Ausstattung, Handlung und wahrnehmendem Betrachter führt zu der Frage nach der Homogenität bzw. Heterogenität von Atmosphären. Böhme geht von kohärent erlebbaren Räumen aus. Tatsächlich ist es denkbar, dass Raumgestaltung, Handlungsszenario und Betrachterhaltung zusammenfallen -

321 Zanker 2000, 214: „Wer an einer feierlichen Prozession teilnahm, wie sie etwa aus Anlaß bestimmter Götter- oder Kaiserfeste stattfanden, erlebte die Stadt anders als ein normaler Passant, der sich im Alltag an einen bestimmten Ort begab.“ Zanker 2004, 56 hat erprobt, das Marsfeld als ,Apotheose-Landschaft‘ zu lesen - eine Bedeutung, die insbesondere im Rahmen des Rituals aktiviert worden sein wird. Der Ansatz ließe sich m. E. auch auf emotional codierte, häusliche Räume übertragen; vgl. Zanker 2000, 214.

322 Diese Wahrnehmungsform ist strukturell mit derjenigen eines Flaneurs im Stadtraum vergleichbar, wie er von Simmel für das moderne Großstadtleben skizziert wurde, s. Zanker 2000, 216-219; eine solch unspezifische Aufmerksamkeit (bzw. sogar Interessenlosigkeit) nimmt auch Brilliant 1984, 15 als mögliche Wahrnehmungshaltung an.

323 Haug - Kreuz 2016a; 2016c, 295; Haug 2017; Kamleithner 2016, 57.

324 Haug - Kreuz 2016b, 80 f.

325 Binder 2016, 33. 
zwingend ist dies aber nicht. So kann die Raumgestaltung homogen ausfallen und damit auf spezifische Handlungsszenarien und Betrachterhaltungen zugeschnitten sein - alle DecorElemente eines Cubiculum können etwa auf Erotik verweisen. Architektur und Decor können aber auch gezielt polyvalent angelegt sein und somit sehr unterschiedliche Diskurse stimulieren. In diesen Fällen bedient der Decor unterschiedliche ästhetische und inhaltliche Kategorien und vermag so, Auge und Geist in Bewegung zu halten, den Betrachter zu unterhalten ${ }^{326}$. So kann die Wahrnehmung jeweils auf die zu einem Handlungskontext ,passenden' Aspekte fokussieren, andere hingegen abblenden. Auch eine Handlungskonstellation kann auf einen konkreten räumlichen Rahmen Bezug nehmen - Kulthandlungen finden etwa häufig in Verbindung mit spezifischen Kultinstallationen statt. Typischerweise sind aber Handlungskonstellationen wie das Convivium in sich komplex und polyvalent. Eine lineare ,Passung von Handlung und Decor-Raum ist folglich auch aufgrund der Komplexität der Handlungen unplausibel. Schließlich hat sich für die Betrachterhaltung gezeigt, dass man verschiedene Aufmerksamkeitslagen und damit auch Rezeptionsformen in Rechnung stellen muss.

Eine Kongruenz von Raumgestaltung, Handlungskonstellation und Betrachteraufmerksamkeit dürfte somit einen Sonderfall dargestellt haben. Wenn allerdings Decor-Räume für ein Handlungsszenario ,unpassend' waren, wenn etwa ein Geschäftstreffen in einem mit erotischen Szenen ausgestatteten Raum stattfand, so vermochte der Decor die Atmosphäre entsprechend anzureichern $^{327}$. Decor stiftet Orientierung und Sinn jenseits einer unmittelbaren oder auch nur mittelbaren Bezugnahme auf Handlungsformationen ${ }^{328}$.

(7) Dieser Aspekt führt zu einer - bei Böhme ebenfalls ausbleibenden - kulturellen und sozialen Kontextualisierung, mithin der Historisierung von Atmosphären ${ }^{329}$. Alle Aspekte, die hier als konstitutiv für die Emergenz von Atmosphären aufgefasst werden - die Gestaltung des Raumes, Handlungskonstellationen und menschliches Erleben - unterliegen einem historischen Wandel. Wie Atmosphären geschaffen werden, welche Stimmungen erzeugt werden, welche emotionalen Erwartungen und Reaktionsmuster eine Zeit kennt ${ }^{330}$, lässt sich als kulturell signifikant beschreiben. Auch die Frage der stärkeren Homogenität oder Heterogenität von Decor-Räumen lässt sich so einer Historisierung zuführen.

(8) Die Historizität des Atmosphärischen hat zur Folge, dass Antiquiertheit bzw. Modernität zu atmosphärischen Qualitäten werden können. Decor-Räume, denen man ,ihr Alter ansieht', besitzen eine eigene Biografie, die im Raum ihre Spuren hinterlässt ${ }^{331}$. Objekte und Räume vermögen so $\mathrm{zu}$ Erinnerungsträgern $\mathrm{zu}$ werden, sie sind gewissermaßen imprägniert mit

326 Für die Domus Aurea, s. Haug 2014, 230; vgl. Mayer 2012, 190 für die Skulpturenausstattung der Villa dei Papiri. 327 Muth 1998, 55-58 geht von einem stärker deterministischen Konzept aus, hat aber letztlich auch den hier stark gemachten Aspekt im Auge. Konkret Muth 1998, 58: „Lebensaktivität konstituiert bzw. definiert den Raum in seiner Bedeutung als Lebenskontext; Raum definiert aber auch zugleich die sich in ihm abspielende Aktivität in ihrer sozialsituativen Dimension. Raum und Aktivität bestimmen aufgrund der Forderung nach decor den Charakter des Raumschmucks, werden aber zugleich auch wieder durch ihn infolge seiner decorativen Bedeutung in ihrem ambientalfunktionalen Profil definiert.“

328 Den Begriff des Ambientalen, den Muth 1998, 68 hier einsetzt, scheint mir etwas irreführend, suggeriert er doch ebenfalls eine geradezu deterministische Festlegung auf räumlich-funktionale Zusammenhänge.

329 Böhme 1995, bes. 34-39 bedient sich historischer Beispiele - die Theorie der Gartenkunst von Hirschfeld und das Grimm'sche Märchen Jorinde und Joringel - ohne sich der historischen Bedingtheit etwa der ,sanftmelancholischen` Stimmungen bewusst zu sein. Kritik an der Ahistorizität auch bei Kamleithner 2016, bes. 55-61, die in Bezug auf Georg Simmel und Jonathan Crary historisch spezifische Modi der Aufmerksamkeit und Zerstreuung betont. Anschaulich zur Historizität des Atmosphärischen Göbel 2016, bes. 214. Kritik an der fehlenden sozialen und kulturellen Kontextualisierung bei Löw 2008, 45: „He [Böhme] construes the people of a given epoch as sexless subjects without social imprinting. Böhme considers atmospheres to be objectively perceivable.“

330 Besonders gut greifbar für die Epoche der Empfindsamkeit, s. Lehnert 2011, $13 \mathrm{f}$.

331 Mit Blick auf Ruinen und der Frage von re-use, Göbel 2015. 
Erinnerung ${ }^{332}$. Auch wenn nur der kundige ,Leser` diese Spuren in konkrete Erinnerungen zu übersetzen imstande ist, so bleibt die historische ,Aura' erlebbar ${ }^{333}$. Räume und Objekte stabilisieren folglich durch ihre materielle Präsenz das kollektive Gedächtnis und werden über das kommunikative Gedächtnis - im Fall der Häuser durch die Familien, die darin leben permanent mit neuen Formen der Sinnstiftung aufgeladen ${ }^{334}$.

Die nachfolgende Analyse zu Decor-Prinzipien in pompejanischen Stadthäusern wird sich des Konzepts der Atmosphäre bedienen, um das Zusammenwirken von Architektur, Decor und Handlung zu beschreiben.

332 In Bezug auf Objekte analysiert bei Habermas 1999, 279: „Je mehr unterschiedliche biographische Bezüge ein Objekt auf sich vereint, umso umfassender repräsentiert es seine Biographie und umso bedeutsamer ist es der Person“. Auf der Basis von Objekten wird es, so Habermas, möglich, Lebensgeschichten (oder auch Familiengeschichten) zu einer Erzählung zu verdichten; Schäfer 2012, 121f. verweist auf den Schriftsteller John Steinbeck und seine literarisch verfassten Reiseerlebnisse (Die Reise mit Charley). Darin berichtet er über ein Hotelzimmer in Chicago, das noch nicht für den neuen Gast vorbereitet war, dass er anhand der Spuren, die der Vorbenutzer hinterlassen habe, Überlegungen zu dessen Charakter angestellt habe.

333 Mit dem von Walter Benjamin entlehnten Begriff der Aura als Raumqualität Lehnert 2011, 9.

334 Zur Situierung der materiellen Kultur zwischen kollektivem und kommunikativem Gedächtnis - Ullrich 2015, 72-

77. 
